\title{
RHEOLOGICAL PROPERTIES OF GELLAN GELS CONTAINING FILLER PARTICLES
}

\author{
A Thesis \\ Presented to \\ The Faculty of Graduate Studies \\ of \\ The University of Guelph \\ by \\ STEPHAN JAMPEN
}

In partial fulfilment of requirements

for the degree of

Master of Science

September, 1998

(C) Stephan Jampen, 1998 
National Library of Canada

Acquisitions and Bibliographic Services

395 Wellington Street Ottawa ON KIA ON4 Canada
Bibliothèque nationale du Canada

Acquisitions et services bibliographiques

395, ne Wellington Ottawa ON K1A ON4

Canada
The author has granted a nonexclusive licence allowing the National Library of Canada to reproduce, loan, distribute or sell copies of this thesis in microform, paper or electronic formats.

The author retains ownership of the copyright in this thesis. Neither the thesis nor substantial extracts from it may be printed or otherwise reproduced without the author's permission.
L'auteur a accordé une licence non exclusive permettant à la Bibliothèque nationale du Canada de reproduire, prêter, distribuer ou vendre des copies de cette thèse sous la forme de microfiche/film, de reproduction sur papier ou sur format électronique.

L'auteur conserve la propriété du droit d'auteur qui protège cette thèse. $\mathrm{Ni}$ la thèse ni des extraits substantiels de celle-ci ne doivent être imprimés ou autrement reproduits sans son autorisation.

$0-612-35899-2$ 


\section{ABSTRACT \\ RHEOLOGICAL PROPERTIES OF GELLAN GELS CONTAINING FILLER PARTICLES}

Stephan Jampen

University of Guelph, 1998
Advisor:

Professor M.A. Tung

Flow properties of dilute and concentrated gellan polysaccharide solutions were investigated under low-shear and intermediate shear rates, respectively, to study behaviour of the polymer in water. Hot gellan solutions with added $\mathrm{Ca}^{2+}$ formed gels upon cooling. Influences of rigid (glass) and deformable (gellan) particles dispersed in gellan gels were then investigated. Composites with inclusions at $0,10,20$ and $30 \%$ volume fractions (VF) were tested under small deformation oscillatory shear and mechanical compression to failure.

In gels containing rigid particles, $G^{\prime}$ decreased initially, then increased, exhibiting a minimum around $20 \%$ VF. The increase in $G^{\prime}$ at higher VF was attributed to physical interactions among particles. $G^{\prime}$, failure strength and apparent modulus decreased linearly with increasing VF for gels containing deformable particles. The decrease in $G^{\prime}$ with increasing VF may be attributed to particle deformation under stress from the matrix, or separation of particles from the matrix, thereby causing gel weakening. 


\section{Acknowledgements}

I would like to express my gratitude to Dr. Marvin Tung and to the other members of the Food Packaging Research Group for their support and suggestions throughout my research project. I would also like to thank the members of my committee: Drs. Arthur Hill, Yukio Kakuda and Donald Mercer for their intellectual and practical input.

Thanks are extended to Sylvia Yada for her time and effort in helping me put this project into writing and for her comradery and her unique "intellectual" support/motivation while sharing the same office space for hours on end. Also, to all the staff and patrons of the Grad Lounge - Cheers!!

I dedicate this thesis to my parents, Rudolf and Irène, who encouraged me to follow my dreams and always allowed me to do my own thing. A special thanks also goes out to Marianne Schoch for her friendship and support.

This research was made possible through research grants provided by the Natural Sciences and Engineering Council of Canada. 


\section{Table of Contents}

Page

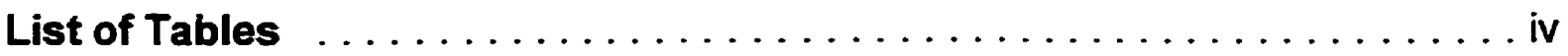

List of Figures $\ldots \ldots \ldots \ldots \ldots \ldots \ldots \ldots \ldots \ldots \ldots \ldots$

1. INTRODUCTION $\ldots \ldots \ldots \ldots \ldots \ldots \ldots \ldots \ldots \ldots \ldots \ldots \ldots \ldots \ldots$

2. LITERATURE REVIEW $\ldots \ldots \ldots \ldots \ldots \ldots \ldots \ldots \ldots \ldots \ldots \ldots$

$2.1 \quad$ Background . . . . . . . . . . . . . . . . . 3

2.2 Gellan Polymer ..................... 3

2.2.1 Gellan Structure $\ldots \ldots \ldots \ldots \ldots \ldots \ldots \ldots \ldots \ldots$

2.2.2 Gelation Theory $\ldots \ldots \ldots \ldots \ldots \ldots \ldots \ldots \ldots$

2.2.3 Gel Strength $\ldots \ldots \ldots \ldots \ldots \ldots \ldots \ldots \ldots \ldots$

2.3 Gel Microstructure $\ldots \ldots \ldots \ldots \ldots \ldots \ldots \ldots \ldots \ldots$

2.3.1 Scanning Electron Microscopy $\ldots \ldots \ldots \ldots \ldots \ldots 7$

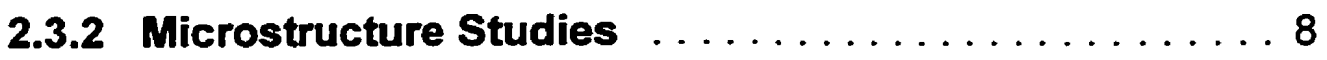

2.4 Particle Sizing . . . . . . . . . . . . . . . 9

2.5 Food Polymer Rheology . . . . . . . . . . . . . . 10

2.5.1 Dilute Solutions $\ldots \ldots \ldots \ldots \ldots \ldots \ldots \ldots \ldots \ldots$

2.5.2 From Dilute To Concentrated Solutions .... . . . 16

2.5.2.1 Modelling of Flow Curves ........... 20

2.5.2.2 Flow Properties of Polymer Solutions . . . . . . 21

2.5.3 From Solutions To Gels . . . . . . . . . . . . 22

2.5.3.1 Dynamic Rheological Testing . . . . . . . . 22

2.5.3.2 Large Deformation Testing ............ 24

2.6 Composite Gels . . . . . . . . . . . . . . . . . 25

2.6.1 Theoretical Models . . . . . . . . . . . . . . . 25

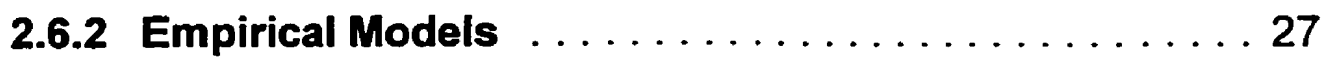

2.6.3 Food-Based Composite Studies .......... 27

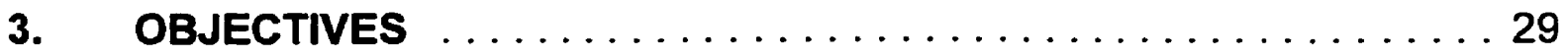

4. MATERIALS AND METHODS $\ldots \ldots \ldots \ldots \ldots \ldots \ldots \ldots \ldots \ldots \ldots$

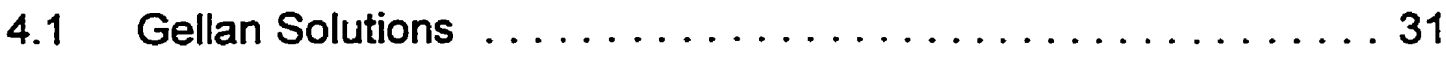

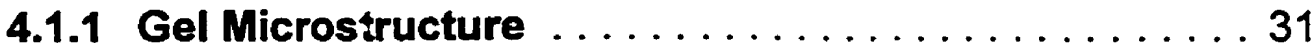


4.2 Gellan Bead Production . . . . . . . . . . . . . . . 32

$4.3 \quad$ Particle Sizing . . . . . . . . . . . . . . . . . . . 35

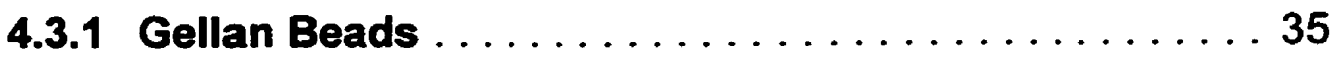

4.3.2 Glass Beads . . . . . . . . . . . . . . . 36

4.4 Composite Gellan Gels . . . . . . . . . . . . . . . . 36

4.4.1 Composite Gels Containing Gellan Beads . . . . . . . 37

4.4.2 Composite Gels Containing Glass Beads . . . . . . 40

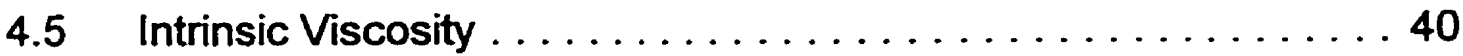

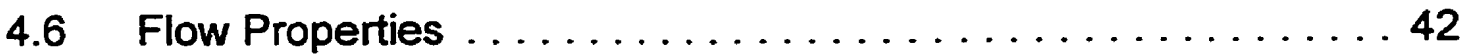

4.7 Small Amplitude Oscillatory Testing .............. 43

4.8 Large Deformation Testing . . . . . . . . . . . . . . 44

5. RESULTS AND DISCUSSIONS $\ldots \ldots \ldots \ldots \ldots \ldots \ldots \ldots \ldots$

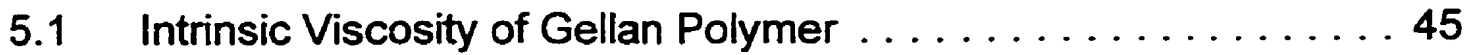

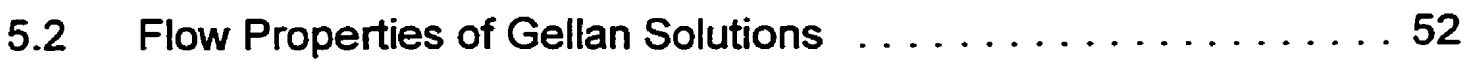

5.2.1 Concentration Effects $\ldots \ldots \ldots \ldots \ldots \ldots \ldots \ldots \ldots . \ldots \ldots$

5.2.2 Temperature Effects . . . . . . . . . . . . . 56

5.3 Small Amplitude Oscillatory and Large Deformation Testing . . 60

5.3.1 Effects of Calcium Concentration ...........61 61

5.3.2 Filler Particle Effects ................ 68

5.3.2.1 Gellan Gels With Rigid Filler Particles .... . . 68

5.3.2.2 Gellan Gels With Deformable Filler Particles . . 74

5.3.2.3 Particle-matrix Relationships ........... 79

5.3.3 Modelling of Gellan Composite Gels ......... 83

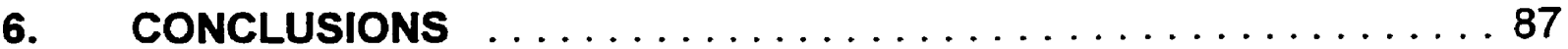

7. REFERENCES $\ldots \ldots \ldots \ldots \ldots \ldots \ldots \ldots \ldots \ldots \ldots \ldots \ldots \ldots \ldots$

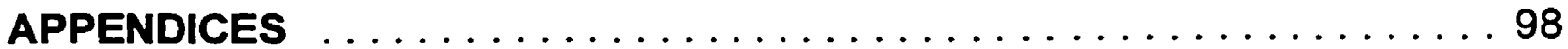

Appendix $1 \mathrm{~A} \quad$ Examination of the Possibility of Time Effects in a $0.5 \%$ Gellan Polymer Solution ......... 98

Appendix $1 \mathrm{~B} \quad$ Test for Statistical Difference in Flow Data . . . . .999

Appendix 2 Determination of [COO] in Gellan Polymer .... . 100

Appendix $3 \mathrm{~A} \quad$ Statistical Analyses of True Stress at Failure Data ................... 101

Appendix 3 B Comparison of Slopes of True Stress at Failure Data 


\section{List of Tables}

Table

Page

4.1 Ion content of gellan polymer used for isoionic dilution calculation . . . 41

5.1 Intrinsic viscosity values of gellan polymer solutions at various $\mathrm{Na}^{+}$ion concentrations . . . . . . . . . . . . . . . . . 49

5.2 Apparent stiffness parameter "B-value" for gellan using the Smidsrød and Haug (1971) relationship, calculated at various ion concentrations 50

5.3 Flow behaviour parameters for gellan solutions at different polymer concentrations . . . . . . . . . . . . . . . . 55

5.4 Flow parameters of various models for $0.5 \%$ gellan solutions at different temperatures $\ldots \ldots \ldots \ldots \ldots \ldots \ldots \ldots \ldots$ 


\section{List of Figures}

Figure

Page

2.1 Tetrasaccharide repeat unit of gellan polymer in its natural, acylated state

2.2 Conceptual model of a Newtonian fluid constrained between two parallel plates showing the imaginary fluid planes sliding over each other

2.3 Representative flow curves or rheograms for a Newtonian fluid ..... 18

2.4 Representative flow curves of a pseudoplastic (shear rate thinning) fluid

4.1 Flow diagram and process parameters for gellan bead production . . . 33

4.2 Gellan bead separation, washing, and concentration procedures . . . 34

4.3 Exploded view of PVC mould used to form gel disks for small amplitude oscillatory testing

4.4 Cylindrical mould and cutting guide used for sample preparation

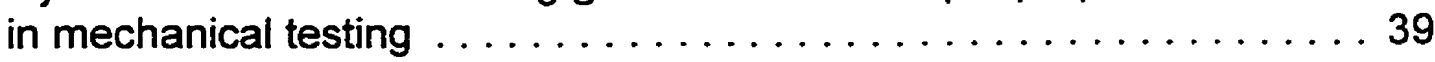

5.1 Reduced viscosity of dilute gellan polymer solutions at various counterion concentrations at $25^{\circ} \mathrm{C}$

5.2 Inherent viscosity of gellan polymer solutions at various counterion concentrations at $25^{\circ} \mathrm{C}$

5.3 Intrinsic viscosity as a function of the inverse square root of ionic concentration at $25^{\circ} \mathrm{C}$

5.4 Critical concentration determination of gellan polymer solutions at $25^{\circ} \mathrm{C}$

5.5 Flow curves of gellan polymer solutions at various polymer concentrations, measured at $45^{\circ} \mathrm{C}$ using a coaxial cylinder and a $6 \mathrm{~cm} 1^{\circ}$ cone and plate fixture

5.6 Influence of temperature on flow curves of a $0.5 \%$ gellan solution, measured using cone and plate geometries. 
5.7 Variation of apparent viscosity taken at various shear rates for a $0.5 \%$ gellan solution measured over a range of temperature.

5.8 Apparent viscosity as a function of temperature for a

$0.5 \%$ gellan solution. Temperature was changed at $3 \mathrm{C} / \mathrm{min} . \ldots . .59$

5.9 Influence of $\mathrm{Ca}^{2+}$ on $\mathrm{G}^{\prime}$ of a $1.0 \%$ gellan gel as measured using small amplitude oscillatory testing

5.10 Effects of $\mathrm{Ca}^{2+}$ ion concentration on true stress at failure (A) and apparent modulus $(B)$ of a $1.0 \%$ gellan gel . . . . . . . . . 63

5.11 Fracture patterns of $1.0 \%$ gellan gels containing various amounts of $\mathrm{Ca}^{2+}$ ions

5.12 SEM Micrographs of $1.0 \%$ gellan gels containing various amounts of $\mathrm{Ca}^{2+}$

5.13 Influence of glass bead volume fraction on the true stress at failure of $1.0 \%$ gellan matrices containing different $\mathrm{Ca}^{2+}$ concentrations $\ldots 70$

5.14 Influence of glass bead volume fraction on the apparent modulus of $1.0 \%$ gellan matrices containing various $\mathrm{Ca}^{2+}$ concentrations $\ldots \ldots 72$

5.15 Influence of glass bead inclusions on the storage modulus of $1.0 \%$ gellan matrices containing various $\mathrm{Ca}^{2+}$ concentrations as measured using oscillatory testing

5.16 Influence of gellan bead volume fraction on true stress at failure of $1.0 \%$ gellan gels at various $\mathrm{Ca}^{2+}$ concentrations

5.17 Influence of gellan bead volume fraction on apparent modulus of $1.0 \%$ gellan gels at various $\mathrm{Ca}^{2+}$ concentrations $\ldots \ldots \ldots \ldots \ldots 76$

5.18 Influence of gellan bead volume fraction on storage modulus, $\mathrm{G}^{\prime}$, of $1.0 \%$ gellan gels at various $\mathrm{Ca}^{2+}$ concentrations $\ldots \ldots \ldots \ldots \ldots 77$

5.19 Representative true stress - strain curve of $1.0 \%$ gellan gels containing various volume fractions (VF) of glass beads

5.20 Relative rigidity of composite $1.0 \%$ gellan gels containing glass beads as a function of dispersed phase volume fraction, showing a quadratic function 
5.21 Relative rigidity of composite $1.0 \%$ gellan gels containing $0.010 \mathrm{M} \mathrm{Ca}^{2+}$ gellan beads as a function of dispersed phase volume fraction, showing linear functions $\ldots \ldots \ldots \ldots \ldots \ldots \ldots \ldots \ldots$ 


\section{INTRODUCTION}

Carbohydrate polymers (also known as hydrocolloids) are important food ingredients because of the variety of functional properties they can impart in formulated foods. Carbohydrate polymers can be used as thickening or gelling agents and as textural stability enhancers. In addition, some of these polymers are indigestible by humans, making them attractive as food ingredients because of their low caloric contribution. The growing consumer interest in reduced fat and reducedcalorie foods has led to the increased use of carbohydrate polymers as food ingredients. However, before fat and/or other compounds are replaced by carbohydrate polymers, it is important for food scientists to have a thorough understanding of the functional properties of such ingredients in relation to other components in a food product.

Many manufactured foods can be considered as complex matrices in which different components interact to provide the desired structures. In these composite foods, the particulate inclusions may also interact with and modify the structural matrix. The resultant texture of a food system is thought to be a function of all "interactions" between the various phases present. The interactions of these phases can be documented by microscopy. According to Stanley and Tung (1976), food texture may be considered to be a direct consequence of its microstructure, which is ultimately a function of chemical composition.

The interactions of carbohydrate polymers with other constituents of formulated food systems must be studied in order to predict or control the resulting 
textures. Replacement of the fat phase in foods has often proven difficult from the viewpoints of sensory and consumer acceptance. A major problem has been the difference in texture or "mouthfeel" of the reduced fat products.

Previous studies of phase interactions have used rigid filler particles in model protein gel systems (Richardson et al., 1981; Ross-Murphy and Todd, 1983; Langley and Green, 1989). Rigid filler particles were found to have a structural reinforcement effect on the rheological properties of the protein gels. These model systems have been adopted from synthetic polymer science, but have not proven very useful when applied to food systems.

Many composite foods are very complex in nature, having a defined continuous phase and one or more dispersed phases. The dispersed phases (water, fats, gases) are typically weaker than the supporting matrix. Most previous research in food composites has centred around rigid particle inclusions, rather than using filler particles with strengths and/or rigidities equal to or less than that of the supporting matrix. Accordingly, studies of deformable particles in continuous matrices should provide a better understanding of the influence of phase separated components on the resultant rheological and failure properties in structured foods. 


\section{LITERATURE REVIEW}

\subsection{Background}

A composite food can be defined as one in which two or more phases interact to create the resultant structure and texture of the food. In this context, phase refers to any liquid, solid or gaseous component. Both protein and carbohydrate polymers have been studied extensively as textural and structural control agents in foods (Blanshard and Muhr, 1982; Jost, 1993; Shand et al., 1993). Proteins can act as stabilizers at component interfaces and can also form the supporting continuous matrix. Conversely, carbohydrate polymers function mainly as gelling and thickening agents, with limited capabilities to influence dispersed particle interactions.

Derivatives of cellulose and starch are very common thickening and gelling agents in use at present. However, with the advent of biotechnology and industrial fermentation technology, new and unique carbohydrate polymers such as xanthan, welan, rhamsan and gellan have been developed. Applications for these newer polymers in food formulations are increasing as researchers develop a greater understanding of their novel properties.

\subsection{Gellan Polymer}

Gellan polymer is a carbohydrate polysaccharide obtained as an exocellular secretion of Pseudomonas elodea, and has only recently been approved for direct use in food (Anon., 1992). Because gellan is derived from a microbial fermentation, 
the problems of availability and variability in quality often associated with other gelling agents are less likely to be of concern. One of the novel attributes of gellan polymer is its ability to form a variety of gel textures depending on various combinations of polymer concentration and metal ion types (Sanderson, 1990). Thus, gellan can be used to create new and distinct gel textures and properties ranging from hard, brittle structures to ones which are soft and compliant (easily deformed).

\subsubsection{Gellan Structure}

Gellan polymer is composed of a tetrasaccharide repeat unit of $B-D$ glucose, $B-D$ glucuronic acid and $\alpha-L$ rhamnose in a molar ratio of 2:1:1. A 1-3, instead of a 1-4, glycosidic linkage between the $B-D$ glucose and the $\alpha-L$ rhamnose of the next repeat unit induces a twist in the linear chain, thus allowing for a helical conformation (Jansson et al., 1983; O'Neill et al., 1983; Sanderson and Clark, 1984). In its natural form, gellan has been found to contain both O-acetyl and Oglyceryl substitutions at the 6 and 2 positions, respectively, of the 1-3 linked glucose residue (Figure 2.1; Kuo et al., 1986). Without deacylation, the gellan gels are cohesive and compliant; however, for commercial use, the deacylated form is more desirable in order to provide a wider range of gelling characteristics (Sanderson, 1990). 


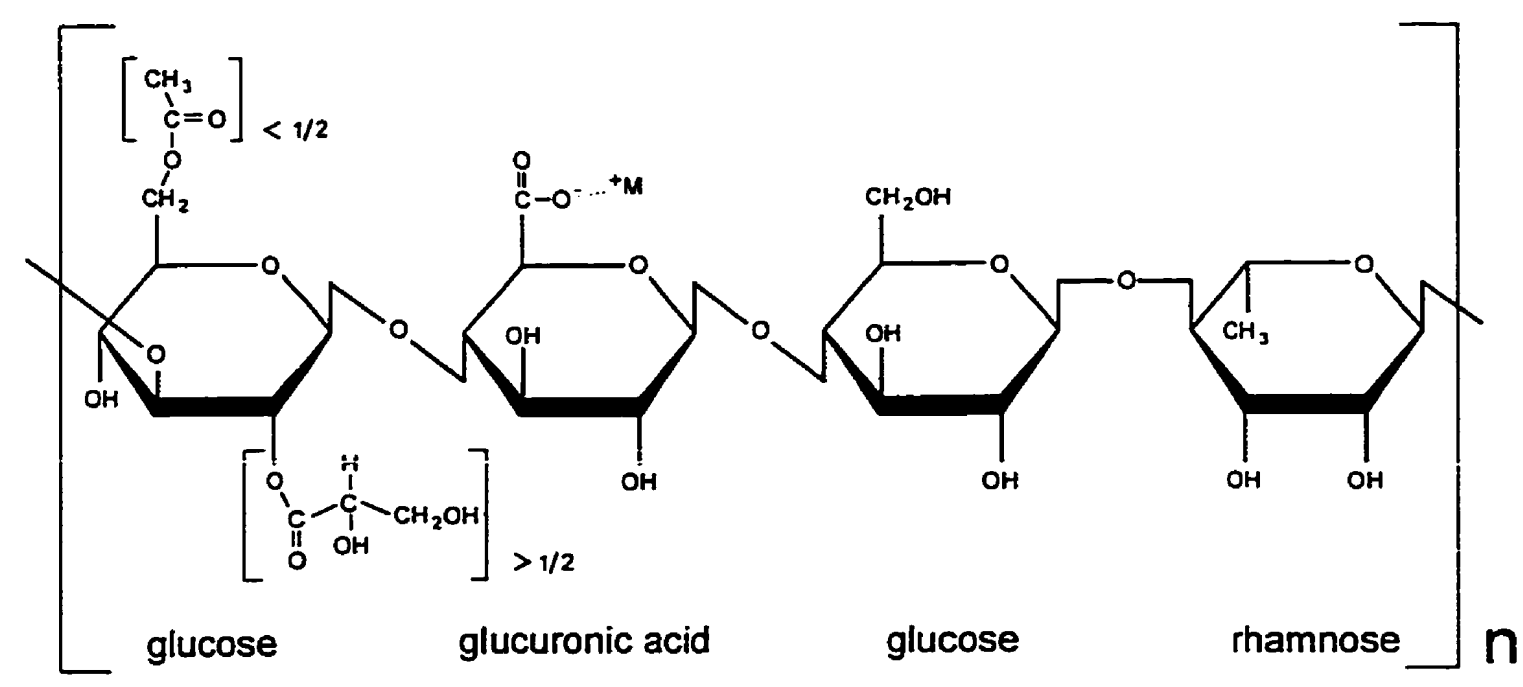

Fig. 2.1 Tetrasaccharide repeat unit of gellan polymer in its natural, acylated state.

\subsubsection{Gelation Theory}

When dispersed in a solution of hot water and metal cations, gellan polymer will form a gel upon cooling. The three-dimensional structure is believed to be formed by the cross-linking of two adjacent molecules, intertwined to form double helical junction zones. Junction zones are formed and stabilized through the interaction of metal ions with the carboxyl groups of the $B-D$ glucuronic acid (Upstill et al., 1986; Chandrasekaran et al., 1988).

In a heated gellan solution, polymer chains exist as disordered coils. Cooling without the presence of metal cations leads to the formation of weak, thermoreversible interactions such as hydrogen bonding and van der Waals attractions between adjacent polymer chains. However, with the introduction of metal cations, interactions formed with the carboxyl groups are much stronger and more stable. Divalent cations may bridge two adjoining carboxylic acid sites, thus 
causing local aggregation of the helices. Monovalent cations may only "shield" the carboxyl group, perhaps allowing for more hydrogen bonding to occur between the polymer helices, also leading to aggregation and gel formation (Chandrasekaran et al., 1988; Moritaka et al., 1991).

Gelation of gellan solutions is spontaneous and occurs at a characteristic temperature which is dependent on both polymer concentration and metal cation concentration (Tang et al., 1997). According to thermodynamics, if gelation is spontaneous, the Gibbs free energy, $\Delta G$, for the reaction must be negative:

$\Delta G_{\leq} 0$

where,

$$
\Delta G=\Delta H-T \Delta S
$$

Moritaka et al. (1992) found that gelation of gellan solutions was exothermic, accompanied by a polymer reconfiguration from a random to a more ordered structure, leading to a decrease in entropy, $-\Delta S$. This means the reaction was energy favoured but entropy hindered, thus, reaction spontaneity was dependent on temperature and the relative magnitudes of $\Delta H$ and $\Delta S$.

\subsubsection{Gel Strength}

The strength of the resulting gellan gel matrix was found to be dependent on polymer concentration as well as the valency and concentration of the metal cations used to form the gel (Sanderson and Clark, 1984; Moritaka et al.,1991; Tang et al., 1995). Higher concentrations of monovalent cations $\left(\mathrm{Na}^{+}\right.$or $\left.\mathrm{K}^{+}\right)$were needed to obtain gel strengths similar to those formed using divalent cations $\left(\mathrm{Ca}^{2+}\right.$ or $\left.\mathrm{Mg}^{2+}\right)$. Sanderson and Clark (1984) reported that a 25-fold greater monovalent cation 
concentration was needed to obtain gels comparable in strength to divalent cation cross-linked gels.

With both mono and divalent cations, gel strength maxima were observed at high cation concentrations (Tang et al., 1997). Maximal gel strength was found to correspond to the stoichiometric relationship between the number of cations and the number of carboxyl groups present (Sanderson and Clark, 1984; Tang et al., 1997). When the stoichiometric equivalence was surpassed, Tang et al. (1997) suggested that a competition for anionic sites arose, imposing repulsive forces which resulted in weakened gels.

\subsection{Gel Microstructure}

\subsubsection{Scanning Electron Microscopy}

Scanning electron microscopes use a finely focused electron beam that is moved across a conductive specimen surface in a raster motion (Slayter and Slayter, 1992). High energy primary electrons from the incident beam penetrate the stabilized sample surface a small distance, causing the release of other lower energy secondary electrons which are subsequently attracted to a positively charged detector and amplified to give a signal. The signal varies according to the sample topography and the quantity of secondary electrons released. The amplified signal is used to modulate the intensity of the image-forming electron beam projected onto a cathode ray tube (CRT) where each position and level of intensity corresponds to an equivalent position on the sample surface, thereby creating a topographical response of the surface with a large depth of field on the CRT screen. 
Sample preparation for SEM studies includes fixation and dehydration to maintain stability under the high vacuum conditions in the electron microscope. However, in many food systems where large amounts of water are present, the fixation and dehydration processes may cause structural alterations known as artifacts. The development of cryomicroscopy techniques allows for the observation of samples in the hydrated state provided that they are at a very low temperature. Biological samples are generally stable below $-130^{\circ} \mathrm{C}$, because the vapour pressures of the components are very low and ice crystal changes are minimal (Caldwell et al., 1992). Samples may be sublimated slightly to remove some of the water from the surface, thus exposing the underlying structure of the supporting matrix (Bachmann and Mayer, 1987; Slayter and Slayter, 1992).

In cryo-SEM procedures, small samples are frozen very rapidly by plunging them into a liquid cryogen. Rapid freezing leads to the development of very small ice crystals which are easily sublimated to reveal sample structure. The use of liquid propane as the cryogen has been found to result in better resolution for high moisture samples because of the increased freezing rates associated with the thermal properties of propane (Costello and Corless, 1978). These properties include a low melting point, a high boiling point, and good thermal conductivity and specific heat (Robards and Sleyter, 1985).

\subsubsection{Microstructure Studies}

The microstructure of a food system is a function of its chemical composition, and in turn, is responsible for texture (Stanley and Tung, 1976). Various 
researchers have used cryomicroscopy to examine the microstructure of food gel systems. For example, Colombo and Späth (1981) obtained good results using cryomicroscopy to study the structural differences between protein gels and various cheese analogues such as $2 \%$ calcium alginate gels. However, linking structure to texture was found to be more difficult.

A considerable amount of work has been carried out using protein systems with included fat particles in an attempt to model the interaction of fat with protein and relate this to mechanical properties. Aguilera and Kinsella (1991) and Aguilera et al. (1993) observed differences in the microstructure of gels made with whey protein isolates (WPI) and those made with skim milk powder (SMP), and these differences could be correlated to the mechanical properties of the gels. The SMP gels were weaker than the WPI gels and they found that WPI could be used to reinforce SMP gels.

\subsection{Particle Sizing}

For food composites, establishing the size of particle inclusions is important because particle size is known to affect both the texture and stability of the system. This is true particularly for emulsions, where large particles will impart poor mouthfeel characteristics and will decrease emulsion stability over time. In the past, light microscopy was commonly used as a method for particle size determination, especially in the study of emulsions (Walstra et al., 1969; Chang et al., 1972; Tung and Jones, 1981). Light microscopy is an easy and inexpensive method to estimate particle size distribution, but some problems may be encountered when using this 
technique (Walstra et al., 1969): 1) particles of less than $1 \mu \mathrm{m}$ are difficult to see; 2) it is sometimes difficult to differentiate a particle from the background; and 3) larger particles may be flattened by the coverslip, thus leading to an over-estimation of their size. However, the use of proper stains and good microscopy techniques will often help alleviate these problems.

Light scattering techniques can also be used to measure particle size distributions in various materials, such as fat globule size in milk and other emulsions (Gelin et al., 1994), and to monitor emulsion destabilization over time. In a review of food emulsions, Dalgleish (1996) briefly described various light scattering techniques along with their inherent advantages and disadvantages. Dentini et al. (1988) used light scattering techniques to study the solution properties of gellan, however, no literature citations were found describing the use of microscopy or light scattering techniques to study gellan particles.

\subsection{Food Polymer Rheology}

Rheology can be defined as the science of the deformation and flow of matter. The way a particular substance behaves under specified applied forces or deformations can be used to characterize the material. Comprehensive reviews on the general subject of rheology have been completed by van Wazer et al. (1963) and Walters (1975). More specifically, food rheology and food polymers have been reviewed by Sone (1972), Muller (1973), Rao (1977), Lapasin and Pricl (1995), and Steffe (1996). 
True liquids have no defined shape and will flow irreversibly when acted upon by an external force, and will continue to do so until the force is removed. Adding soluble materials to a pure liquid will change the way the fluid reacts to applied external forces. Studies on the rheological properties of solutions can best be discussed in relation to solution concentration, because of the distinct differences in behaviour observed as concentration is changed.

\subsubsection{Dilute Solutions}

The addition of very small amounts of some solutes to a suitable solvent will affect the rheological response of the solution. At these high dilutions, interactions among the added species become statistically negligible such that rheological differences between the dilute solution and pure solvent can be attributed to the hydrodynamic volume of the species added. For macromolecules such as gellan, the magnitude of the effects on the rheological properties is dependent on the molecular size and conformation the molecule adopts in the solution (Lapasin and Pricl, 1995). The term intrinsic viscosity, [n], has been developed to quantify these rheological properties and is defined as a measure of the contribution by the polymer molecule to the viscosity of a solution as it relates to fundamental properties such as molecular weight, chain rigidity and polymer coil dimensions (Morris et al., 1981; Launay et al., 1986).

With the addition of polymer to a solvent, an increase in solution viscosity can be measured, however, the solvent properties are also important to the resultant value obtained. At a specified temperature and concentration, a number of 
parameters can be calculated to obtain a value for intrinsic viscosity. Relative viscosity, $\eta_{r}$, is the ratio of the viscosity of the solution, $\eta$, to that of the solvent, $\eta_{s}$,:

$$
\eta_{r}=\frac{\eta}{\eta_{s}}
$$

Specific viscosity, $\eta_{s p}$, is a measure of the relative difference in viscosity between the solvent and the solution and is defined as follows:

$$
\eta_{\mathrm{sp}}=\frac{\left(\eta-\eta_{\mathrm{s}}\right)}{\eta_{\mathrm{s}}}
$$

Reduced viscosity, $\eta_{\text {red }}$, and inherent viscosity, $\eta_{\text {in }}$, are defined by $\eta_{s p} / C$ and $\left(\ln \eta_{\mathrm{r}}\right) / \mathrm{C}$, respectively, where $\mathrm{C}$ refers to polymer concentration. Intrinsic viscosity is then defined as the limit of $\eta_{\text {red }}$ or $\eta_{\text {in }}$ as polymer concentration, $C$, approaches zero, which is intended to reflect the influence of the polymer on the solvent when polymer-polymer interactions become progressively less significant.

The Huggins and Kraemer empirical expressions, named after the scientists who developed them, are used to extrapolate $\eta_{\text {red }}$ and $\eta_{\text {in, }}$ respectively, to zero concentration:

$$
\begin{aligned}
& \frac{\eta_{s p}}{C}=[\eta]+k_{1}[\eta]^{2} C+\left\{k_{1}^{\prime}[\eta]^{3} C^{2}\right\} \\
& \frac{\left(\operatorname{Ln} \eta_{r}\right)}{C}=[\eta]-k_{2}[\eta]^{2} C+\left\{k_{2}^{\prime}[\eta]^{3} C^{2}\right\}
\end{aligned}
$$

Both equations are used in reporting intrinsic viscosity, often yielding a truncation point at zero concentration when plotted on linear coordinates. The terms in the \{\} braces are included in the equations because of the deviation from linearity in experimental data as polymer concentration increases (Launay et al., 1986). 
The Huggins and Kraemer expressions apply only to uncharged polymers. However, many polymers such as gellan are macroions in that they have an overall net charge (polyelectrolytes). Intramolecular equal-sign repulsive charges have important effects on physico-chemical properties such as viscosity (Lapasin and Pricl, 1995). The decrease in ionic strength as a polymer is diluted causes polymer chain reorientation, ultimately affecting viscosity. By adding sufficient amounts of counterions to "neutralize" the macroion molecules, data are more consistent with those of uncharged polymers. These observations were reported by Morris et al. (1981) and Launay et al. (1984) who studied $\lambda$-carrageenan, and by Cuvelier and Launay (1986) in their research on xanthan polymer.

Attempts have been made to model the effects of ion concentration on intrinsic viscosity of polyeletrolytes in order to give an indication of the stiffness of the molecule as a function of ionic strength. The "LF model", developed by Fixmann (1982) and Le Bret (1982), extended the Krathy-Prorod (KP) worm-like model for polymers in solution to include the effects of electrostatic charge. The LF model assumes that the polymer chain can be described by a worm-like tube whose stiffness is increased by the electrostatic charges indigenous to the polymer. These authors suggested that the persistence length, $L_{T}$, which is the average projection of $r^{2}$ (radius of gyration) of an infinitely long worm-like chain onto the tangent vector (Lapasin and Pricl, 1995), is made up of two summed components $L_{0}$ and $L_{\mathrm{e}}$ :

$$
L_{T} \approx L_{0}+L_{e}
$$

where $L_{0}$ represents the intrinsic persistence length which is related to the backbone structure, and is independent of the electrostatic charge; and $L_{\theta}$ represents the 
electrostatic persistence length, and is dependent on the electrostatic charge. A stiffness parameter can be estimated by considering the ratios of $L_{0}$ and $L_{e}$ in that chain flexibility will change as a function of ionic concentration. Application of this model has been limited because many of the parameters needed in determining persistence lengths cannot be derived analytically, but must be obtained computationally (Tobitani and Ross-Murphy, 1997).

Earlier, a semi-empirical approach was postulated by Smidsrød and Haug (1971), because intrinsic viscosity, [n], was shown to vary approximately as the inverse square-root of ionic concentration, $I^{-0.5}$ :

$$
[\eta]=K M^{0.5}\left(1+k n^{0.5}+k^{\prime} n^{0.5} I^{-0.5}\right)
$$

where $\mathrm{K}$ denotes a constant related to the stiffness of the polymer (from MarkHouwink equation, $\left.[\eta]=\mathrm{KM}^{\mathrm{a}}\right), \mathrm{M}$ is the molecular weight of the polymer, $\mathrm{k}$ and $\mathrm{k}^{\prime}$ are coefficients, and $\mathrm{n}$ is the number of segments.

A linear relationship was observed when intrinsic viscosity data were plotted with respect to $I^{-0.5}$, therefore supporting the postulated relationship (Smidsrød and Haug, 1971). Equation (8) could then be simplified to two parameters, namely the slope of the line and the intercept:

$$
[\eta]=[\eta]_{\infty}+S I^{-0.5}
$$

where $[\eta]_{\infty}$ is the intrinsic viscosity at infinite ionic strength, and the slope, $S$, is a stiffness parameter. A large slope would indicate that the polymer was very sensitive to ions, therefore suggesting a "flexible polymer" which could easily change conformation as a result of electrostatic effects. However, equation (9) was also found to be dependent on molecular weight. Smidsrød and Haug (1971) found 
that a plot of $\log S$ vs $\log [\eta]_{\infty}$ for different molecular weights resulted in straight lines, suggesting that $S$ and molecular weight were related when $[\eta]_{\text {o }}$ was taken at a specific ion concentration as measured in molarity. By convention, ion concentration has been established at $0.1 \mathrm{M} \mathrm{NaCl}$ :

$$
S=B\left([n]_{0.1}\right)^{u}
$$

The exponent, $U$, was approximated to be between 1.2 and 1.4. The value for $B$ has become known as the "B-value" and is specific for each polymer dispersed within a solution of known ionic strength. Therefore, by knowing the intrinsic viscosity and assuming an average exponent of 1.3 , the above expression can be used to estimate an "apparent stiffness" coefficient, B, without knowing the molecularweight of the polymer.

There is some debate as to the meaning of the apparent stiffness parameter. A simplistic interpretation is that the smaller the B-value, the stiffer the polymer molecule. However, according to Tobitani and Ross-Murphy (1997), the B-value cannot be related directly to the stiffness of the polymer because it assesses only the electrostatic contributions and does not consider the permanent nonelectrostatic components of the intrinsic viscosity. This concern for separating the electrostatic and non-electrostatic effects on viscosity is not limited to the Smidsrød and Haug model, but also to the LF model described earlier; therefore, any given stiffness parameter should be treated as an "apparent" stiffness coefficient.

Measurements of viscosity needed for the above calculations must be made at low shear rates such that the solution viscosity is independent of shear rate. For typical polymer solutions, viscosities obtained in the Newtonian low shear rate plateau would be appropriate for this purpose. Low shear rate viscosity 
measurements can be made with glass capillary, falling ball and rolling ball viscometers, or rotational viscometers with low speed drive systems and highly sensitive stress measuring elements.

\subsubsection{From Dilute To Concentrated Solutions}

In dilute solutions, it is assumed that the individual species discussed above are far enough apart such that they have negligible influence on each other and thus move freely in solution under the effects of Brownian motion. However, with increasing concentration, collisions become more frequent to the point where there may be continuous interaction among molecules, leading to chain overlap, interpenetration and entanglement (Lapasin and Pricl, 1995). This is known as the critical concentration of the polymer, $\mathrm{C}^{\star}$, and is recognized by a marked increase in specific viscosity as a function of polymer concentration.

In studying the rheological properties of solutions above $C^{\star}$, many parameters have been defined. For instance, steady shearing flow can be defined as continuous deformation (rate of strain or shear rate), which takes place in the $x$ direction, at velocity, $v$, where infinitesimally thin parallel planes slide over one other in the direction of a constant force, $F$, associated with a small volume of fluid as illustrated in Figure 2.2. In this illustration, the element of fluid being sheared is constrained between top and bottom surfaces of area, $A$, separated by a vertical distance, $y$. For such a system, shear stress is taken as the force distributed over the area of the sheared planes, $F / A=\sigma$, and the shear rate is the velocity gradient through the fluid, $\delta v / \delta y=\dot{y}$. In steady flow, the resistance of the fluid to flow, 
known as viscosity, $\eta$, provides an opposing balance to the applied force. In simple or Newtonian fluids, shear stress, $\sigma$, is directly proportional to the shear rate, $\dot{\gamma}$ :

$$
\sigma=n \dot{\gamma}
$$

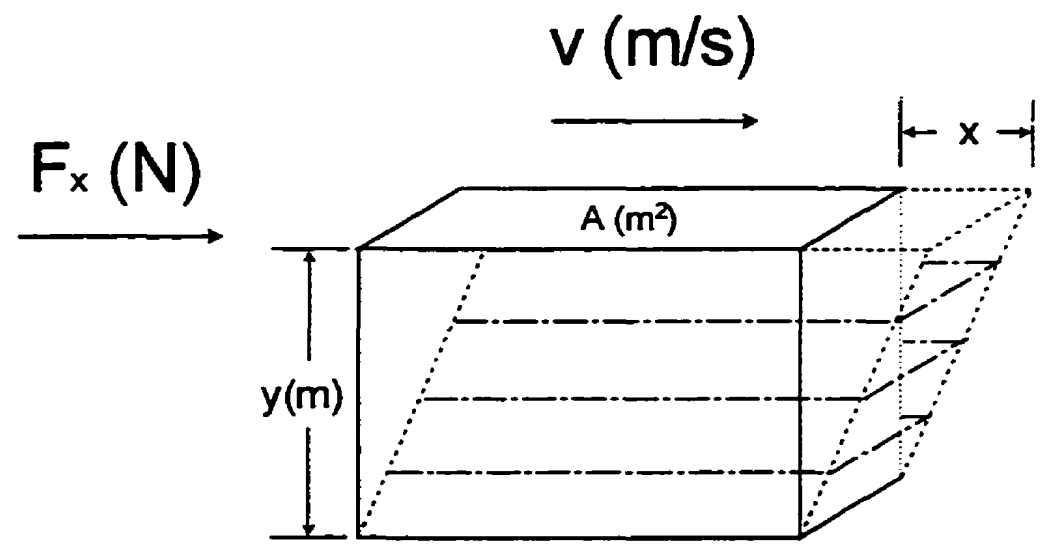

Fig. 2.2 Conceptual model of a Newtonian fluid constrained between two parallel plates showing the imaginary fluid planes sliding over each other.

where $\eta$ is the proportionality constant, which represents the viscosity of the fluid. An alternative expression of this relationship would be:

$$
\eta=\sigma / \gamma
$$

Units for these quantities would be as follows: $\sigma=N / m^{2}=P a ; \gamma=m / s / m=s^{-1}$; and $\eta=P a / s^{-1}=P a s$.

Because shear stress and shear rate are directly proportional, plotting data obtained in an experiment where corresponding shear stress and shear rates were measured would yield a straight line with slope equal to the viscosity, $\eta$ (Figure 2.3). These data could also be plotted according to the model shown by equation 12 .

Most food systems do not follow this behaviour and are thus considered to be non-Newtonian fluids. Flow of a non-Newtonian fluid is defined by a rheogram 
which is not linear and may not pass through the origin on arithmetic co-ordinates (Steffe, 1996). Three broad categories may be considered when classifying non-
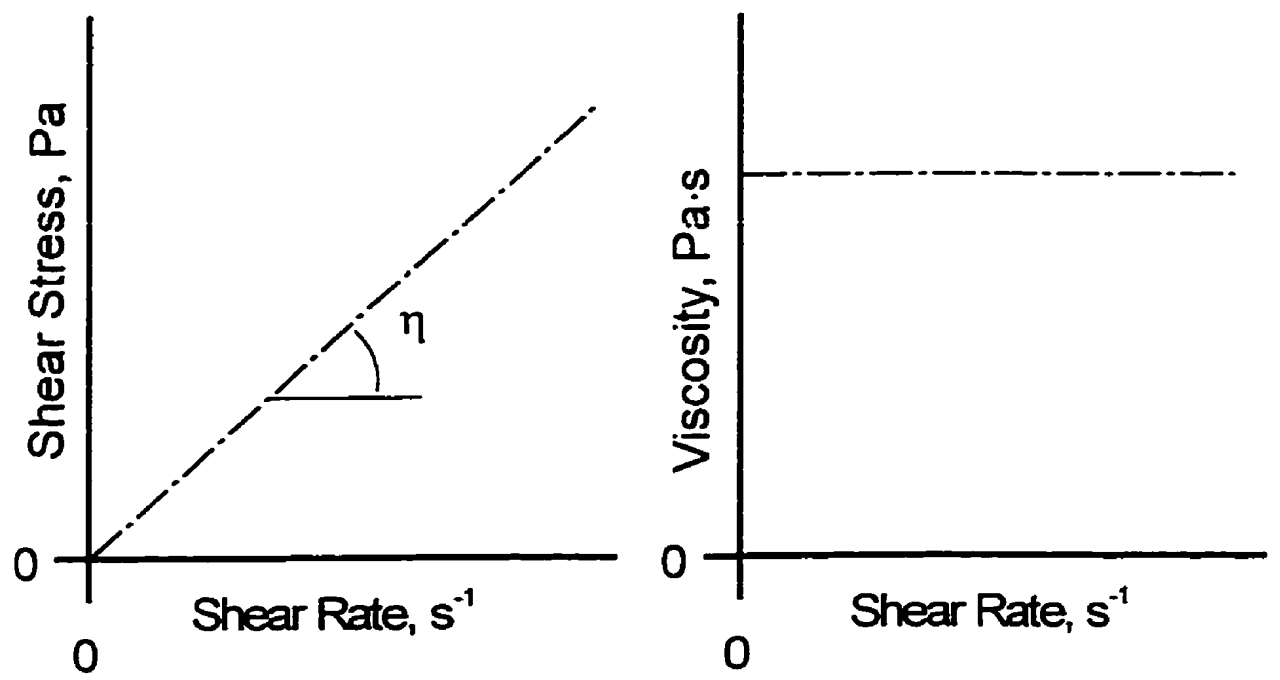

Fig. 2.3 Representative flow curves or rheograms for a Newtonian fluid.

Newtonian behaviour: (1) time-independent fluids where shear stress is dependent only on shear rate; (2) time-dependent fluids where shear stress is both a function of shear rate and the length of time the stress is applied; and (3) viscoelastic fluids where partial elastic recovery is seen upon the removal of the applied force. In all of these cases, the proportionality constant associated with the stress/rate ratio can no longer be termed viscosity, thus it has become known as apparent viscosity, $\eta_{\text {app }}$, which must be considered in regard to its relationships as functions of shear stress or shear rate.

Time-independent fluids can be further grouped into two classes: pseudoplastic (shear rate thinning) and dilatant (shear rate thickening). Figure 2.4 is an example of typical pseudoplastic behaviour. High molecular weight polymer dispersions often exhibit this pseudoplastic behaviour and is attributed to the 
following explanation.
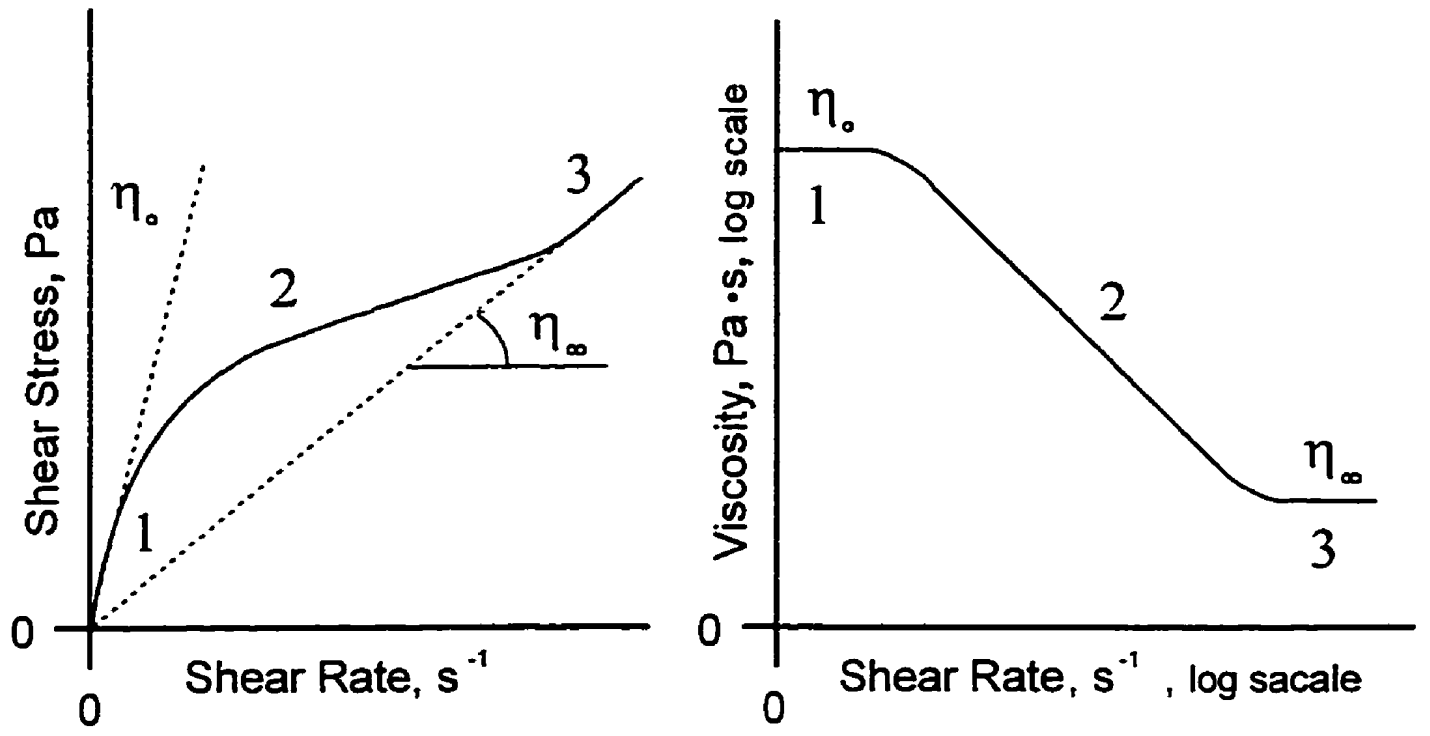

Fig. 2.4 Representative flow curves of a pseudoplastic (shear rate thinning) fluid.

When the fluid is at rest, molecules may become randomly oriented and entangled in an effort to attain maximal entropy as a result of the natural Brownian motion of the molecules. With the application of very low shear rates, shear stresses may be proportional to shear rates because the infiuence of shearing is balanced by the Brownian motion of the particles, effectively preserving the random structure. The fluid is thus exhibiting Newtonian-like behaviour and on a typical rheogram, this region is known as the Newtonian plateau or zero shear viscosity, $\eta_{0}$. As shear rates increase, the random fluid structure begins to break down, resulting in a decrease in viscosity. The decrease in viscosity may be attributed to the progressive orientation of molecules to the laminar shear planes. This decrease is often linear on logarithmic co-ordinates and is well described by flow models. At 
extremely high shear rates, many fluids will again show Newtonian behaviour as a result of all randomness in the fluid having given way to alignment to the shear planes such that no further streamlining is possible. At such shear rate ranges, shear stress may again become proportional to shear rate resulting in a second Newtonian-like region known as the infinite shear rate viscosity, $\eta_{\infty}$.

\subsubsection{Modelling of Flow Curves}

Various theoretical and empirical models for time-independent flow curves have been developed, of which the simplest and most popular is the Power-law model:

$$
\sigma=m \dot{\gamma}^{n}
$$

where $m$ and $n$ are parameters known as the consistency coefficient and the flow behaviour index, respectively. The flow behaviour index, $n$, can be used to distinguish between shear thinning $(n<1)$ and shear thickening $(n>1)$ types of flow. The consistency coefficient, $m$, is numerically equal to the shear stress or apparent viscosity at a shear rate of $1 \mathrm{~s}^{-1}$ and has units of $\mathrm{Pa} \cdot \mathrm{s}^{n}$.

A more complex model which has also been used to model time-independent fluid flow is the Power-law plastic or Herschel-Bulkley model:

$$
\sigma=\sigma_{y}+m^{\prime} \dot{\gamma}^{\prime \prime}
$$

The parameters $m^{\prime}$ and $n^{\prime}$ are analogous to the corresponding parameters of equation (13). An estimate of the yield value, $\sigma_{y}$, may be obtained experimentally or by a mathematical least squares algorithm (Steffe, 1996).

Neither of these two models will describe a pseudoplastic fluid over the entire shear rate range as described in section 2.5.2. The Power-law is advantageous 
when there is no apparent yield stress and the shear rate range to be modeled falls within section 2 of Figure 2.4. If a yield stress is evident, the Herschel-Bulkley model may be used.

\subsubsection{Flow Properties of Polymer Solutions}

Carbohydrate polymers of both natural or modified origins are used in the food industry as thickeners and textural modifiers in a variety of products, such as gravies, salad dressings, milkshake mixes, and instant breakfast mixes. Many dispersions containing small particulate material and/or high molecular weight polymers have been found to display pseudoplastic behaviour (Stanley et al., 1996). Krumel and Sarkar (1975) studied various natural and modified carbohydrate polymers and found that all exhibit some degree of pseudoplasticity, meaning that the viscosity decreases as a function of shear rate, but without a noted yield value. A plot of log viscosity vs log shear rate resulted in a typical three part curve as described in section 2.5.2, Figure 2.4. Similar results were found by Lopes Da Silva et al. (1992) when studying high-methoxyl pectins and locust bean gum at steady shear. Resultant rheograms were sensitive to extrinsic factors such as temperature and concentration, and intrinsic factors such as $\mathrm{pH}$ and ionic strength. However, the intrinsic factors were relevant only when the polymer itself was sensitive to these properties. The study of flow properties of ungelatinized starch from various plant sources have also been studied yielding similar results (Härröd, 1989; Hoover and Vasanthan, 1992). No literature was found with regard to the flow properties of gellan polymer solutions considering the factors of polymer concentration and 
temperature.

\subsubsection{From Solutions To Gels}

At increasingly high concentrations of polymer, intermolecular associations can affect the macroscopic properties of the system. As discussed for gellan in the presence of cations, intermolecular interactions can ultimately lead to a disorder-toorder transition resulting in a three-dimensional gel network. The rheological and mechanical properties of these systems can be measured using a variety of techniques. Both dynamic rheological testing and large deformation testing have been used to assess gellan gels (Nakamura et al., 1993; Tang et al., 1995).

\subsubsection{Dynamic Rheological Testing}

Some food gels, when exposed to small deformations in either stress or strain, show partial elastic recovery upon removal of the deforming force. Therefore, these materials exhibit both solid-like elastic and fluid-like viscous behaviour simultaneously. This property is known as viscoelasticity and is found in many polymer solutions and multi-phase systems.

Viscoelastic properties can be measured using creep tests, stress relaxation and small amplitude oscillatory testing. The latter method has become the most valuable for food gel systems due to the quantitative information that can be gained about the gel structure on a molecular level. Small amplitude oscillatory rheological tests subject the material to small sinusoidal stresses or strains; therefore these tests are intended to be non-destructive and to satisfy the requirements of linear 
viscoelasticity based on infinitesimal strain and stress. As these tests are commonly carried out in shearing rheometers, the following discussion and terminology will apply to the shearing mode of deformation.

A sinusoidally varying applied shear strain, $Y$, may be written as a function of time, $t$, and frequency, $\omega$ :

$$
V=y_{0} \sin (\omega t)
$$

where $Y_{0}$ is the maximum strain amplitude, and $\omega$ is the oscillatory frequency expressed in radians per second. Dynamic strain or shear rate will be the first derivative of strain with respect to time:

$$
\frac{d y}{d t}=\dot{\gamma}=\omega \gamma_{0} \cos (\omega t)
$$

According to Hooke's law for ideal solids, stress is directly proportional to strain:

$$
\sigma=k y
$$

By substituting equation (15) into (17), stress can be expressed as:

$$
\sigma=k y_{0} \sin (\omega t)
$$

However, for Newtonian fluids, stress is directly proportional to shear rate, therefore, by substituting equation (16) into (11):

$$
\sigma=n \omega y_{0} \cos (\omega t)
$$

For a purely elastic solid, the shear stress wave will be in phase with the resultant shear strain wave. For a purely viscous material, the shear stress wave (equation (18)) will be $90^{\circ}$, or one quarter cycle out of phase with the applied shear strain wave (equation (19)). Viscoelastic materials, which have both solid and viscous characteristics, will exhibit behaviour which is some intermediate combination of these two ideal responses. 
Since there are two components in viscoelastic materials, the stress function can be written to incorporate both elastic and viscous components:

$$
\sigma=v_{0}\left[G^{\prime} \sin (\omega t)+G^{\prime \prime} \cos (\omega t)\right]
$$

where $\mathrm{G}^{\prime}$, or the storage modulus, is a measure of the energy recovered per cycle of sinusoidal shear deformation, and is defined by the stress in phase with the strain divided by the strain in sinusoidal deformation. The loss modulus, $G^{\prime \prime}$, is an estimate of the energy dissipated per cycle, and is defined by the stress out of phase with the strain divided by strain in sinusoidal deformation. Both terms are expressed in units of Pascals $(\mathrm{Pa})$.

The ratio of loss and storage moduli can provide information about the magnitude of viscous energy loss in relation to elastic energy stored and is numerically equal to the tangent of the phase shift angle in a cyclic deformation:

$$
\tan \delta=\frac{G^{\prime \prime}}{G^{\prime}}
$$

\subsubsection{Large Deformation Testing}

During processing as well as consumption (mastication), foods are exposed to large deformations. Large deformation tests of structured foods are most commonly carried out in compression between parallel flat surfaces and can be used to establish both empirical and fundamental physical and mechanical properties of the material. However, empirical models have very limited predictive capacity (Bagley, 1983).

Engineering stress, $\sigma_{0}$, may be defined as the force per initial undeformed cross-sectional area: 


$$
\sigma_{0}=\frac{F}{A_{0}}
$$

In large deformation compression testing, Henkey's stress and strain must be calculated in order to represent the true stress and strain during the loading process, and for determining maximal strength. True stress, $\sigma_{\text {true }}$ may be defined as the force per unit area of the deformed material at any moment during the deformation process, and at the point of failure (Nussinovitch et al., 1990):

$$
\sigma_{\text {true }}=\frac{F_{\max }\left(L-\Delta L_{\text {max }}\right)}{A_{0} L}
$$

where $F_{\max }$ is the compressive force at failure, $\Delta L_{\max }$ is the corresponding deformation at failure, $A_{0}$ is the original contact surface area, and $L$ is the original length of the sample.

The corresponding engineering strain, $\varepsilon$, for a cylindrical sample compressed between two parallel lubricated plates is defined as:

$$
\varepsilon=\Delta L / L
$$

where $L$ is the initial length of the specimen. True normal strain is given by the following equation (Hamman, 1983):

$$
\varepsilon_{\text {true }}=-\ln [1-(\Delta L / L)]
$$

\subsection{Composite Gels}

\subsubsection{Theoretical Models}

Theoretical models developed to explain mechanical and rheological behaviour of composite materials have been derived from the field of polymer 
science. Most are based on an assumption of complete binding between the continuous and dispersed phases. A review of these models was compiled by Chow (1980). Simple models of food systems usually consist of more than two phases with water usually being the predominant phase. Therefore, application of synthetic polymer models to food-based composite systems may be limited because the presence of large amounts of water may affect interactions between the matrix and particles, which these models are unable to account for.

For composite gels, assuming complete adhesion between the phases, Lewis and Nielson (1970) derived the following model to obtain the modulus ratio G/G:

$$
\frac{G}{G_{0}}=\frac{1+A B \varphi}{1-B \alpha \varphi}
$$

where $G$ is the modulus of the composite, and $G_{0}$ is the modulus of the matrix or continuous phase. The constant, $A$, accounts for the geometry of the filler phase and the Poisson ratio, $v$, of the matrix, and is defined by:

$$
A=\frac{7-5 v}{8-10 v}
$$

The Poisson ratio, determined from a compression test, is defined as the ratio of lateral strain to axial strain. The constant, $B$, accounts for the relative moduli of the filler and matrix (equal to 1 for large $G / G_{0}$ ratios) and is defined by:

$$
B=\frac{G_{f} / G_{o}-1}{G_{f} / G_{0}-A}
$$

where $G_{f}$ is the modulus of the filler particle. The parameter, $\alpha$, is dependent on the maximum packing fraction of filler, $\varphi_{m}$, and the volume fraction, $\varphi$, of the included 
particles:

$$
\alpha=1+\left[\left(1-\varphi_{m}\right) / \varphi_{m}^{2}\right] \varphi
$$

\subsubsection{Empirical Models}

Due to the difficulty in applying theoretical models to experimental results for food-based systems, many researchers have used empirical relationships to describe their data. For example, Ross-Murphy and Todd (1983) developed the following equation to describe glass bead inclusions in a gelatin matrix:

$$
\sigma_{\mathrm{r}}=(1-\varphi)^{-5 / 2} \cdot\left(1-\varphi^{1 / 3}\right)
$$

where $\sigma_{\mathrm{r}}$ is the relative stress at failure and $\Phi$ is the volume fraction occupied by the glass beads.

\subsubsection{Food-Based Composite Studies}

Some research has been carried out on structure and behaviour of foodrelated gels containing filler particles. The principal studies in this field have focused on protein gels (Richardson et al., 1981; Ross-Murphy and Todd, 1983; Brownsey et al., 1986,1987; Brownsey and Morris, 1988; Langley and Green, 1989; Green et al., 1990; McClements et al., 1993). Carbohydrate gels, in the form of starch gels, have been studied by Ring and Stainsby (1982); while Nussinovitch et al. (1992) used alginate and $\mathrm{K}$-carrageenan polymers to form their matrices.

Using rigid glass bead inclusions dispersed in a whey protein matrix, Langley and Green (1989) observed an overall increase in the relative stress at failure with increasing volume fraction. However, there was an initial decrease in relative stress 
at failure until the volume fraction reached approximately $20 \%$. Thomas (1994) observed similar behaviour with polystyrene microsphere inclusions in whey protein gels, however, the gel strength minimum was seen between 5 and $10 \%$ volume fraction, and was dependent on filler particle size. Alternately, with gelatin gel studies, also using rigid filler particles, an overall gel strength increase was observed (Richardson et al., 1981; Ross-Murphy and Todd, 1983).

Other filler particles such as Sepharose have been used by Ring and Stainsby (1982), Brownsey et al. (1987), and Green et al. (1990). In these studies, relative compressive stress reinforcement was not as great as with glass beads, and was found to be related to the mechanical properties of the filler particles, with more compliant particles having the least contribution to structural reinforcement. This finding was also noted in a comparison of compression test data of full- and reduced-fat cheeses, where full-fat cheese exhibited a softer structure as compared to the low-fat cheese (Emmons et al., 1980; Masi and Addeo, 1986).

In whey protein gels made with lipid inclusions, relative stress at failure continued to decline as the rigidity of the filler particle decreased (Green et al., 1990). These researchers found that a gel containing butterfat was stronger than a gel made with a vegetable oil. An attempt was made to measure the influence of deformability by testing gels containing fats of different hardness at the same temperature, and harder fats did indeed exhibit higher relative strengths. 


\section{OBJECTIVES}

In order to better understand the roles of individual food phases on the overall textural properties of a composite food, it is important as a first step to study model systems in which the components may be more readily controlled, as opposed to more complex foods. A model composite system would consist of a matrix, representing the continuous phase, and particulates, representing the dispersed phase of the composite food system. The major objective of the present research study was to investigate the influence of the mechanical and rheological properties of both the matrix and the filler particles on the overall textural properties of selected model composite systems.

To achieve this objective, fundamental rheological properties of a model continuous phase based on the bacterial polysaccharide, gellan, were examined in order to better understand its functionality in a gel-forming structured food. A variety of textures may be produced simply by altering the concentration of metal ions used to make the gellan gels. Also, the rapid gelling characteristics of gellan made it well suited for creating deformable beads of varying rigidities.

To better test the influence of the rheological properties of the filler particle on the overall structure of the composite, both rigid (glass) beads and deformable (gellan) beads were considered as filler particles for inclusion in the gellan matrix. Relative rheological and mechanical properties of the matrix in comparison to the rigidities of the filler particles could then be measured. The objective of these measurements was to test the hypothesis that in a weak matrix, a rigid particle provides structural reinforcement, but in a strong matrix, a weak particle decreases 
the overall rheological and mechanical properties of the system. As a final step, the information obtained from the present research was compared to the existing theoretical and empirical models used to describe the behaviour of composites. 


\section{MATERIALS AND METHODS}

\subsection{Gellan Solutions}

Gellan carbohydrate polymer was obtained from NutraSweet Kelco (San Diego, CA) under the brand name of Kelcogel F. Aqueous solutions of gellan were made on a weight to weight basis as required for specific studies, and heated to boil. When required, calcium in the form of anhydrous $\mathrm{CaCl}_{2}$ (Fisher Scientific, Ottawa, ON) was added to the solutions in concentrations ranging from 0.004 to $0.5 \mathrm{M} \mathrm{Ca}^{2+}$, to obtain the desired final gel characteristics. Any water lost due to evaporation was added back prior to cooling and the onset of gelation.

\subsubsection{Gel Microstructure}

Gellan gel structure was examined using cryo-SEM procedures. Small gel samples ( $2 \mathrm{~mm} \times 2 \mathrm{~mm} \times 5 \mathrm{~mm}$ ) were cut from gels prepared as above, and gently inserted into metal rivets so that the gel protruded out of the top opening. Each rivet was then immersed into liquid propane for 15 seconds to freeze. Samples were subsequently stored under liquid nitrogen until use. Under freezing conditions, the entire rivet was placed into a copper mounting block and fractured to expose the gel structure. Fractured gels were allowed to sublimate for 20 to 30 minutes under high vacuum and cold temperatures $\left(-180^{\circ} \mathrm{C}\right)$, then sputter-coated with gold to an approximate thickness of $30 \mathrm{~nm}$. The gel structures were observed using a Hitachi S-570 SEM (Hitachi Ltd., Tokyo, JP) at -120 to $-160^{\circ} \mathrm{C}$ with an accelerating beam voltage of $5-10 \mathrm{kV}$. 


\subsection{Gellan Bead Production}

Because of its rapid gelling properties and its ability to form gels of varying rigidity by selecting polymer and metal ion concentrations, gellan polymer was chosen as the material with which to prepare deformable beads from.

Geilan beads were made using the principles of a water-in-oil emulsion. Initially, calcium, at three concentration levels was added to $1.0 \%(w / w)$ gellan solutions, as described above, to obtain three bead rigidities based on the $\mathrm{Ca}^{2+}$ concentration: $0.005,0.01$ and $0.015 \mathrm{M} \mathrm{Ca}^{2+}$. A $1.0 \%$ gellan solution and oil, both heated to $95^{\circ} \mathrm{C}$ in separate beakers, were combined and blended at high shear in a 1:4 (v/v) ratio, using a commercial Waring Blendor (Waring Products Division, Dynamics Corp. America, New Hartford, CT). Before coalescence of the unstable gellan solution-in-oil dispersion could occur, the mixture was poured over ice chips (Figure 4.1). This procedure served to reduce the temperature sufficiently to induce gelation of the gellan, thereby creating beads which averaged $100 \mu \mathrm{m}$ in diameter.

The hydrophobic nature of the oil and the high percentage of water in the gellan beads allowed the particles to be separated easily from the oil by washing with water. A subsequent rinse with hexane in a separation funnel was carried out to remove residual oil from the beads (Figure 4.2). The slight difference in density between the beads and the water was used as a convenient method of concentration; the beads settled to the bottom of the collection flask over a 1-2 day settling period. Much of the excess water, along with non-bead material which floated to the surface, was easily pumped off, leaving a concentrated bead dispersion behind. Additional process parameters are given in the flow diagrams, 
Figures 4.1 and 4.2.

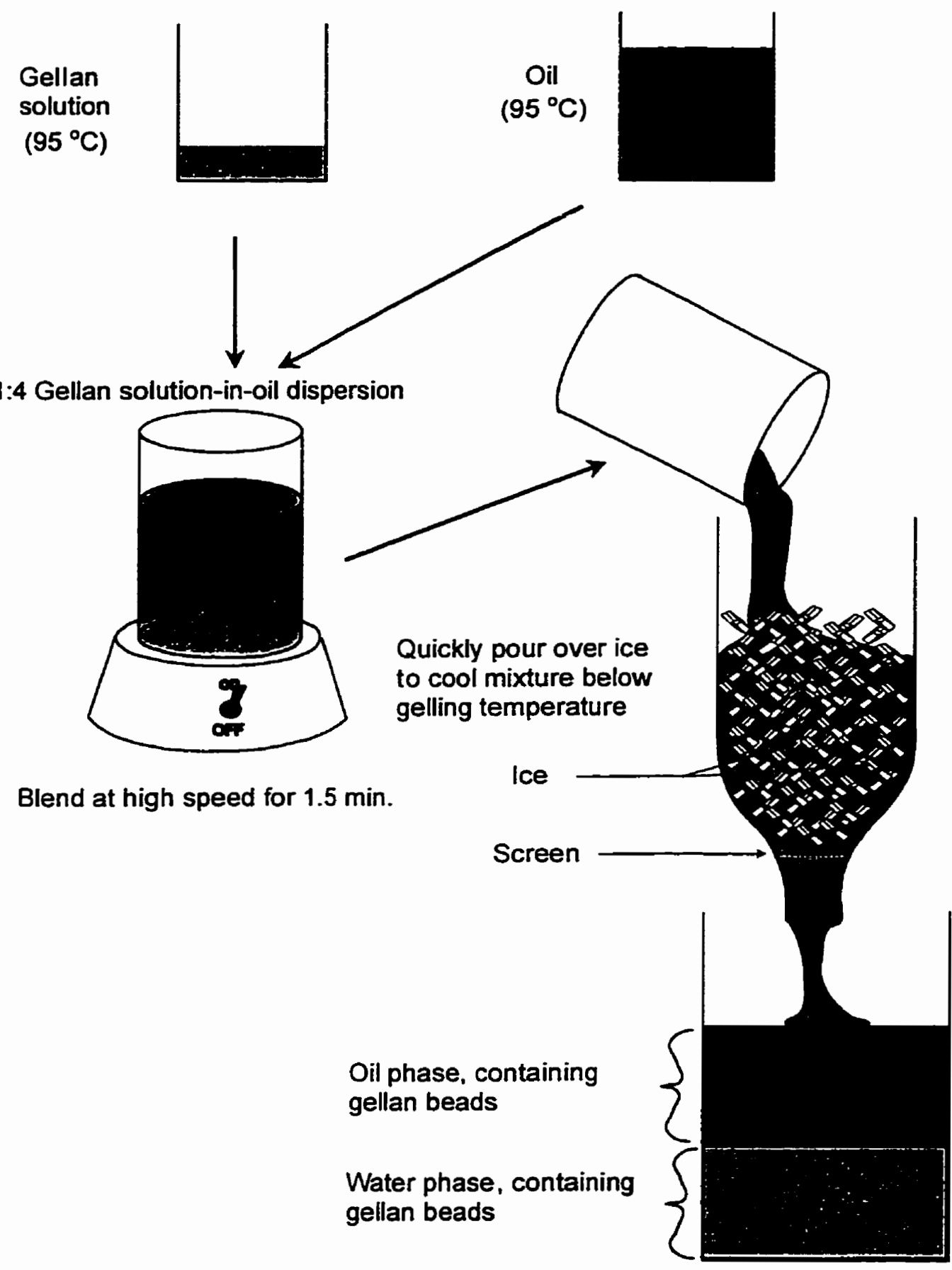

Fig. 4.1 Flow diagram and process parameters for gellan bead production. 


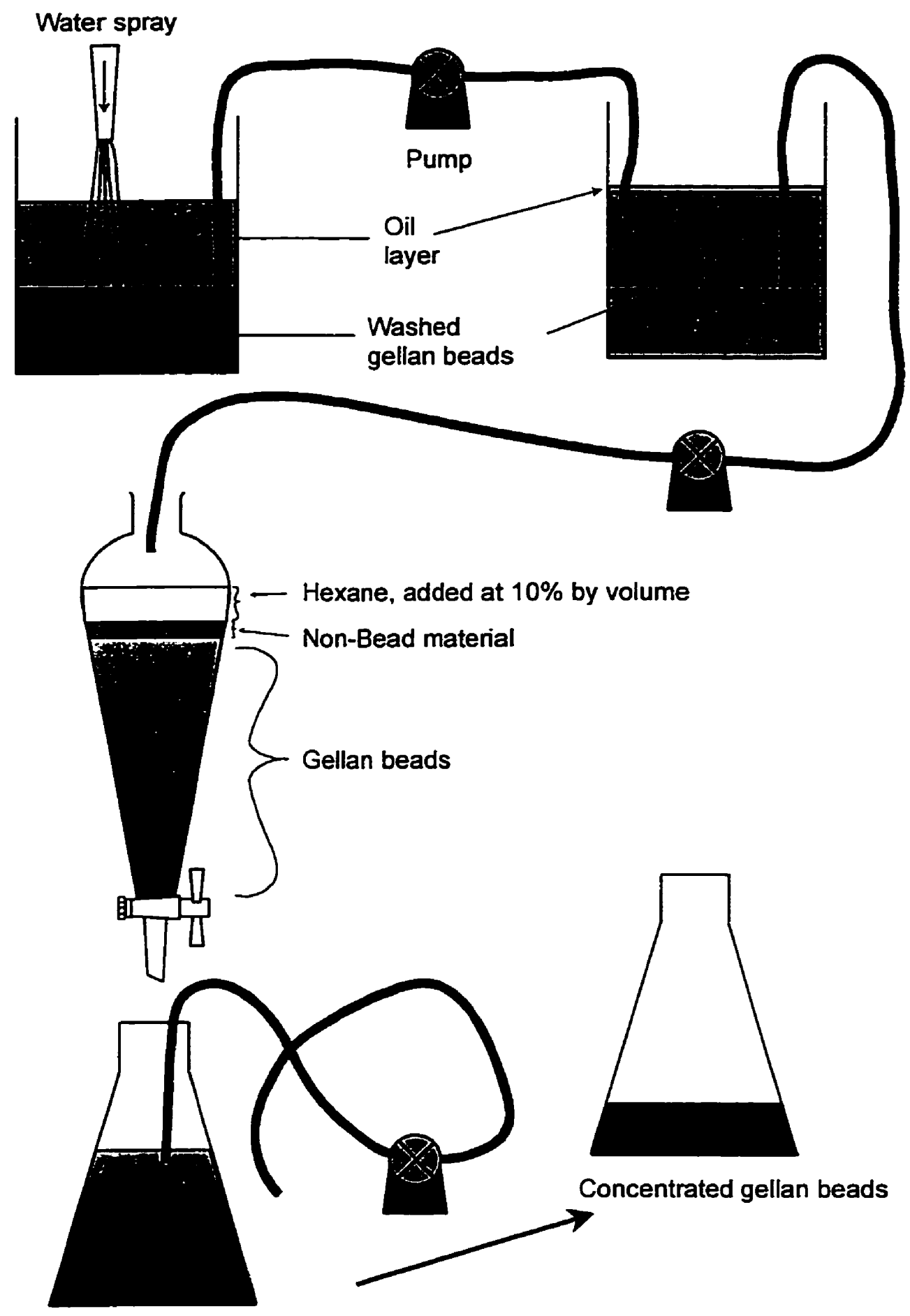

Settle, pump off supernatant

Fig. 4.2 Gellan bead separation, washing and concentration procedures. 


\subsection{Particle Sizing}

\subsubsection{Gellan Beads}

Gellan beads produced from each of the three gellan solutions $(0.005,0.01$ and $0.015 \mathrm{M} \mathrm{Ca}^{2+}$ ) were suspended in a small amount of water on a microscope slide, stained with toluidine blue and viewed under medium and high power with a brightfield light microscope. The graduated scale visible in the microscope eyepiece was calibrated with a stage micrometer slide and subsequently used to determine particle size. Areas for measurement were chosen randomly and all beads in the field of view were sized for each gellan dispersion. Average particle size was found to be $100 \mu \mathrm{m}$, with a distribution ranging from 20 to $300 \mu \mathrm{m}$.

For comparative purposes, the gellan particle size distribution was also established with a laser light scattering technique using a Malvern Mastersizer $\mathrm{X}$ (Malvern Co., Malvern, UK) and supporting software. With this technique, the average particle size of gellan beads was also found to be $100 \mu \mathrm{m}$, but the distribution was greater (10 to $600 \mu \mathrm{m}$ ) and normal only when plotted on logarithmic coordinates. The Mastersizer displayed particle size distribution data calculated on a volume basis. These data were converted to a number distribution and normalized with respect to the total number of beads in solution, allowing for the calculation of a percent concentration when combining these data with a population density.

A population density of the stock bead suspension was determined by counting the number of beads in a field of view on a slide of known volume. The percent volume concentration of gellan beads was then used to calculate how much 
stock suspension would have to be added to make a composite gel of predetermined bead volume fraction.

\subsubsection{Glass Beads}

Glass beads in three size ranges were purchased from Jencons Scientific Ltd. (Bridgeville, PA). Bead size and distributions were determined with the aid of scanning electron microscopy (SEM). A sample of each size range was mounted on SEM stubs with the aid of "sticky tabs", sputter-coated with $30 \mathrm{~nm}$ of gold at ambient temperature, and observed in a Hitachi S-570 Scanning Electron Microscope (Tokyo, JP). Five images of each glass bead size were captured to disk and analyzed using Mocha Image analysis software (Jandel Scientific, Sausalito, CA). The diameter of all beads visible on each SEM image was measured. These images revealed uniform sphericity and a narrow, normally distributed particle size distribution ranging from 50 to $100 \mu \mathrm{m}$ with an average of $80 \mu \mathrm{m}$.

\subsection{Composite Gellan Gels}

Composite gels were prepared using gellan solutions for the gel matrix, and either gellan or glass beads as the particle inclusions. The gellan solutions used for all composite gels ranged from 0.0035 to $0.020 \mathrm{M} \mathrm{Ca}^{2+}$. Calculated volumes of glass beads or gellan bead stock solution were added to $1.0 \%(w / w)$ gellan solutions $\left(95^{\circ} \mathrm{C}\right)$ at 10,20 and $30 \%$ volume fractions (VF). A 0\% VF gellan gel (containing no beads) was also prepared to serve as the reference. The gellan bead/gellan solution mixtures were poured into PVC moulds to form thin disk-shaped gels for 
small amplitude oscillatory rheological testing, and into tube moulds to form samples for large deformation testing, as described below (section 4.4.1). The glass bead/gellan solution mixtures were treated differently, however, to prevent glass beads from settling out before gelation was complete (section 4.4.2).

\subsubsection{Composite Gels Containing Gellan Beads}

To prepare gels for small amplitude oscillatory testing the hot composite gellan bead/gellan solution mixtures, prepared as above, were poured directly into the mid-plate section of the PVC mould shown in Figure 4.3. The mould consisted of top and bottom plates, and a mid-plate of known thickness containing $2.0 \mathrm{~cm}$ diameter holes in which the gel disks were cast. This disk diameter corresponded to the rheometer fixture being used. Two different mid-plate sections were used, corresponding to sample disk thicknesses of 3200 and $4600 \mu \mathrm{m}$.

A temperature-stable laminated retort pouch film was attached to the bottom of the mid-plates with adhesive tape to prevent leakage as gellan mixtures were poured into the mould. Care was taken not to incorporate any air bubbles during pouring. Assembly of the mould, by adding the bottom and top plates and fastening the sections together as shown, was completed immediately after pouring to minimize evaporation. Gels in the mould were allowed to cool to ambient temperature before testing.

Gels for large deformation testing were prepared by pouring the hot composite gellan bead/gellan solution mixtures into metal tubes $(2.1 \mathrm{~cm}$ i.d. $\times 20$ cm long), stoppered at both ends, and allowed to cool. A cutting guide was 
developed to ensure uniform and square cuts from the cylindrical gel samples. The tube mould fitted directly into one end of the cutting guide; the gel was pushed from the tube towards calibrated slits in the guide (Figure 4.4). A single sided razor blade (with the back removed) was used to cut gel disks following the guide slits. Two aspect ratios (thickness to diameter) were chosen for the disks, corresponding to 0.5 and 1.0 times the gel sample diameter.

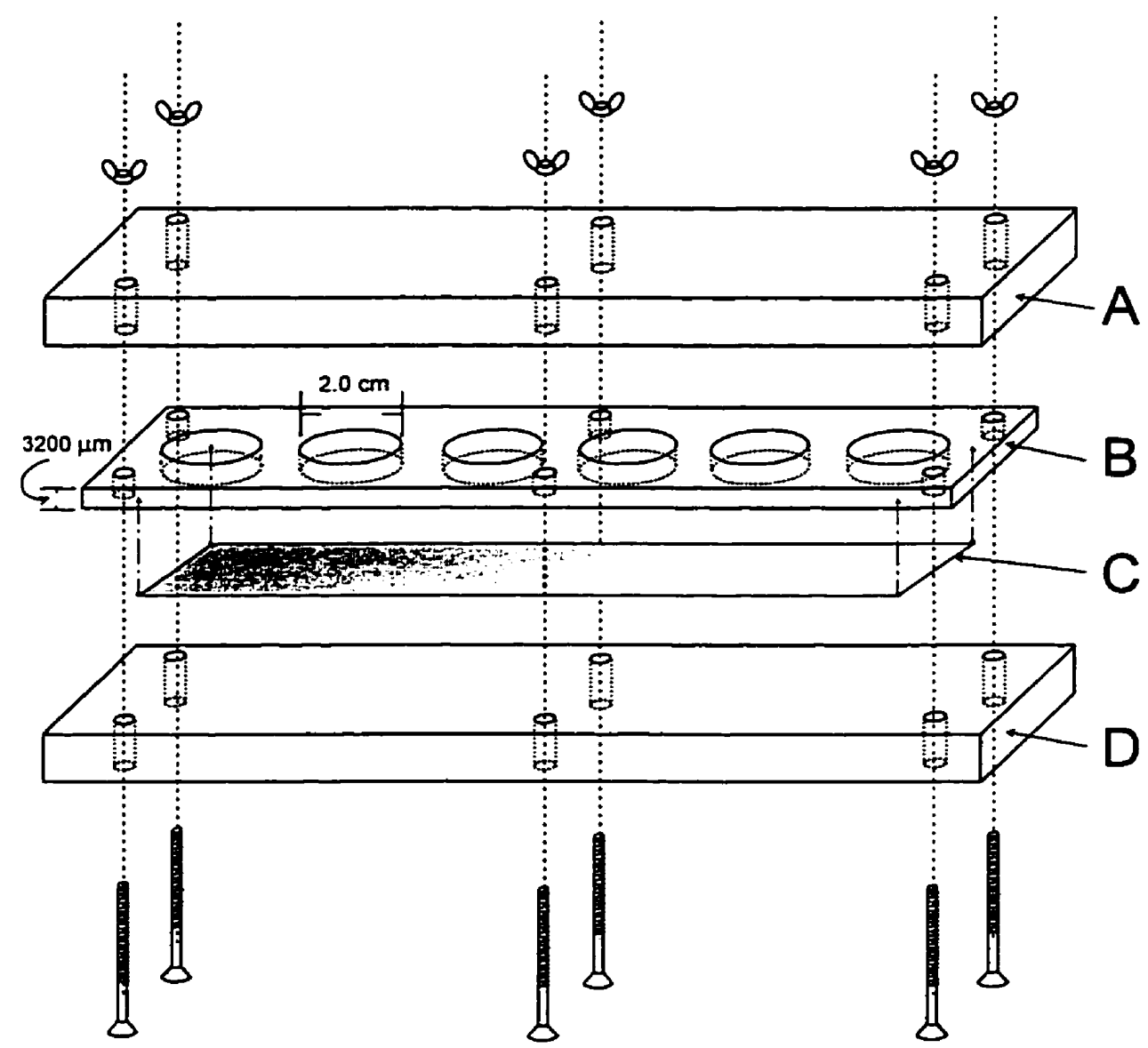
A - Top plate
B - Mid plate
C - Temperature-stable film
D - Bottom plate

Fig. 4.3 Exploded view of PVC mould used to form gel disks for small amplitude oscillatory testing. 


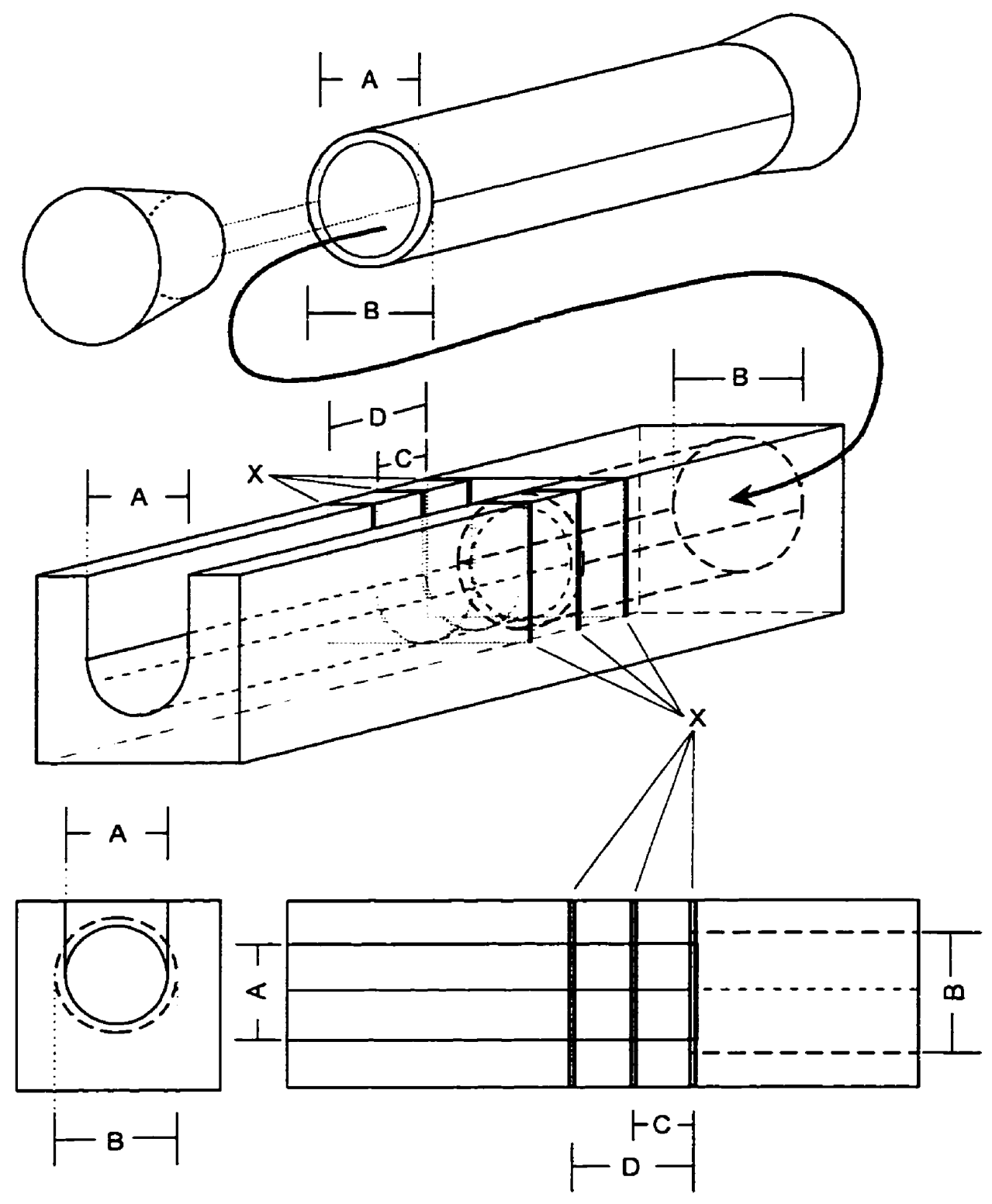

A - Inside tube diameter = sample diameter

$B$ - Outside tube diameter

C - Slit corresponding to a height to diameter ratio of 0.5

$D$ - Slit corresponding to a height to diameter ratio of 1.0

$X$ - Slits used for cutting gel with razor blade

Fig. 4.4 Cylindrical mould and cutting guide used for sample preparation in mechanical testing. 


\subsubsection{Composite Gels Containing Glass Beads}

Composite gels for both small amplitude oscillatory testing and large deformation failure testing were prepared in a similar manner. The glass bead/gellan solution mixtures were kept in beakers and allowed to cool in a refrigerator with sufficient stirring to keep the glass beads from settling out. Stirring was discontinued when a noticeable increase in viscosity was detected visually, just prior to gelation. Once gelled, the samples were removed from the refrigerator and allowed to equilibrate to room temperature. A thin-walled open tube $(2.0 \mathrm{~cm}$ i.d. $)$ was used to cut out rod-like sections of gel from the beakers.

Using the mid-plates of the PVC mould as a guide, disks of $3200 \mu \mathrm{m}$ were cut from the gel rods to obtain samples for small amplitude oscillatory testing. Large deformation testing samples were cut from the gel rods using the cutting guide as described in 4.4.1.

\subsection{Intrinsic Viscosity}

A rolling ball viscometer (AMV-200, Anton Paar, Graz, AU) was used in measuring the zero shear viscosity of the dilute gellan solutions. The viscometer was fitted with a $0.90 \mathrm{~mm}$ glass capillary tube containing a $0.794 \mathrm{~mm}$ steel ball; calibration was carried out using distilled water at experimental capillary tube angles of 40,50 , and $60^{\circ}$. A circulating water bath was used to control the temperature of the instrument at $25.0^{\circ} \mathrm{C}$. Viscosity measurements of the dilute gellan solutions were also made at the above angles. Viscosity values were calculated by the KVS Software (Ver. 3.15) used to run the AMV-200 from a personal computer by using 
the rolling time of the ball between two reference positions along the tube and the densities of the ball and test solution as input data.

Gellan solutions to be tested were prepared by boiling a known weight of gellan $(0.2000 \mathrm{~g}$ to $0.0100 \mathrm{~g})$ in a small volume of water in a beaker, adding a calculated amount of $\mathrm{Na}^{+}$counterion $(0$ to $1.0 \mathrm{M})$, transferring the mixture to a $100.00 \mathrm{~mL}$ volumetric flask and filling to volume. $\mathrm{Na}^{+}$counterion $(\mathrm{NaCl})$ addition was carried out as an isoionic dilution in order to keep the total ion concentration associated with the polymer the same at all polymer concentrations. By knowing the amount of ions contributed by the polymer, and the desired final concentration, it was possible to calculate the difference in order to obtain the amount of counterion to be added. In this study, the amount and type of ions associated with the polymer were determined by averaging data obtained by the manufacturer with those from an independent testing laboratory (Table 4.1).

Table 4.1 Ion content of gellan polymer used for isoionic dilution calculation.

\begin{tabular}{cccccc} 
& $\mathrm{Ca}^{2+}(\%)$ & $\mathrm{Mg}^{2+}(\%)$ & $\mathrm{Na}^{+}(\%)$ & $\mathrm{K}^{+}(\%)$ & $\mathrm{P}(\%)$ \\
\hline $\begin{array}{c}\text { Independent } \\
\text { Lab }^{1}\end{array}$ & 0.76 & 0.1 & 0.53 & 4.9 & 0.12 \\
$\begin{array}{c}\text { NutraSweet } \\
\text { Kelco }\end{array}$ & 0.31 & 0.1 & 0.4 & 3.8 & 0.15 \\
\hdashline Average & 0.53 & 0.1 & 0.465 & 4.35 & 0.135 \\
\hline
\end{tabular}

1 Personal communication from V. Marcille-Kerslake, Analytical Services Laboratory, University of Guelph, Guelph, ON

2 "The NutraSweet Kelco Company, Product Nutritional Data: Kelcogel F", NutraSweet Kelco, San Diego, CA 
As a measure of transition from dilute to concentrated polymer rheology, the critical concentration, $C^{\star}$, of gellan polymer solutions was determined. This was accomplished by gradually increasing the polymer concentration $(0.0100 \mathrm{~g}$ to $0.5000 \mathrm{~g}$ ) and determining the corresponding specific viscosity. Gellan solutions for critical concentration determination were made and measured in a similar fashion as those used in intrinsic viscosity data.

\subsection{Flow Properties}

A Carri-Med CLS 500 controlled stress rheometer (TA Instruments, New Castle, DE) was used to measure flow properties of 0.5 to $2.0 \%$ gellan solutions (as prepared in 4.1 , without calcium). Low shear rate tests $\left(0.1\right.$ to $\left.300 \mathrm{~s}^{-1}\right)$ were conducted using a coaxial cylinder fixture $\left(18.5\left(R_{1}\right) \times 20.75\left(R_{2}\right) \times 50 \mathrm{~mm}\right)$ surrounded by a fluid jacket, circulating water to maintain the temperature. Higher shear rate $\left(1\right.$ to $\left.1000 \mathrm{~s}^{-1}\right)$ tests were carried out using both $4 \mathrm{~cm} 4^{\circ}$ and $6 \mathrm{~cm} 1^{\circ}$ cone and plate geometries, with temperature control being achieved with the Peltier plate.

Polymer concentration effects on flow were studied to make inferences about polymer-polymer interaction behaviour. These were measured at $45^{\circ} \mathrm{C}$ in order to be able to compare a full range of concentrations $(0.5-2.0 \%)$ without gelation occurring at higher polymer levels.

Temperature effects were studied by measuring the flow properties of a $0.5 \%$ gellan solution at $5,10,15,20,25,30,35$, and $45^{\circ} \mathrm{C}$, using cone and plate geometries. A temperature sweep was also performed, using the Peltier plate for 
temperature control. A $3 \mathrm{C} / \mathrm{min}$ ramp rate was used to scan the viscosity of a $0.5 \%$ gellan solution during cooling from 35 to $5^{\circ} \mathrm{C}$ and back to $35^{\circ} \mathrm{C}$. In these tests, the gap between the geometry and the Peltier plate was automatically adjusted at 0.2 $\mathrm{mm} / \mathrm{C}^{\circ}$ to compensate for thermal expansion of the geometry and Peltier plate (gap contraction).

\subsection{Small Amplitude Oscillatory Testing}

Oscillatory measurements on the gellan gels were carried out on a Carri-Med $\mathrm{CSL}^{2} 500$ controlled stress rheometer using parallel plate fixtures $(5 \mathrm{~cm}$ and $2 \mathrm{~cm}$ diameter). However, preliminary results showed that there was no difference in the storage or loss moduli between the two plate diameters and sample thicknesses (4600 and $3200 \mu \mathrm{m})$. Therefore, subsequent experiments were carried out using just the $2 \mathrm{~cm}$ parallel plate and a gel thickness of $3200 \mu \mathrm{m}$.

Each gel disk (as prepared in 4.4.1 and 4.4.2) was attached to the fixture using Krazy glue ${ }^{\oplus}$ before the geometry was connected to the Carri-Med. Glue was then spread on the Peltier plate, and the pneumatic ram was raised to make contact with the gellan gel disk. The gap between the upper plate fixture and the lower Peltier plate was preset to correspond to the sample thickness.

The linear viscoelastic range (LVR) for all samples was determined at an oscillatory frequency of $1 \mathrm{~Hz}$ over a torque sweep of $0.64-3000 \mathrm{~Pa}$. For gellan gels, the LVR was influenced by gel rigidity, so that softer, and more compliant gels tended to have a large LVR, while firmer, more rigid gels had a very narrow LVR. 
Gel samples were subjected to a frequency sweep of 0.01 to $10 \mathrm{~Hz}$ at a strain of 0.05 percent, with the Peltier plate controlling the sample temperature at $22.5 \pm 0.1^{\circ} \mathrm{C}$. A sufficiently low strain value was required to compare test results for a wide variety of gel rigidities. The viscoelastic properties, shear storage modulus $\left(G^{\prime}\right)$ and shear loss modulus $\left(G^{\prime \prime}\right)$, were calculated by the system software. All samples were run in triplicate, and the entire experiment was repeated in duplicate.

\subsection{Large Deformation Testing}

A Model 1122 Instron Universal Testing Machine (Instron, Canton, MA) equipped with a $500 \mathrm{~N}$ load cell and Instron Merlin Series IX software was used to evaluate all gels by compression testing. Samples that had been equilibrated to room temperature were compressed to failure (about $90 \%$ of original height) between two parallel lubricated Teflon plates at a crosshead speed of $20 \mathrm{~mm} / \mathrm{min}$. Lubricated plates were used to avoid "barrelling" of the sample as force was applied, and thereby, inducing biaxial extensional flow. In such a case, assuming there is no change in sample volume (incompressable) the ratio of lateral strain to axial strain, the Poisson's ratio, $v$, is equal to 0.5 (Juvinall, 1967). Force versus deformation data were gathered by the software at 10 points per second. These data were then exported to a spread sheet for further analyses. At least 5 replicate gel samples were tested for each duplicate composite gel tube prepared. 


\section{RESULTS AND DISCUSSIONS}

\subsection{Intrinsic Viscosity of Gellan Polymer}

Reduced viscosity $\left(\eta_{\text {red }}\right)$, as calculated from the viscosity values obtained from dilute gellan solutions, was plotted against polymer concentration to obtain a piot typically associated with charged polymers (Figure 5.1). With no added counterion salt $\left(\mathrm{Na}^{+}\right), \eta_{\text {red }}$ increased slightly at concentrations greater than $0.10 \%$ gellan; however, as polymer concentration decreased $(<0.05 \%), \eta_{\text {red }}$ increased sharply. Other researchers have also demonstrated that $\eta_{\text {red }}$ of solutions made with charged polymers and no added electrolytes increased substantially with decreasing polymer concentration (Lapasin and Pricl, 1995; Tobitani and Ross-Murphy, 1997).

Three "electroviscous" effects have been postulated by Lapasin and Pricl (1995) in an effort to explain the increase in viscosity with increasing dilution. First, as a macroion moves through a shear field, any trace counterion clouds present may be distorted from electrical symmetry, thus increasing the drag forces which result in increased viscosities. At the inherent low concentrations of both the polymer and counterions, this effect is probably negligible. Another effect believed to cause an increase in viscosity is that of Coulomic repulsion forces; as two macroions approach one other, their repulsion will change their original pathways in solution, thus dissipating energy which in turn increases the viscosity of the solution. However, the largest viscosity effect most likely comes from the reconfiguration of the polymer in solution as the ionic strength of the solution decreases. When the trace counterions associated with the polymer are diluted, as the polymer is diluted, the net charge on the polymer decreases, resulting in the 
possible expansion of the macromolecule, which in turn may cause an increase in solution viscosity.

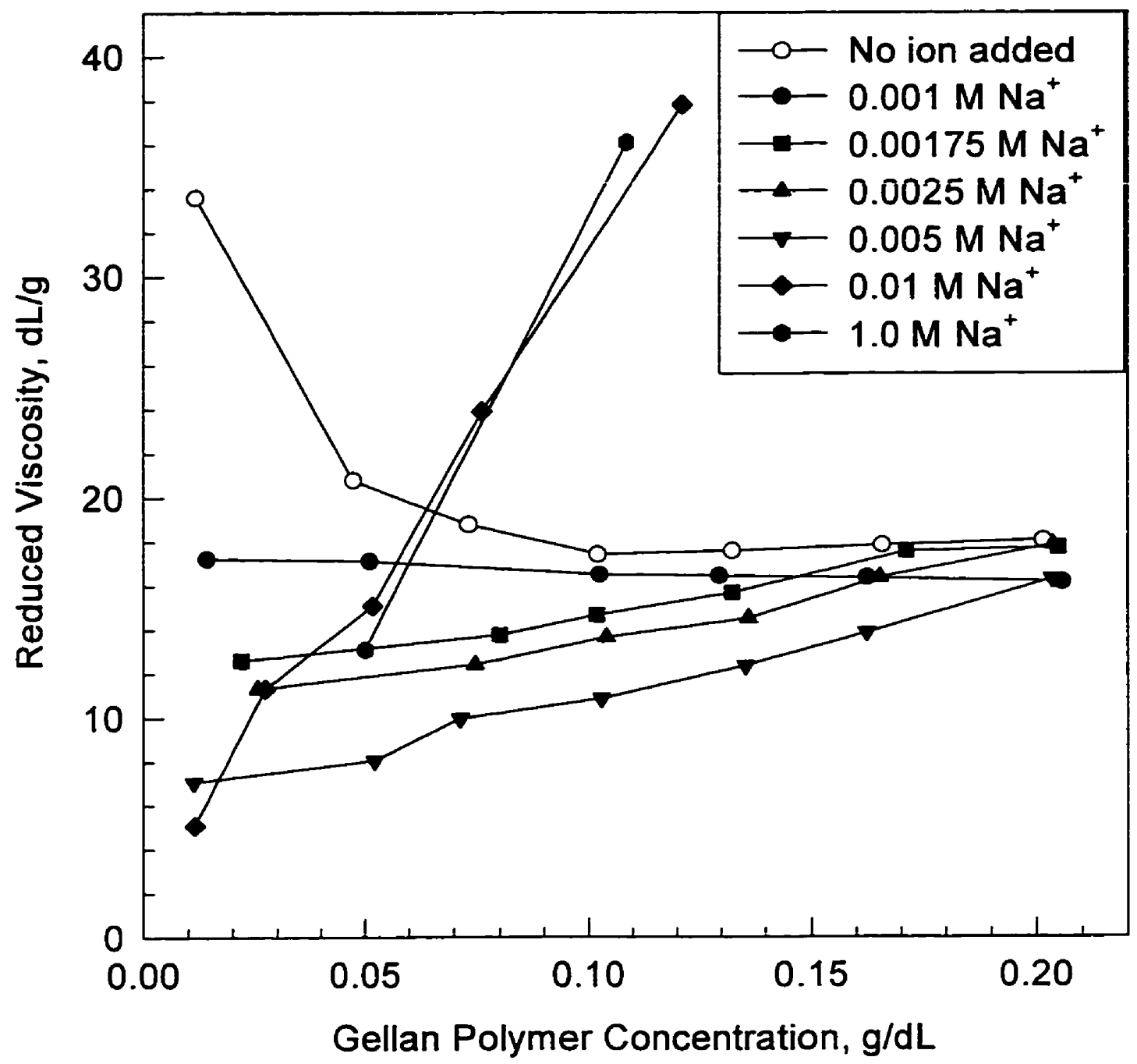

Fig. 5.1 Reduced viscosity of dilute gellan polymer solutions at various counterion concentrations at $25^{\circ} \mathrm{C}$.

Figure 5.1 also shows that the addition of small amounts of $\mathrm{NaCl}$ to the gellan solutions could result in polymer behaviour which is more representative of a non-charged molecule. At $0.001 \mathrm{M} \mathrm{Na}^{+}$, a slight increase in $\eta_{\text {red }}$ was observed as gellan concentration decreased, suggesting that this counterion concentration did 
not eliminate the electroviscous effects. However, at 0.00175 to $0.005 \mathrm{M} \mathrm{Na}^{+}$, reduced viscosity as a function of polymer concentration exhibited a linear decrease, more typical of an uncharged polymer as polymer concentration approached zero.

Viscosity data at higher $\mathrm{Na}^{+}$concentrations were inconsistent and did not follow expected results. During rolling ball viscometric studies, it was noted that the ball did not roll in a smooth and continuous manner, but rather in a "jerky" motion, suggesting that there were "particulates" present which could interfere with the ball's movement. These particulates were likely the result of small aggregates or "domains" which formed upon the association of polymer chains.

Intrinsic viscosity values were determined at four different ion concentrations $\left(0.001\right.$ to $\left.0.005 \mathrm{M} \mathrm{Na}^{+}\right)$to assess the effect of ion concentration. Linear regression extrapolations to zero polymer concentration were carried out using reduced viscosity (Figure 5.1) and inherent viscosity as plotted in Figure 5.2, each of which should provide a similar estimate of intrinsic viscosity upon extrapolation to zero concentration. Table 5.1 shows the intrinsic viscosity values obtained by these two methods, along with the calculated average. The decrease in intrinsic viscosity of gellan as a function of increasing ionic strength may be attributed to conformational changes within the polymer, which could result in a more compact molecule. 


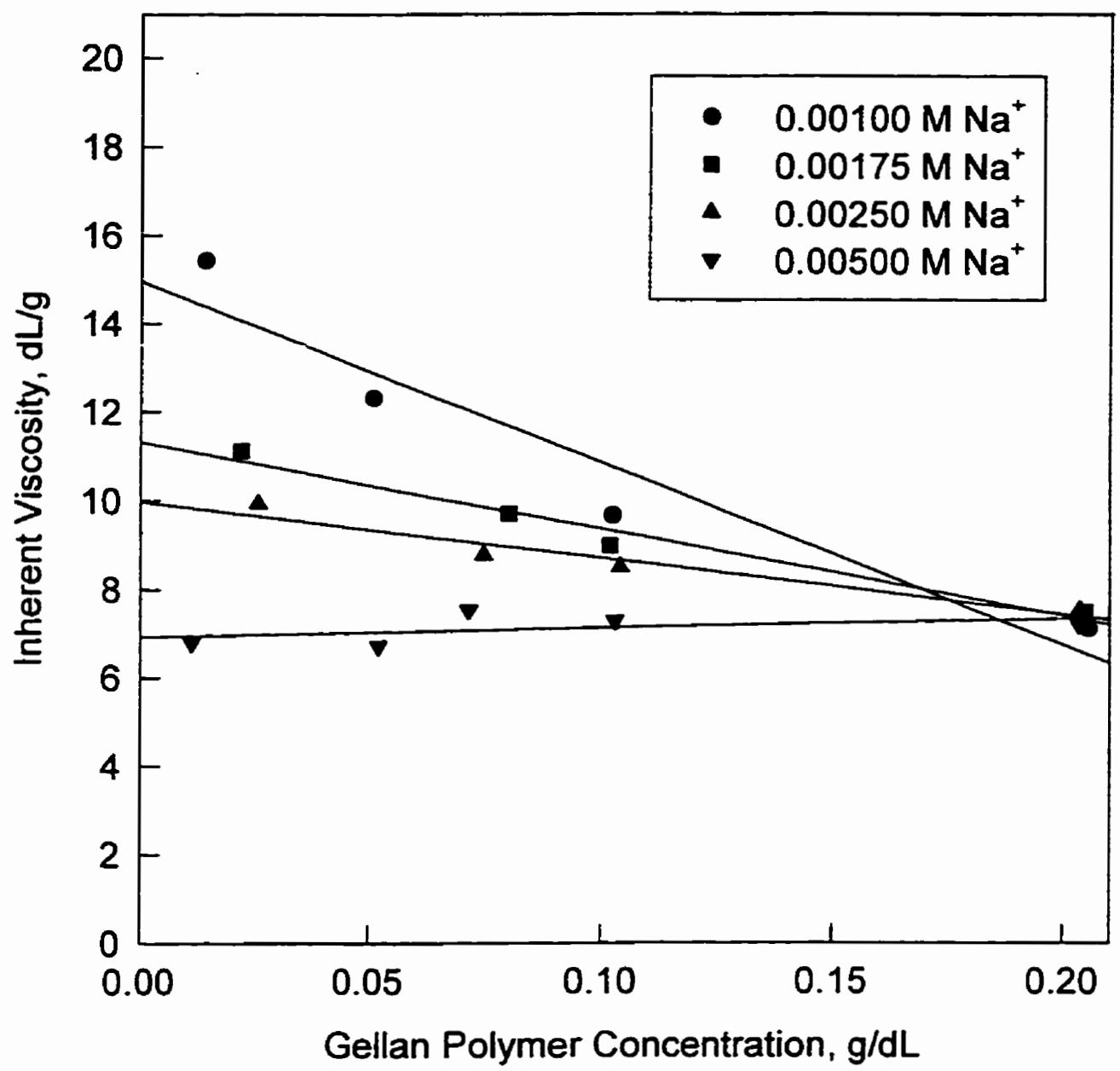

Fig. 5.2 Inherent viscosity of gellan polymer solutions at various counterion concentrations at $25^{\circ} \mathrm{C}$. Linear regression curve fitting was used to extrapolate to zero concentration at the ordinate to obtain an estimate of the intrinsic viscosity for gellan.

The counterion effects can be used to obtain further information with respect to the behaviour of gellan under the applied conditions. The Smidsrød and Haug (1971) model was fitted to the data by plotting average intrinsic viscosity values against the inverse square root of ion concentration, resulting in an accurate fit (Figure 5.3). 
Table 5.1 Intrinsic viscosity values of gellan polymer solutions at various $\mathrm{Na}^{+}$ ion concentrations.

Intrinsic. Viscosity, dL/g

\begin{tabular}{cccc}
$\mathrm{Na}^{+}$ & $\begin{array}{c}\text { From Reduced } \\
\text { Viscosity }\end{array}$ & $\begin{array}{c}\text { From Inherent } \\
\text { Viscosity }^{\mathrm{b}}\end{array}$ & Average \\
\hline 0.001 & 17.3 & 14.96 & 16.13 \\
0.00175 & 11.76 & 11.32 & 11.54 \\
0.0025 & 9.94 & 9.98 & 9.96 \\
0.005 & 6.1 & 6.92 & 6.51 \\
\hline
\end{tabular}

a $\rightarrow$ Linear extrapolation from reduced viscosity data (Figure 5.1)

$b \rightarrow$ Linear extrapolation from inherent viscosity data (Figure 5.2)

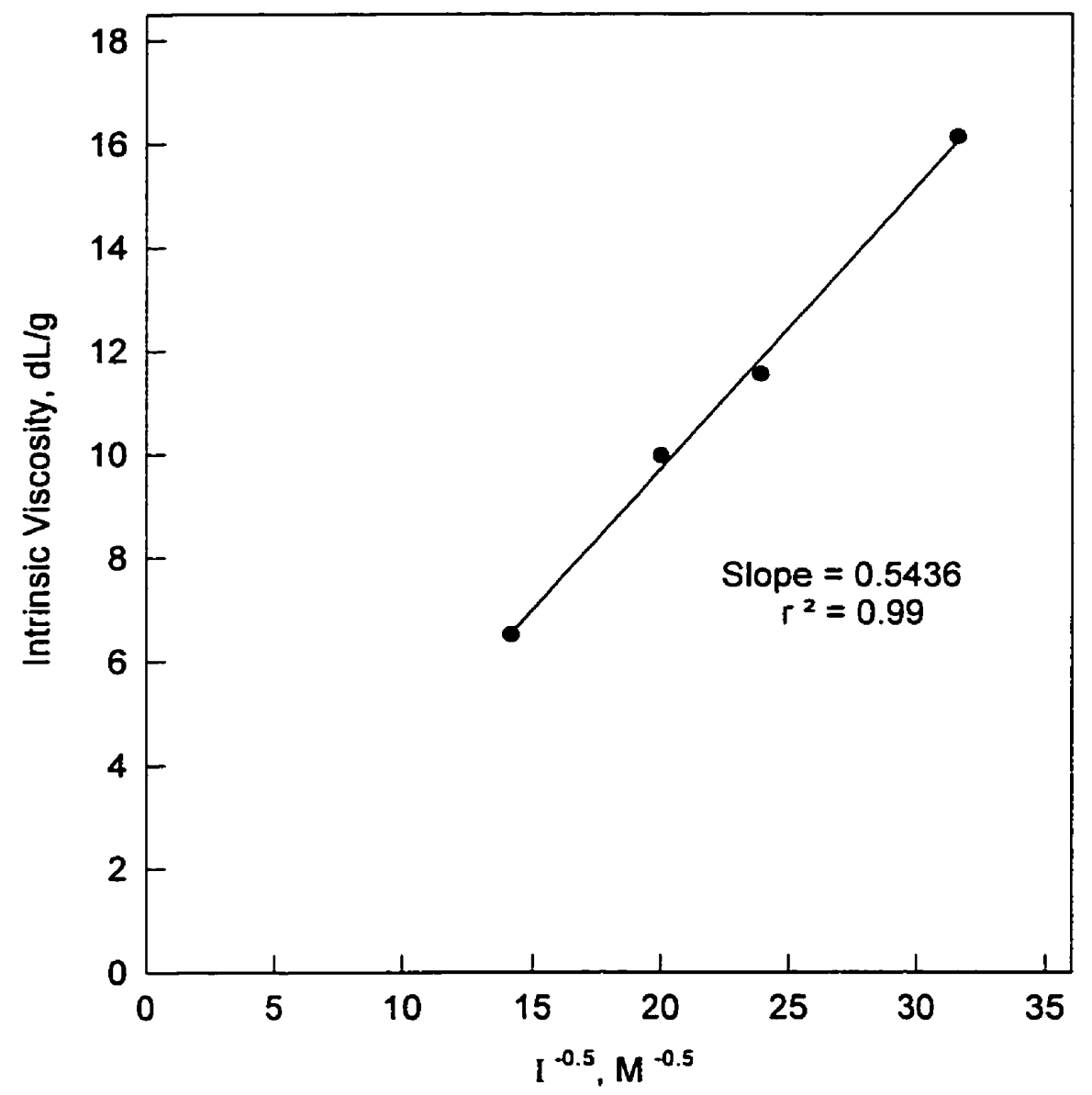

Fig. 5.3 Intrinsic viscosity as a function of the inverse square root of ionic concentration at $25^{\circ} \mathrm{C}$. 
Using equation (10) and an approximate value of 1.3 for the parameter $u$, the B-value or apparent stiffness coefficient for gellan at various counterion concentrations was calculated. The standard ionic concentration reported with B-values in the literature is $0.1 \mathrm{M} \mathrm{NaCl}$, however, as indicated in Figure 5.1, viscosity data could not be obtained above $0.01 \mathrm{M} \mathrm{Na}^{+}$due to intramolecular aggregation of gellan molecules. B-values for gellan were, therefore, calculated for lower ionic concentrations as shown in Table 5.2.

Table 5.2 Apparent stiffness parameter "B-value" for gellan using the Smidsrød and Haug (1971) relationship, calculated at various ion concentrations.

\begin{tabular}{ccc}
$\begin{array}{c}\text { Ionic Concentration, } \\
M\end{array}$ & $\begin{array}{c}\text { Intrinsic Viscosity, } \\
\mathrm{dL} / \mathrm{g}\end{array}$ & $\begin{array}{c}\text { Apparent Stiffness, } \\
\text { "B-value" }\end{array}$ \\
\hline 0.00100 & 16.13 & 0.01463 \\
0.00175 & 11.54 & 0.02262 \\
0.00250 & 9.96 & 0.0273 \\
0.00500 & 6.51 & 0.0475 \\
\hline
\end{tabular}

The B-value data obtained can still provide useful information about the sensitivity of gellan molecules to ions in solution, although no direct comparisons to literature values at $0.1 \mathrm{M} \mathrm{NaCl}$ could be made. Based on the interpretation that the smaller the B-value, the stiffer the polymer, these data indicate that the apparent stiffness of gellan polymer decreases with increasing ion concentration.

Since viscosity data were measured at isoionic counterion concentrations, it can be assumed that the conformation of gellan was constant at a specific polymer concentration. Therefore, an examination of intrinsic viscosity and B-value 
data suggests that, in dilute solutions, gellan exists as a random coil that contracts and becomes more flexible with increasing monovalent cation concentration. This means that the ionic charge of the system could have induced a specific conformation to the gellan polymer. The increase in flexibility with increasing ionic strength may be due to ion substitution. When heated, the polymer expands according to thermodynamic laws, thus potentially breaking any divalent cation intramolecular bridges. Some researchers suggest that gellan becomes a single stranded coil at higher temperatures $\left(>35^{\circ} \mathrm{C}\right.$ ) (Milas et al., 1990). In either case, the available charge site created on one side of the bridge could then be filled with a monovalent cation. As the system is cooled, the polymer may again contract or reconfigure in a double helical formation, effectively trapping the monovalent salt. This monovalent cation substitution reduces the amount of intramolecular bridging, thus making the polymer less rigid and allowing the polymer to become more compact, which in turn may decrease the polymer's viscosity-enhancing effect in solution.

As previously mentioned, the apparent stiffness parameter cannot be directly compared to literature values for other polymers; however, the data may be useful to make some inferences about the nature of the gellan polymer. Observing the trend in the B-value data obtained in this study, suggests that the gellan molecule could be somewhat flexible in solutions containing sodium ions at concentrations up to $0.005 \mathrm{M}$. Using different techniques such as static and dynamic light scattering methods, it has also been difficult to establish the flexibility of gellan. Brownsey et al. (1984) and Okamoto et al. (1993) suggested that gellan is very stiff; however, Dentini et al. (1988) suggested that gellan behaves somewhere between 
a rigid rod and a flexible coil. Disagreement seems to stem from the interpretation of light scattering parameters in that some parameters suggest that gellan is a flexible polymer, while others point towards a rigid polymer.

\subsection{Flow Properties of Gellan Solutions}

\subsubsection{Concentration Effects}

With increasing polymer concentrations, intermolecular interactions become more pronounced, ultimately leading to chain overlap, interpenetration and entanglement. The concentration at which this occurs is known as the critical concentration, $C^{*}$, of the polymer. Above this concentration, the solution may be viewed as randomly entangled polymers as a result of the natural Brownian motion of the molecules when the system is at rest.

Specific viscosity measurements as a function of concentration are presented in Figure 5.4. The critical concentration, $C^{*}$, was determined to be at a gellan polymer concentration of approximately $0.064 \%$. In the case of xanthan polymer, $\mathrm{C}^{\star}$ appears to occur at a concentration an order of magnitude lower, at $0.0024 \%$ (Launay et al., 1986). These results may suggest that gellan polymer, like xanthan, becomes highly associated with water, thus being able to control viscosity well, even at very low concentrations. Perhaps this behaviour is aided by the semi-flexible conformation model suggested by the intrinsic viscosity data of this study, and the light scattering data of other researchers in that the inherent flexibility allows for the attainment of lower entropy levels in solution. Because of this low $\mathrm{C}^{*}$, an increase in polymer concentration would lead to a greater entanglement among molecules. 
As a result, the ability of the polymer to form a three-dimensional structure may be enhanced, thus explaining gellan's unique ability to form rigid gels at very low polymer concentrations in the presence of metal cations.

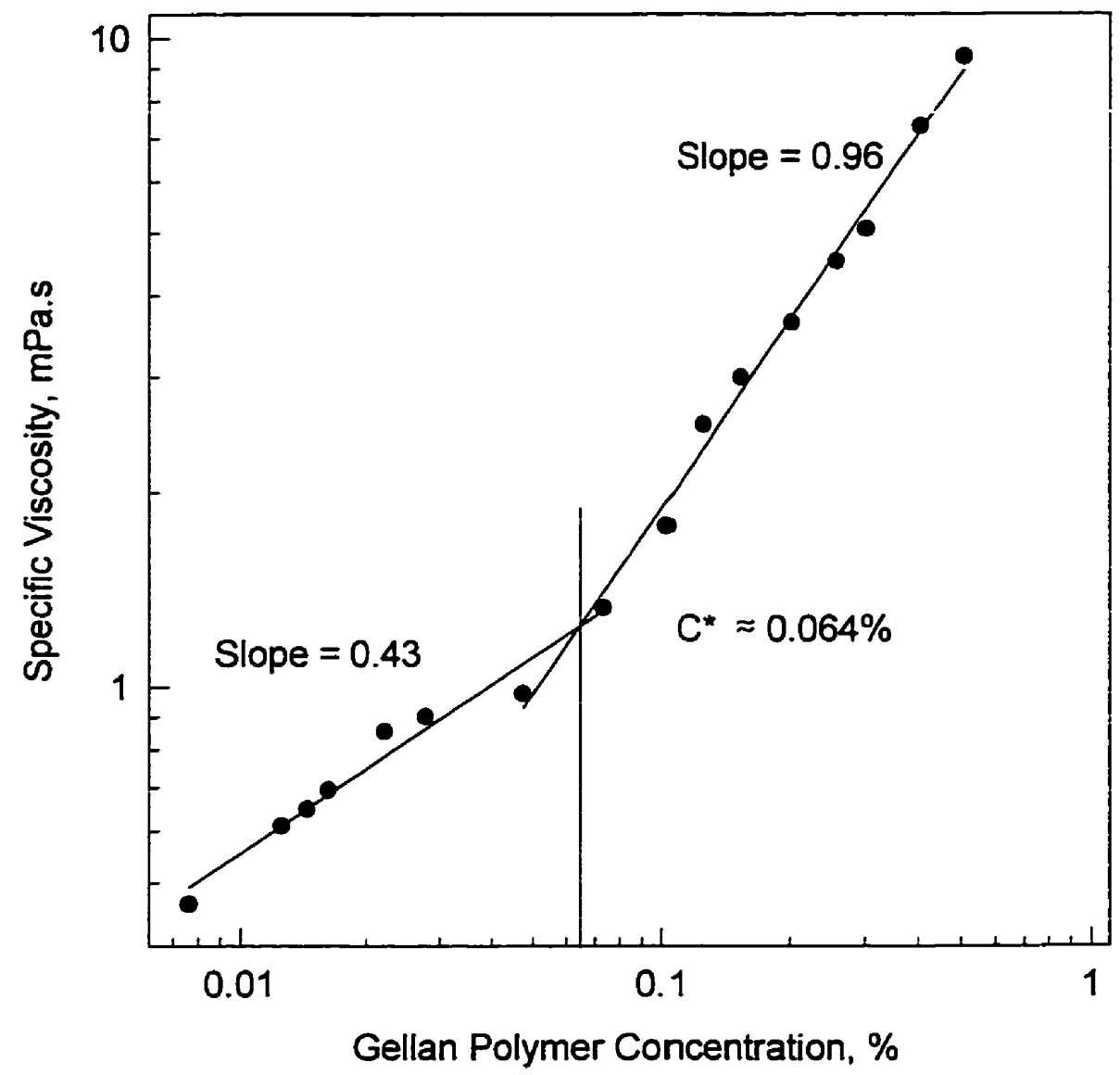

Fig. 5.4 Critical concentration determination of gellan polymer solutions at $25^{\circ} \mathrm{C}$. The change in slope indicates the transition from dilute solution to partial entanglement of molecules, resulting in an increase in low shear viscosity.

The effects of gellan polymer concentration above $C^{*}$ were further studied in steady shearing flow behaviour over a range of shear rates. Preliminary testing indicated that gellan solutions at polymer concentrations above $2.0 \%$ appeared discontinuous, with small gel-like aggregates. Such polymer concentrations, in conjunction with residual metal ions, may be sufficient to cause localized gelation, 
leading to the formation of soft particulates. As a result, concentration effects were studied only for solutions ranging from 0.5 to $2.0 \%$ gellan.

At $45^{\circ} \mathrm{C}$, the flow curves for gellan solutions appeared to be essentially linear over the entire range of concentration, suggesting that flow behaviour could be classified as Newtonian (Figure 5.5). However, upon applying both Newtonian and the Power-law models to the data and observing the trend in the standard error, slight evidence of shear rate thinning was apparent in the $2.0 \%$ solution (Table 5.3 ).

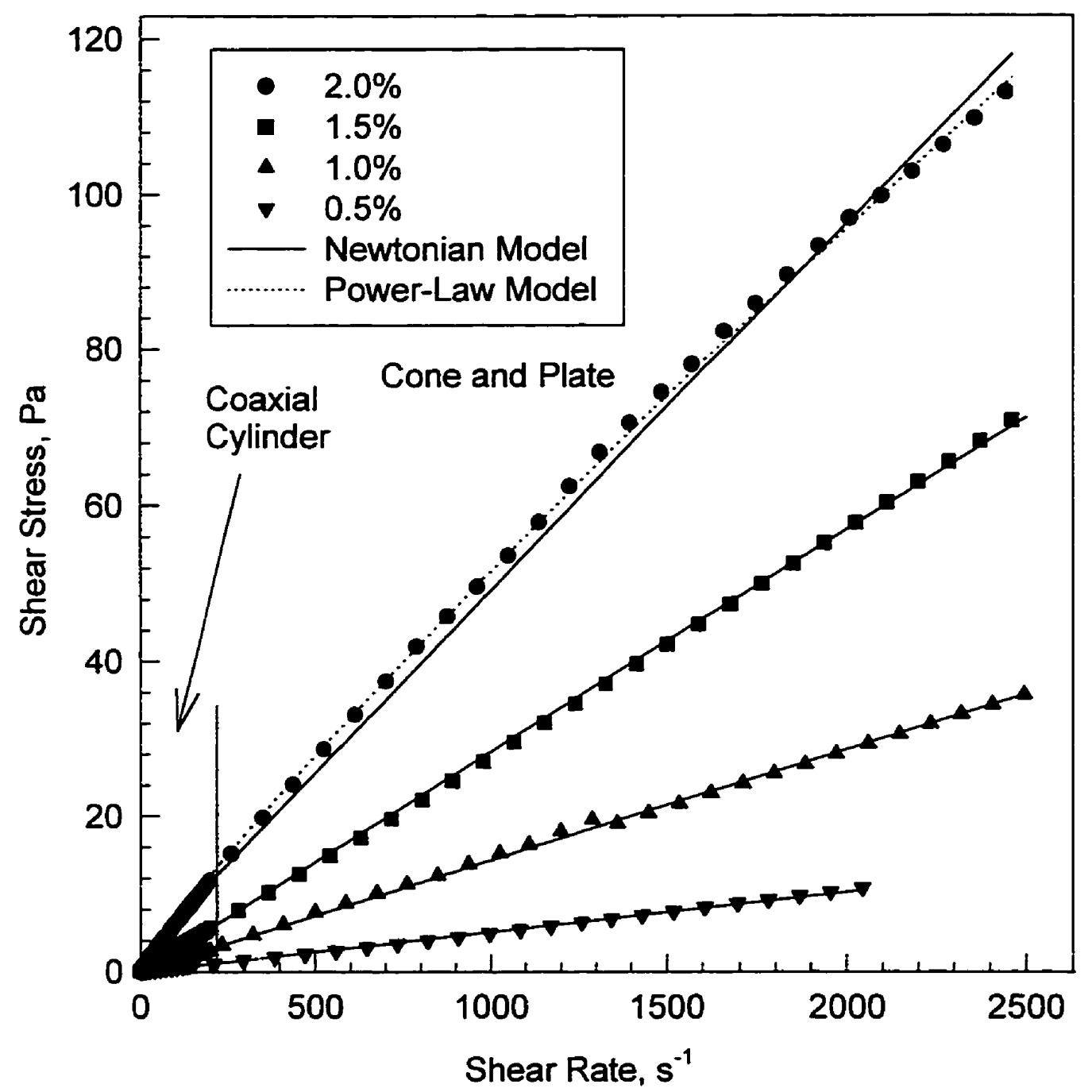

Fig. 5.5 Flow curves of gellan polymer solutions at various concentrations, measured at $45^{\circ} \mathrm{C}$ using a coaxial cylinder and $6 \mathrm{~cm} 1^{\circ}$ cone and plate fixture. 
Table 5.3 Flow behaviour parameters for gellan solutions at different polymer concentrations.

\begin{tabular}{cccccccc} 
& \multicolumn{2}{c}{ Newtonian } & & \multicolumn{3}{c}{ Power-law } \\
\cline { 2 - 3 } $\begin{array}{c}\text { Conc, } \\
\%\end{array}$ & $\begin{array}{c}\eta, \\
\mathrm{mPa} s\end{array}$ & $\begin{array}{c}\text { Standard } \\
\text { Error }\end{array}$ & & $\begin{array}{c}\mathrm{m}, \\
\mathrm{mPa} \mathrm{s}^{\mathrm{n}}\end{array}$ & $\mathrm{n}$ & $\begin{array}{c}\text { Standard } \\
\text { Error }\end{array}$ \\
\hline 0.5 & 5.125 & 0.143 & & 3.47 & 1.053 & 0.101 \\
1.0 & 14.33 & 0.288 & & 16.3 & 0.983 & 0.266 \\
1.5 & 28.47 & 0.386 & & 23.0 & 1.023 & 0.205 \\
2.0 & 48.32 & 2.07 & & 110.6 & 0.890 & 0.699 \\
\hline
\end{tabular}

Using the above rheograms, a function of apparent viscosity versus gellan polymer concentration can be obtained. Plotting these data, it was determined that a linear relationship exists between polymer concentration and apparent viscosity at $200 \mathrm{~s}^{-1}$ when plotted on double log coordinates, suggesting a Power-law type relationship: $\eta_{\mathrm{app}}=\mathrm{a} \mathrm{C}^{\mathrm{b}}$. Evaluation of these parameters yielded the following function of viscosity and concentration under steady shear:

$$
\eta_{\text {app }}\left(\text { at } 200 \mathrm{~s}^{-1}\right)=0.0151 \mathrm{C}^{1.77}
$$

Similar results were obtained by Speers and Tung (1986) studying xanthan solutions. At $45^{\circ} \mathrm{C}$, their values for $a$ and $b$ were $0.0163 \mathrm{~Pa} . \mathrm{s}^{-\mathrm{b}}$ and 1.20 , respectively. In a general review of this topic, Lapasin and Pricl (1995) suggested that, for rigid rods, the exponent, $b$, can vary between 5 and 8 for the above model. Conversely, for random coil polymers, they found an average value of 3.3. In our study, two factors could lead to such a small power. Tine first is that our data were obtained at $45^{\circ} \mathrm{C}$ which is relatively high, but had to be used to be able to obtain a broad enough range without gelation occurring in the sample. Secondly, it may be related to the low $C^{\star}$ and the solution properties for gellan such that, on a relative 
basis, the functionality obtained from a $2 \%$ gellan solution for example, may be comparable to solutions of other polymers at much higher concentrations.

\subsubsection{Temperature Effects}

Flow curves for $0.5 \%$ gellan solutions over a temperature range of 5 to $45^{\circ} \mathrm{C}$ demonstrated that non-Newtonian behaviour became more pronounced at lower temperatures (Figure 5.6). Flow parameter data verified that gellan solutions approached Newtonian flow with increasing temperature (Table 5.4 ). At $45^{\circ} \mathrm{C}$, rheograms appear to be essentially Newtonian; whereas at lower temperatures, the Power-law model more accurately described the rheograms.

Table 5.4 Flow parameters of various models for $0.5 \%$ gellan solutions at different temperatures.

Newtonian

\begin{tabular}{|c|c|c|c|c|c|c|c|}
\hline \multirow[b]{2}{*}{$\begin{array}{l}\text { Temp } \\
{ }^{\circ} \mathrm{C} \\
\end{array}$} & \multicolumn{2}{|c|}{ Newtonian } & \multirow[b]{2}{*}{$r^{2}$} & \multicolumn{4}{|c|}{ Power-law } \\
\hline & $\eta$, Pa.s & $\begin{array}{l}\text { Standard } \\
\text { Error }\end{array}$ & & $m$ & $n$ & $\begin{array}{l}\text { Standard } \\
\text { Error }\end{array}$ & $r^{2}$ \\
\hline 5 & 0.051 & 373.1 & 0.86 & 7.59 & 0.202 & 16.22 & 0.97 \\
\hline 10 & 0.0471 & 352.4 & 0.85 & 6.141 & 0.228 & 18.86 & 0.98 \\
\hline 15 & 0.0422 & 308.8 & 0.85 & 4.142 & 0.273 & 26.55 & 0.98 \\
\hline 20 & 0.0363 & 242.5 & 0.87 & 2.328 & 0.343 & 31.99 & 0.98 \\
\hline 25 & 0.0296 & 195.3 & 0.88 & 0.377 & 0.537 & 16.56 & 0.98 \\
\hline 30 & 0.00737 & 12.36 & 0.99 & 0.00895 & 0.971 & 15.36 & 0.99 \\
\hline 35 & 0.00688 & 0.231 & 0.99 & 0.00276 & 0.911 & 5.65 & 0.99 \\
\hline 45 & 0.00493 & 0.57 & 0.99 & 0.003 & 1.10 & 0.004 & 0.99 \\
\hline
\end{tabular}




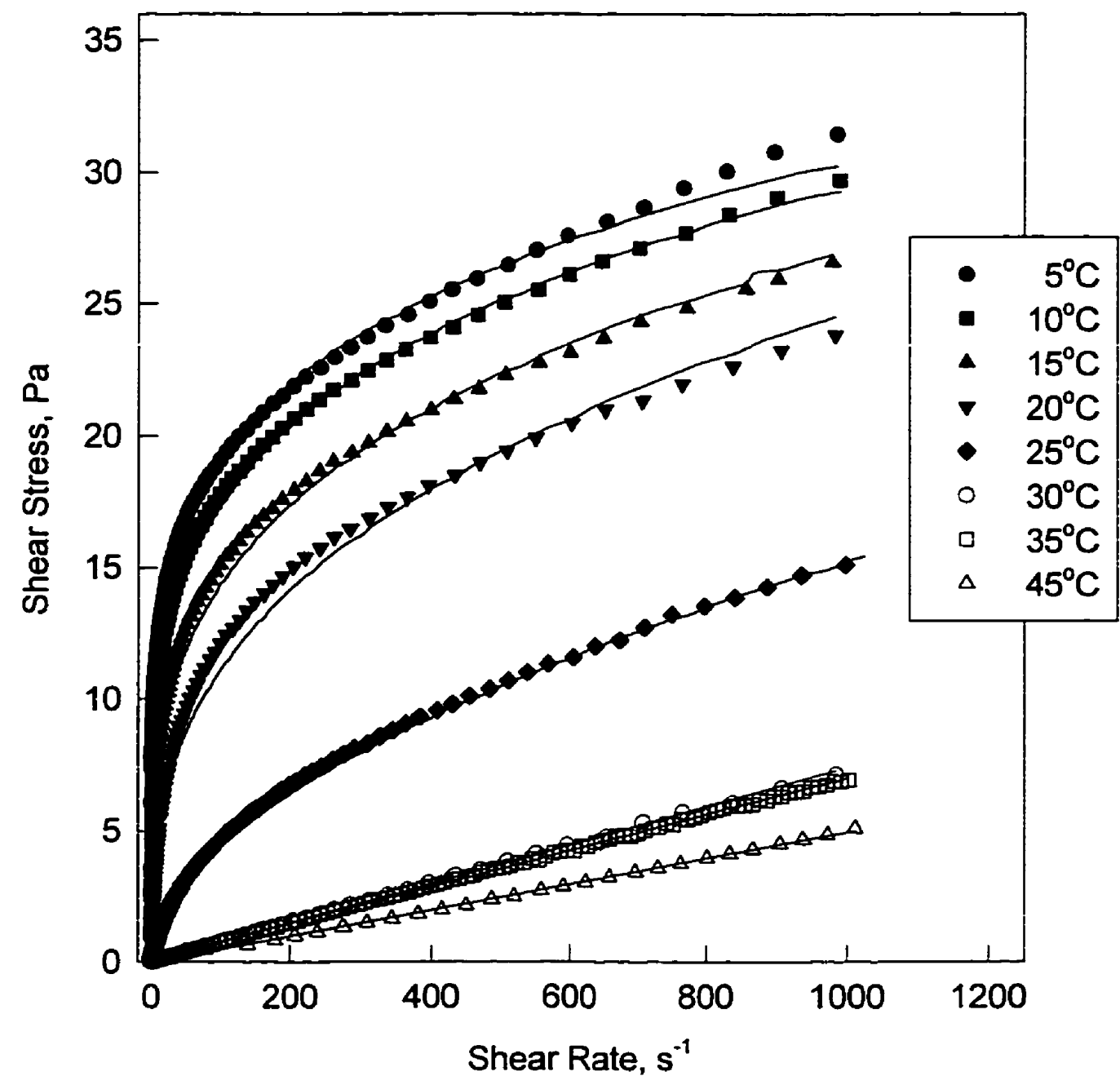

Fig. 5.6 Influence of temperature on flow curves of a $0.5 \%$ gellan solution, measured using cone and plate geometries. Continuous lines are fitted flow models. Corresponding flow parameters are given in Table 5.4 .

An examination of the Arrhenius relationship of temperature and apparent viscosity at various shear rates was found to be a stepped function (Figure 5.7). At higher temperatures, where gellan polymer solutions show Newtonian behaviour, as seen in Figure 5.6, an apparent viscosity vs $1,000 / \mathrm{T}$ plot should exhibit a linear relationship (Steffe, 1996). A second linear region, where gellan shows strong pseudoplastic behaviour, was also found, irrespective of the applied shear rate. 
However, with increasing shear rates, the transition became smaller, but occurred at the same temperature, suggesting that the transition was based on structural changes within the sample.

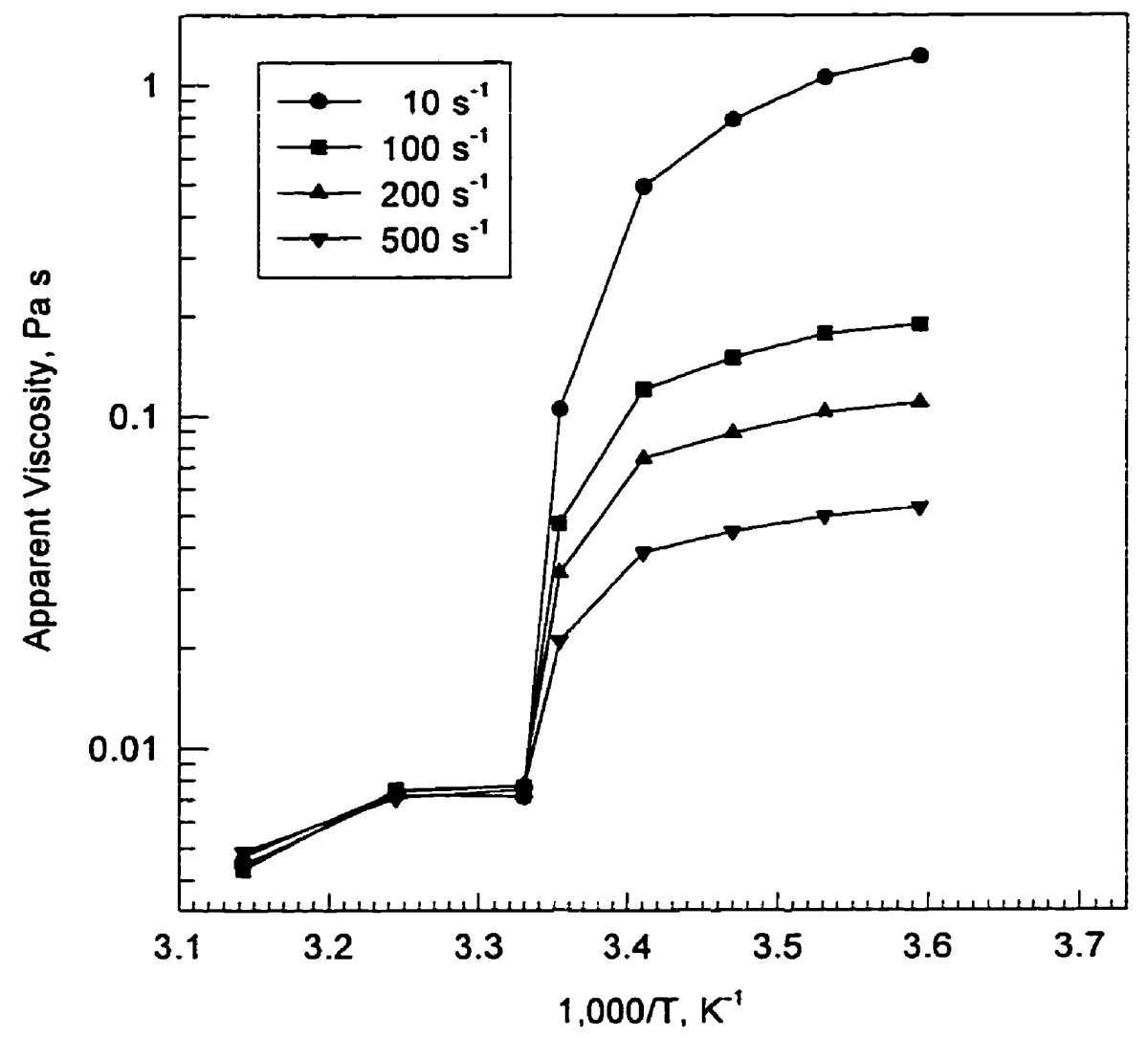

Fig. 5.7 Variation of apparent viscosity taken at various shear rates for a $0.5 \%$ gellan solution measured over a range of temperature.

To make sure that these data were not confounded with time effects, the $5^{\circ} \mathrm{C}$ sample was tested for hysteresis by constructing flow curves where the shear rate was first increased from zero to a predetermined value and then decreased back to zero. Any difference in the resultant curves would indicate time dependence of the sample. Under the applied conditions (shear rate sweep of 0 to $500 \mathrm{~s}^{-1}$ ), no time dependence was evident when comparing up-curves and down-curves using 
significance tests at $p=0.05$ (Appendix $1 \mathrm{~A}, 1 \mathrm{~B})$.

This transition was further explored by measuring the apparent viscosity at specific shear rates over a continuous temperature ramp of $3 \mathrm{C} / \mathrm{min}$ from $35^{\circ} \mathrm{C}$ to $5^{\circ} \mathrm{C}$ and back to $35^{\circ} \mathrm{C}$ (Figure 5.8). In this case, a similar transition was noted as was documented in Figure 5.7. The onset of the transition was measured to be $28^{\circ} \mathrm{C}$, and occurred over a temperature range, depending on the applied shear rate. No substantial difference between the increasing and decreasing temperature scans was observed.

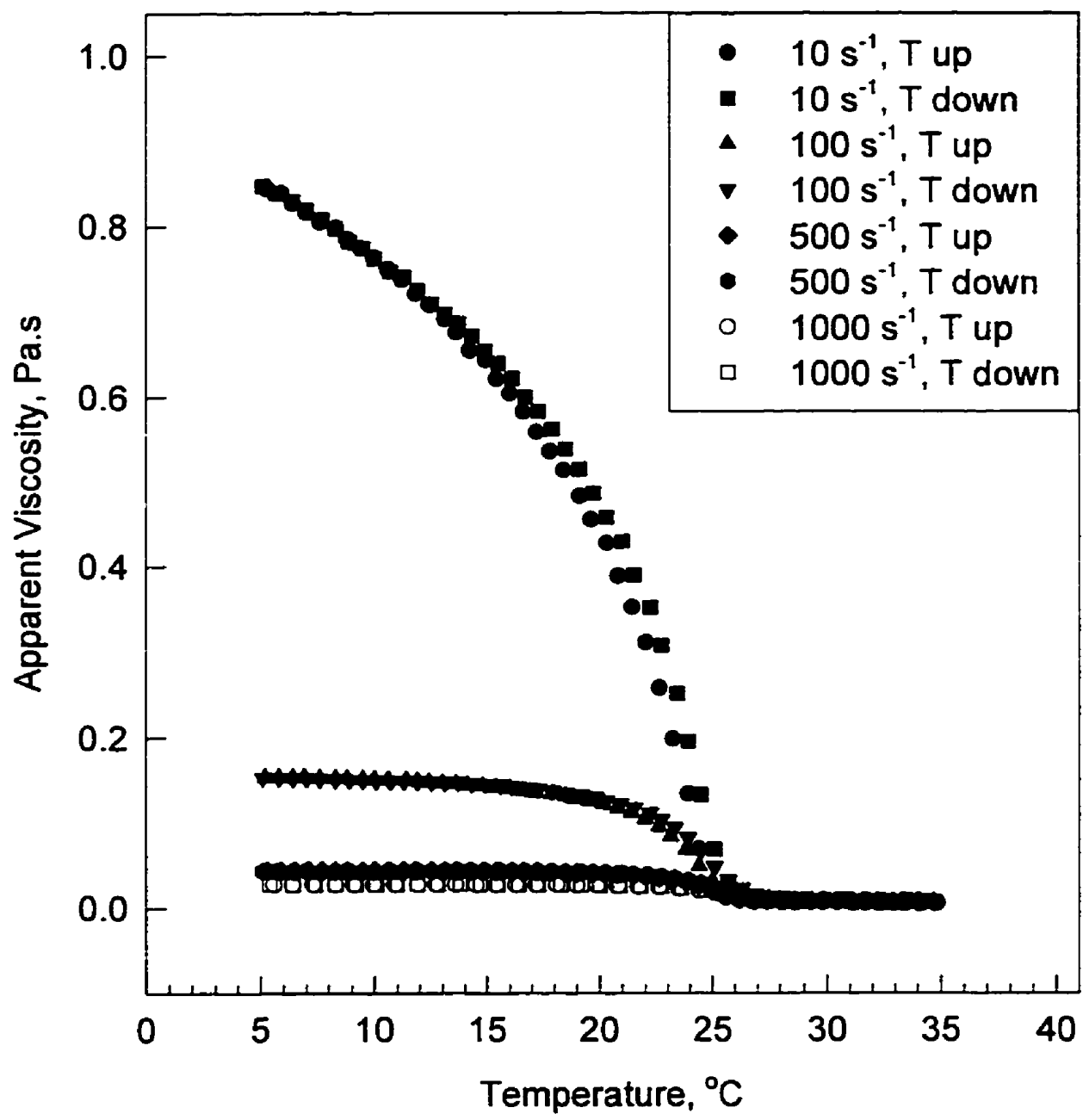

Fig. 5.8 Apparent viscosity as a function of temperature for a $0.5 \%$ gellan solution. Temperature was changed at $3 \mathrm{c} / \mathrm{min}$. 
As indicated earlier, the increase in viscosity with decreasing temperature may be attributed to physical changes within the gellan solution. Previous researchers (Tang et al.,1997) have proven that gellan gelation, in the presence of metal cations, becomes spontaneous below a certain temperature based on thermodynamics. With this in mind, the small amount of cations present in the gellan polymer (Table 4.1) may be enough to cause partial, localized gelation of the polymer solution. As temperatures decreased, "gelation" may have occurred; however, the junction zones or areas of interaction may be spread over such a wide distance that the sample remains essentially liquid under the applied conditions. The resultant sample becomes shear rate dependent because the junction zone interactions or areas of interaction may be sufficiently weak that they may be disrupted under the applied stress, but since the temperature is sufficiently low, the interactions may be created at other locations. With increasing shear rates, the ability to reform the interaction zones may be hindered, thus the observed decrease in viscosity at higher shear rates.

\subsection{Small Amplitude Oscillatory and Large Deformation Testing}

Non-destructive dynamic testing was used to study the viscoelastic properties of various gellan polymer gels. The values obtained from these tests were then compared to large deformation compression tests in an effort to explain the structural properties of gellan gels and to gather additional insight into the gelling mechanisms of this polymer. SEM micrographs were used to provide further support to the interpretation of rheological and mechanical property data. 


\subsubsection{Effects of Calcium Concentration}

Calcium is a divalent ion which is believed to act as a bridge between two adjacent polymer chains at the active (charged) sites, thereby forming, stabilizing and strengthening the three dimensional network (Tang et al., 1995). Both small amplitude oscillatory and large deformation compression tests were used to nondestructively measure the gel rigidity and to destructively measure strength, respectively, of $1.0 \%$ gellan gels formed using calcium ions of varying concentration.

In general, the gel rigidity (as reflected by $G^{\prime}$ ) and the rheological and mechanical properties (as reflected by sample stiffness and stress at failure) of gellan gels reached a maximal value at a specific calcium ion concentration, and then decreased with the addition of more calcium ions. From small amplitude oscillatory data, maximal gel rigidity was found at an ion concentration of about $0.01 \mathrm{M} \mathrm{Ca}^{2+}$ (Figure 5.9).

Figure 5.10A shows that the gel strength maximum, when considering true stress at failure, was at an ion concentration of $0.0065 \mathrm{M} \mathrm{Ca}^{2+}$. When considering apparent modulus, the gel stiffness maximum was observed at about $0.01 \mathrm{M} \mathrm{Ca}^{2+}$, similar to that found using small amplitude oscillatory testing (Figure 5.10B). Each of these parameters allows one to make specific inferences about the structure of gellan polymer gels. Therefore, all components in gel formation must be considered. An interesting starting point is a comparison of the active site on gellan polymer chains, the $\mathrm{COO}^{-}$group, to the amount of $\mathrm{Ca}^{2+}$ added. 


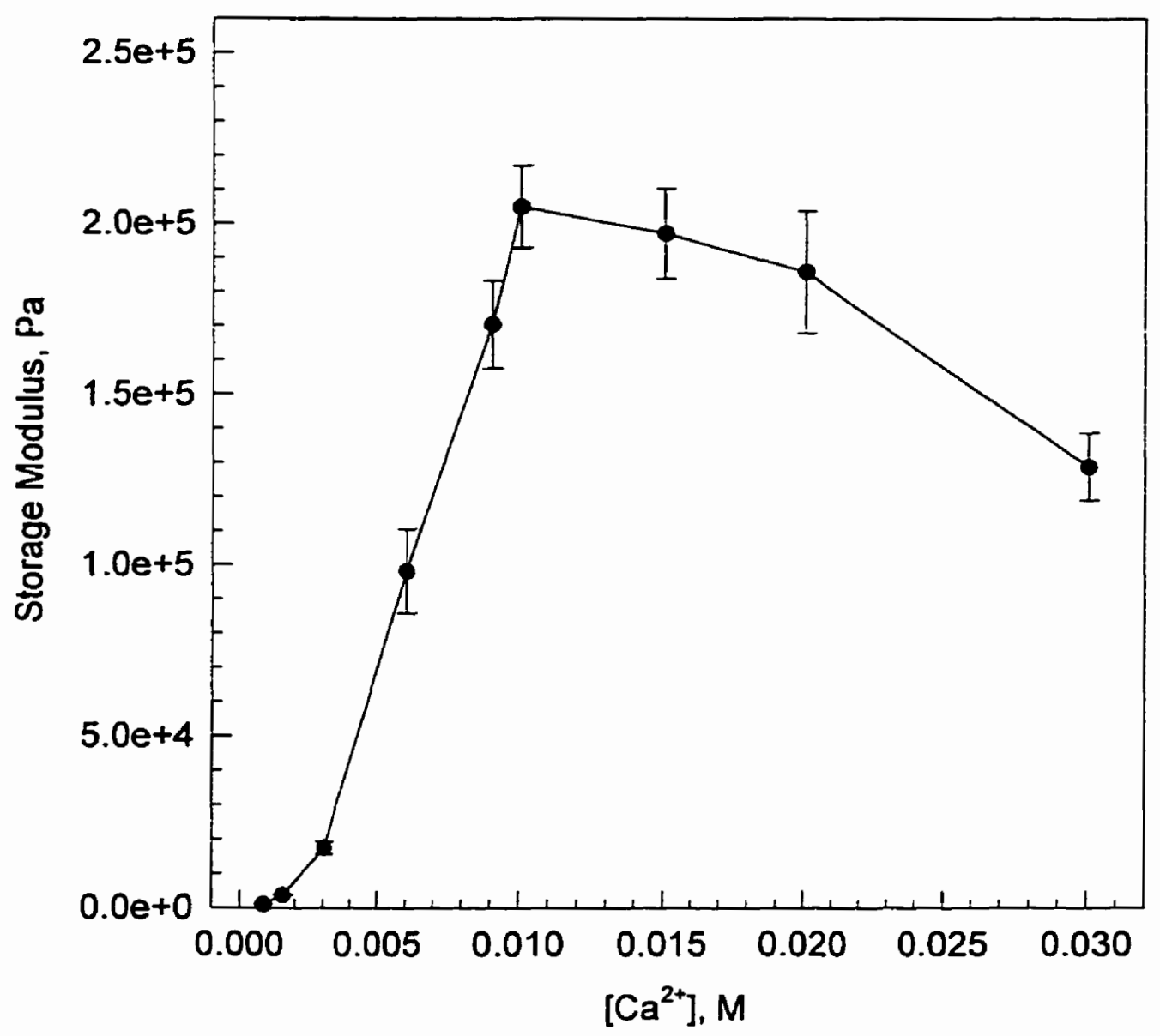

Fig. 5.9 Influence of $\mathrm{Ca}^{2+}$ on $\mathrm{G}^{\prime}$ of a 1.0\% gellan gel as measured using small amplitude oscillatory testing. Each data point is an average of five replicates, and the standard deviations are shown by vertical bars.

The $\mathrm{COO}^{-}$concentration was determined indirectly by calculating the concentration of tetrasaccharide repeat units in a mass per volume gellan solution. Since there is only one $\mathrm{COO}^{-}$group per repeat unit, tetrasaccharide repeat unit concentration is equal to $\mathrm{COO}^{-}$concentration. After accounting for water and other impurities (Table 4.1), the COO concentration for a $1.0 \% \mathrm{w} / \mathrm{V}$ gellan solution was calculated to be $0.013 \mathrm{M}$ (Appendix 2). The stoichiometric equivalence ratio for 


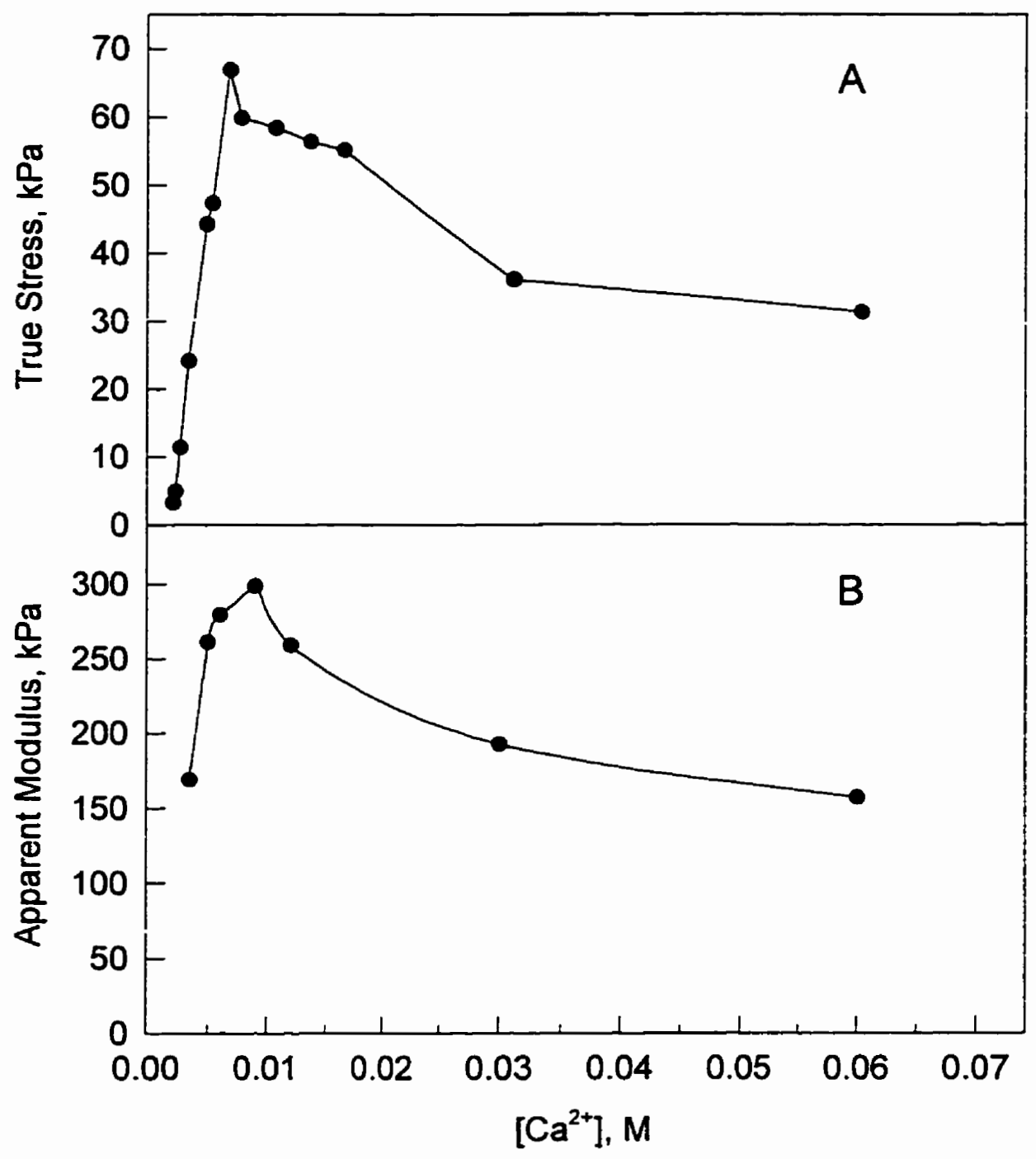

Fig. 5.10 Effects of $\mathrm{Ca}^{2+}$ ion concentration on true stress at failure $(A)$ and apparent modulus $(B)$ of a $1.0 \%$ gellan gel. Each point is an average from five test specimens and two replicated experiments.

calcium with respect to active sites, $\left[\mathrm{Ca}^{2+}\right] /[\mathrm{COO}]$, was then calculated as follows: at maximal true stress this ratio was 0.5 ; however, for the apparent modulus, and for the storage modulus, the ratio was approximately 0.77 . Similar findings for true stress were reported by Tang et al. (1995 and 1996). 
By definition, maximal true stress at failure is a measure of overall strength of the material, which is fundamentally linked to the strength of the structural bonds within the system. In principle, maximal stress at failure for gel.an should occur at $a\left[\mathrm{Ca}^{2+}\right] /[\mathrm{COO}]$ ratio of 0.5 because this is when all the binding sites should be occupied, resulting in the greatest number of possible cross-linkages between the polymer chains, thus yielding the strongest gel. However, an explanation as to why the apparent and storage moduli maxima occur at a $\left[\mathrm{Ca}^{2+}\right] /[\mathrm{COO}]$ ratio greater than 0.5 is more difficult, but it may be linked to the gelling mechanism of gellan, and ultimately the microstructure of gellan gels.

There is considerable discrepancy in the literature as to the nature of gellan gel structure at high ionic concentrations. At lower ionic concentrations, it is generally agreed that gellan adopts a double helical conformation in solution and forms junction zones between adjacent helices in the presence of small amounts of metal cation, as discussed earlier. Two distinct models have been proposed in an attempt to explain the decrease in gel strength with increasing cation concentration; however, neither model appears to provide a completely satisfactory explanation.

Tsiami et al. (1994) proposed a dispersion-like microgel system from the interpretation of relaxation data, thus suggesting that gellan exists as an interaction of small individual gel nuclei. However, these microgel structures were not distinguishable in scanning electron micrographs of gellan gels carried out in the present study.

A second model, proposed by Tang et al. (1997), was developed by interpreting large deformation testing data of gellan. These researchers found that 
the gel strength maximum took place at a value of 0.5 for the stoichiometric equivalence of calcium ions to carboxyl groups present in the system, and that a decrease in gel strength occurred above this ratio. They postulated that the decrease was due to competition between the excess calcium and available binding sites which imposed repulsive forces that prevented the formation of crosslinks, thereby reducing the size of the junction zones and weakening the gellan gel structure.

If the Tang et al. (1997) model was taken to apply at very high calcium ion concentrations, excessive chain repulsion may take place when all the sites become filled, and gelation may not occur at all. In the present study, gel formation was tested up $1.0 \mathrm{M} \mathrm{Ca}^{2+}$, with positive results. However, the gels at the higher calcium concentrations became "lumpy" in consistency and showed considerable syneresis. With increasing cation concentration, the gelling mechanism may progressively change from a polymer-cation-polymer crosslinked network to a polymer-cationwater-cation-polymer linkage similar to that suggested for monovalent cations by Tang et al. (1997). In addition to cation crosslinking, direct polymer-polymer associations through hydrogen bonding with uncharged sugar units may also occur. In other words, for maximal strength, the $\mathrm{Ca}^{2+}$ bridge appears to be the dominant factor, but to attain maximal stiffness and rigidity, the aforementioned polymerpolymer associations may play a role.

Studying the fracture mechanisms by observing fracture surfaces of gellan gels compressed to failure may provide further support to the present model of gellan structure. At low ion concentrations $\left(0.005 \mathrm{M} \mathrm{Ca}^{2+}\right)$, multiple fractures appeared in the gel but little water was exuded (Photo Plate $1 \mathrm{~A}$ ). With increasing 
concentration, up to $0.02 \mathrm{M} \mathrm{Ca}^{2+}$, fracture particles became larger and substantially more water was released (Photo Plate $1 \mathrm{~B}, \mathrm{C}$ ).

Considering the stoichiometric relationship of $\mathrm{Ca}^{2+}$ and $\mathrm{COO}^{-}$with gel strength and rigidity, one can postulate that the three dimensional gel structure of gellan is created by the random crosslinking between outwardly turned carboxyl groups on individual double helical coils with calcium ions. This would allow for direct hydrogen bonding of water to the hydroxyl groups on the sugar backbone of the double helix between the salt bridges, thus allowing for large amounts of water to associate with the structure.

At moderate concentrations of divalent metal cations, above the optimal stoichiometric ratio, the decrease in gel characteristics may be associated with a progressive change from a polymer-cation-polymer crosslinked network to a polymer-cation-water-cation-polymer crosslinked structure. The resultant gel may have a weaker structural network with reduced water-holding capabilities. However, very high divalent cation concentrations may be strong enough to induce conformational changes to the double helical gellan strands which may allow direct polymer-polymer associations to occur. Less water could then associate with the polymer, but since the same amount of water is present in the overall system, this water may now only be physically entrapped within the matrix and could be readily exuded. The ability of the polymer to adopt this conformation may be related to the flexibility of the gellan backbone as suggested by the intrinsic viscosity data found in this study and the light scattering data of Dentini et al. (1988). 


\section{Photo Plate 1}

A $\quad 0.005 \mathrm{M} \mathrm{Ca}^{2+}$

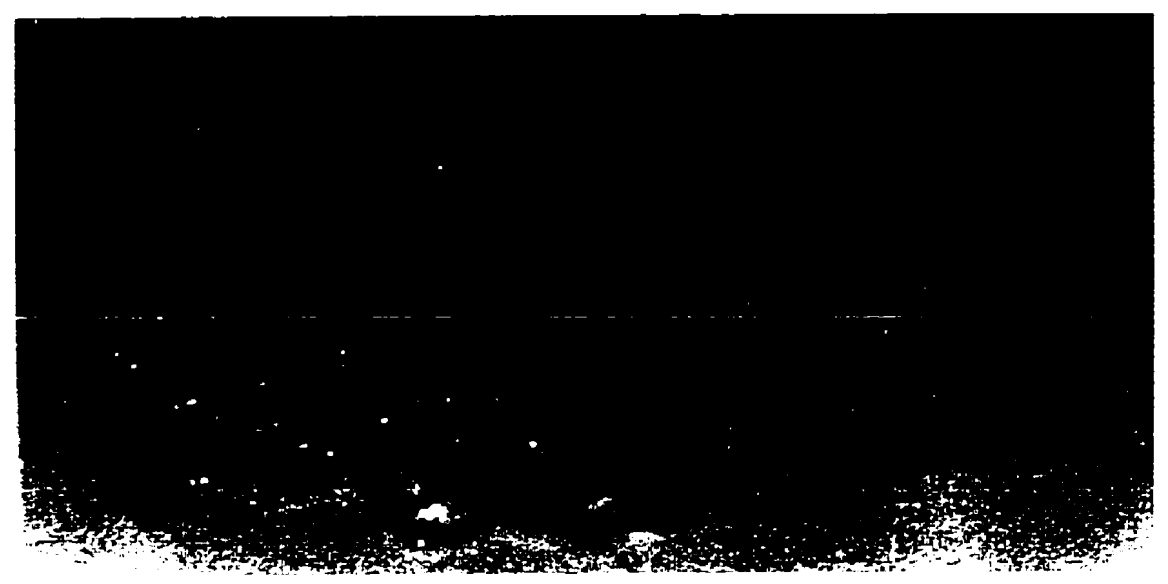

B $\quad 0.010 \mathrm{M} \mathrm{Ca}^{2+}$

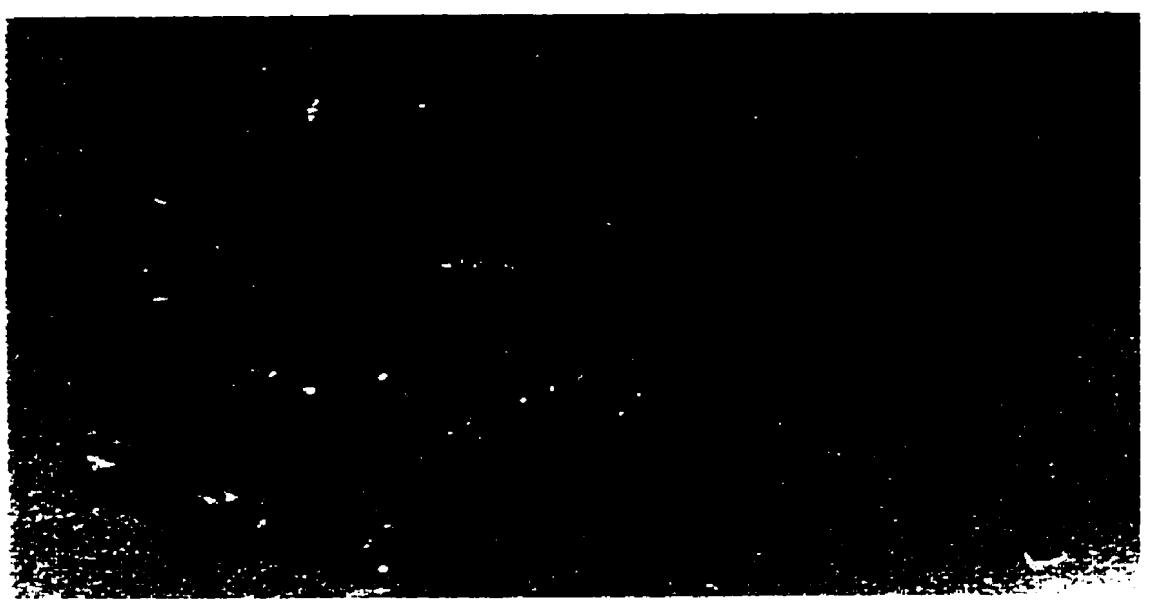

C $\quad 0.020 \mathrm{M} \mathrm{Ca}^{2+}$

Fig. 5.11 Fracture patterns of $1.0 \%$ gellan gels containing various amounts of $\mathrm{Ca}^{2+}$ ions. Magnification $1.5 \mathrm{X}$. 
Scanning electron micrographs prepared from various gellan gels revealed no distinct structural differences in the gels made using a range of calcium concentrations above and below the stoichiometric equivalence $(0.004$ to $0.03 \mathrm{M}$ $\mathrm{Ca}^{2+}$ ) (Photo Plate 2A, B, F). The fibrous structure evident in the micrographs may actually be linked to sample preparation. Ice sublimation over time revealed a decrease in fibre diameter as more water was removed through sublimation (Photo Plate 2 E, F). Therefore, the underlying structure of gellan gels may be considerably more delicate than was revealed by cryo-SEM images. The application of advanced light scattering techniques may be useful to obtain a better measurement of the void spaces within a gellan gel structure.

\subsubsection{Filler Particle Effects}

The influences of both rigid and deformable filler particles on the strength and rigidity of gellan gel matrices at various calcium ion concentrations were examined. The rigid filler particles used in this study consisted of $80 \mu \mathrm{m}$ diameter glass beads, while the deformable filler particles were prepared from gellan solutions as described in section 4.2.

\subsubsection{Gellan Gels With Rigid Filler Particles}

The addition of glass beads in a gellan gel matrix resulted in a decrease in failure strength and stiffness of the gels, irrespective of the cation concentration of the supporting gel matrix. Using true stress at failure as a test parameter (Figure 5.13), $40 \%$ of the gel strength was lost with the addition of glass beads at a $10 \%$ volume fraction. As the glass bead volume fraction was increased from 10 to $30 \%$, 
$\mathrm{Ca}^{2+}$ Effects:

\section{Photo Plate 2}

A $\quad 0.004 \mathrm{M} \mathrm{Ca}^{2+}$

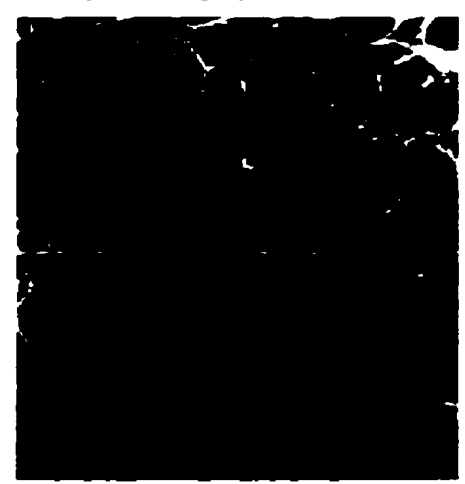

C $\quad 0.06 \mathrm{M} \mathrm{Ca}^{2+}$

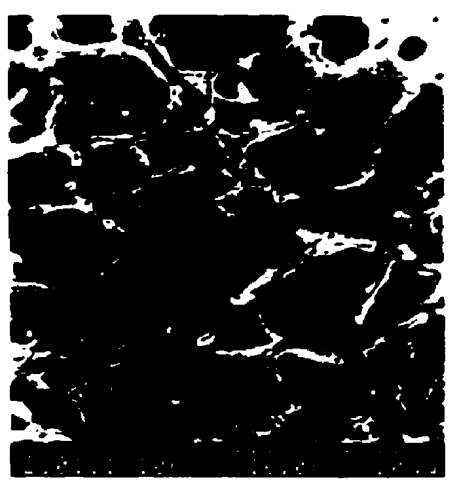

Sublimation Effects

E

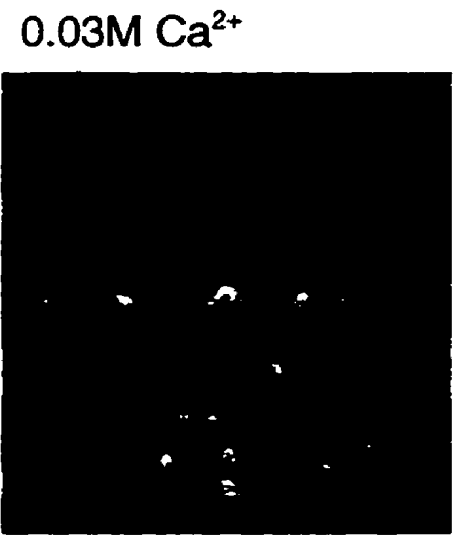

B $\quad 0.006 \mathrm{M} \mathrm{Ca}^{2+}$

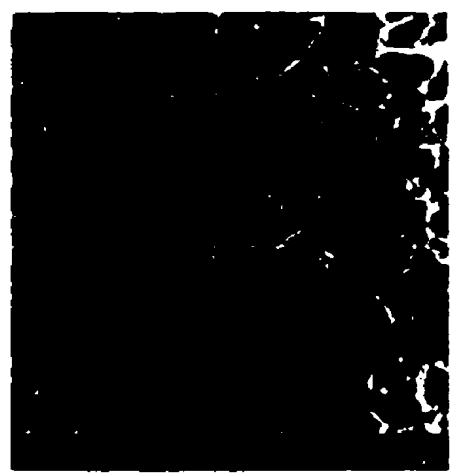

D $\quad 0.500 \mathrm{M} \mathrm{Ca}^{2+}$

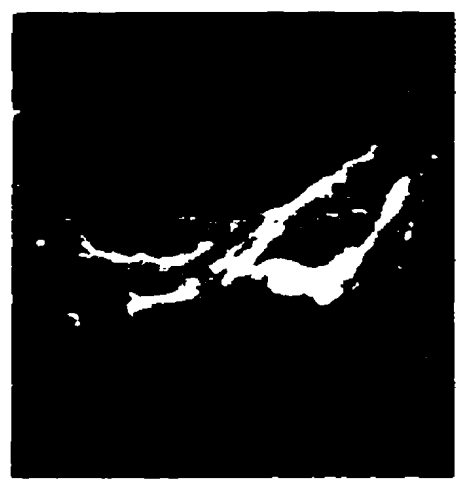

F $\quad 0.03 \mathrm{M} \mathrm{Ca}^{2+}$

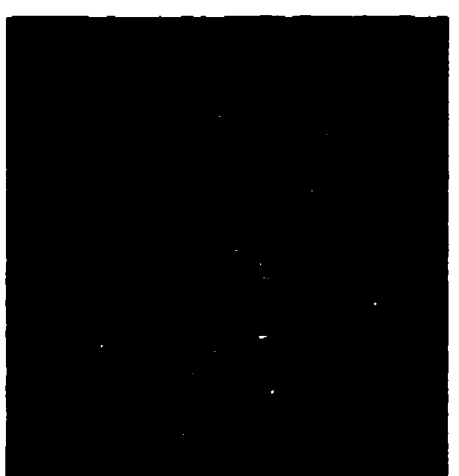

Fig. 5.12 SEM Micrographs of $1.0 \%$ gellan gels containing various amounts of $\mathrm{Ca}^{2+}$. Magnification: $\mathrm{A}, \mathrm{B}, \mathrm{C}=10,000 \mathrm{X}$; for $\mathrm{D}, \mathrm{E}, \mathrm{F},=15,000 \mathrm{X}$. 
the $0.010 \mathrm{M}$ and $0.015 \mathrm{M}$ calcium gels exhibited only minor reductions in gel strength, whereas the lower concentration gel $\left(0.005 \mathrm{M} \mathrm{Ca}^{2+}\right)$ exhibited a further $40 \%$ reduction in gel strength.

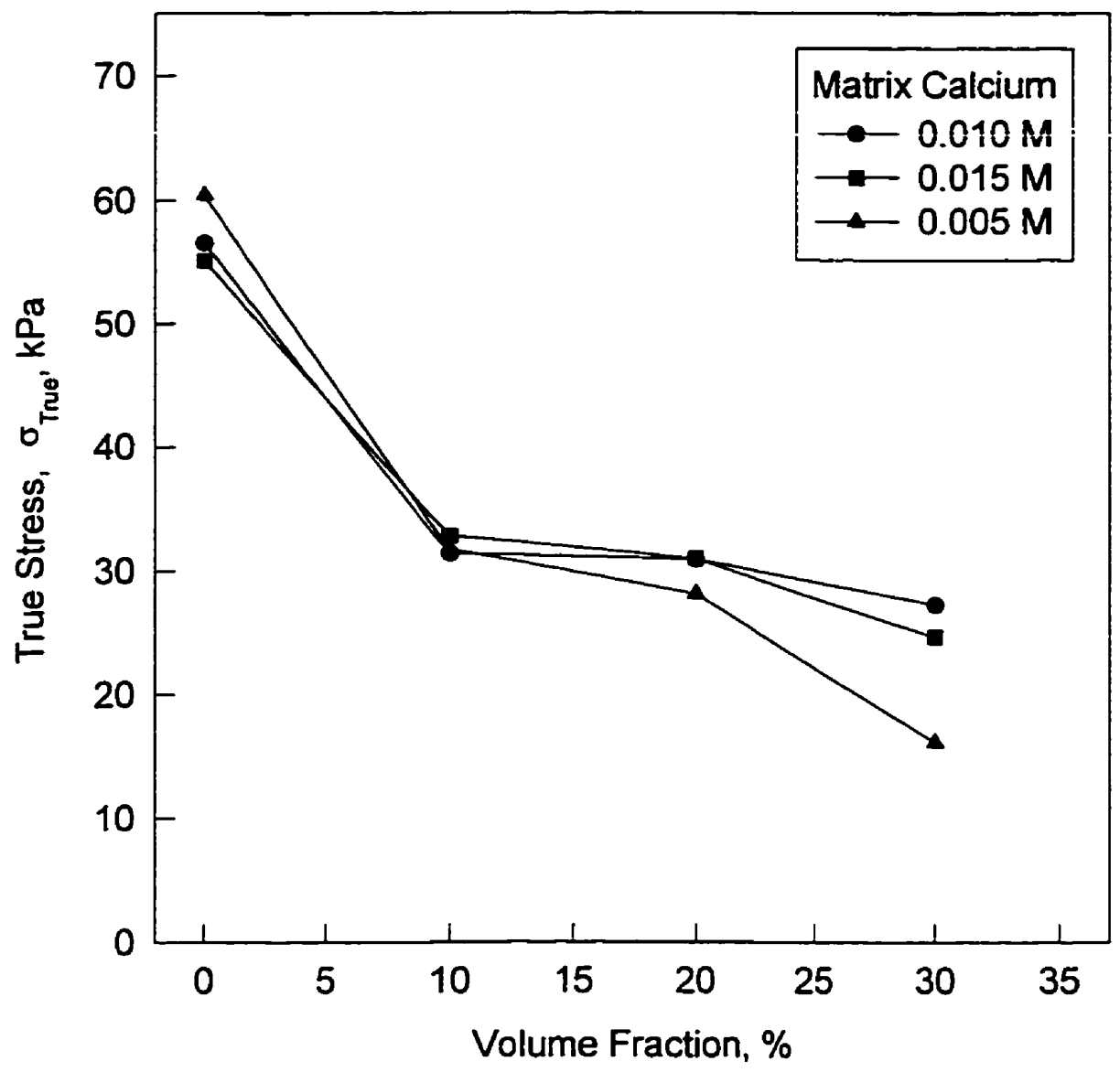

Fig. 5.13 Influence of glass bead volume fraction on the true stress at failure of $1.0 \%$ gellan matrices containing different $\mathrm{Ca}^{2+}$ concentrations. Each point is an average from five test specimens and two replicates.

These results are in line with previous explanations for failure tests of gels without filler particles as a function of $\mathrm{Ca}^{2+}$ ion concentration. The $0.005 \mathrm{M}$ gel was very close to the 0.5 stoichiometric equivalence of $\left[\mathrm{Ca}^{2+}\right] /[\mathrm{COO}]$, and the resultant gel could be considered strong, yet brittle. The addition of rigid particles such as glass beads to this system may act as local fracture inducers, making the system 
more vulnerable to fracture. Conversely, gels with higher $\mathrm{Ca}^{2+}$ ion concentrations would be expected to be tougher, as discussed in the previous section, due to structural changes (such as increased polymer-polymer associations) which have been attributed to the presence of additional cations. These tougher gels would be better able to support the addition of filler particles, as demonstrated with glass beads beyond a $10 \% \mathrm{VF}$.

A similar trend as with true stress at failure was observed for the apparent modulus data of gellan gels containing filler particles (Figure 5.14). Apparent modulus decreased as the volume fraction of glass beads increased; however, the increase in compliance observed was only about $15 \%$ with the addition of beads at $10 \%$ VF. Again, the $0.005 \mathrm{M}$ system behaved least favourably of the three gels tested, and likely for the same reasons as mentioned above. At a VF over $20 \%$, the apparent modulus of the $0.010 \mathrm{M}$ gel matrix appeared to level off, suggesting that some structural reinforcement may be occurring at higher glass bead volume fractions. Volume fractions above $30 \%$ could not be tested because sample dispersions became too thick and no longer gelled properly.

Small amplitude oscillatory studies carried out to measure the rigidity of various gellan gel systems resulted in some interesting findings. A trend of decreasing gel rigidity with increasing glass bead volume fraction was observed only up to $20 \%$ VF; beyond this VF the rigidity (storage modulus) increased again (Figure 5.15). Other researchers have also reported rigidity minima, although their results were obtained using large deformation testing which makes the direct comparison of results more difficult. Nevertheless, Langley and Green (1989) found a similar minimum at a $20 \%$ VF using glass beads in a whey protein matrix. 


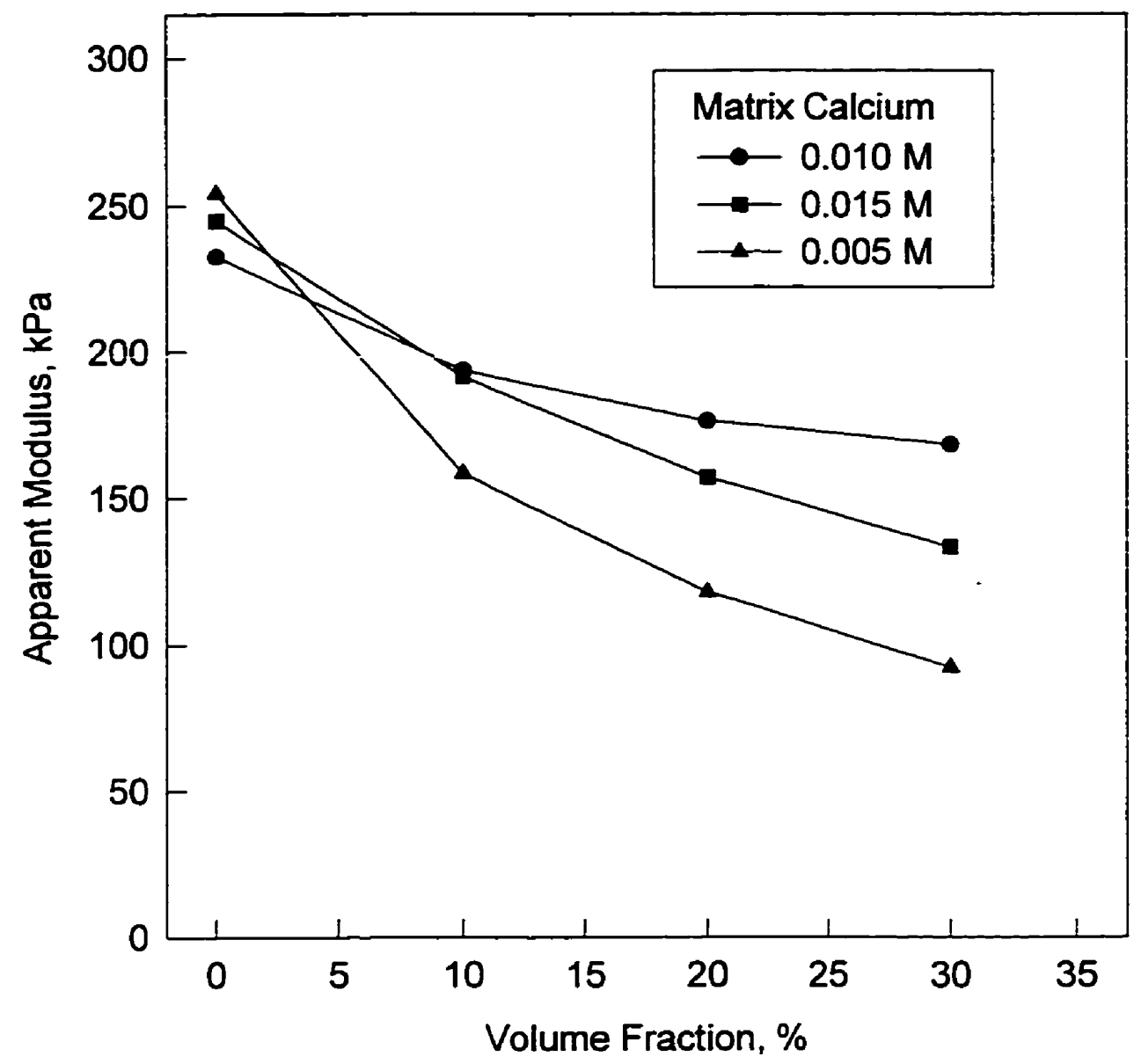

Fig. 5.14 Influence of glass bead volume fraction on the apparent modulus of $1.0 \%$ gellan matrices containing various $\mathrm{Ca}^{2+}$ concentrations. Each point is an average from five test specimens and two replicated experiments.

Thomas (1994) reported gel strength minima with the addition of smaller diameter ( 0.1 to $3 \mu \mathrm{m})$ polystyrene microspheres into a whey protein matrix; minima occurred between 5 and $10 \%$ VF, with differences being attributed to particle size.

Oscillatory rheological tests may be more sensitive to small changes in the sample, and it is interesting to note that the viscoelastic properties may not necessarily correlate with the results of large deformation failure testing. In this study, lower gel strengths at failure were observed for higher volume fractions of 


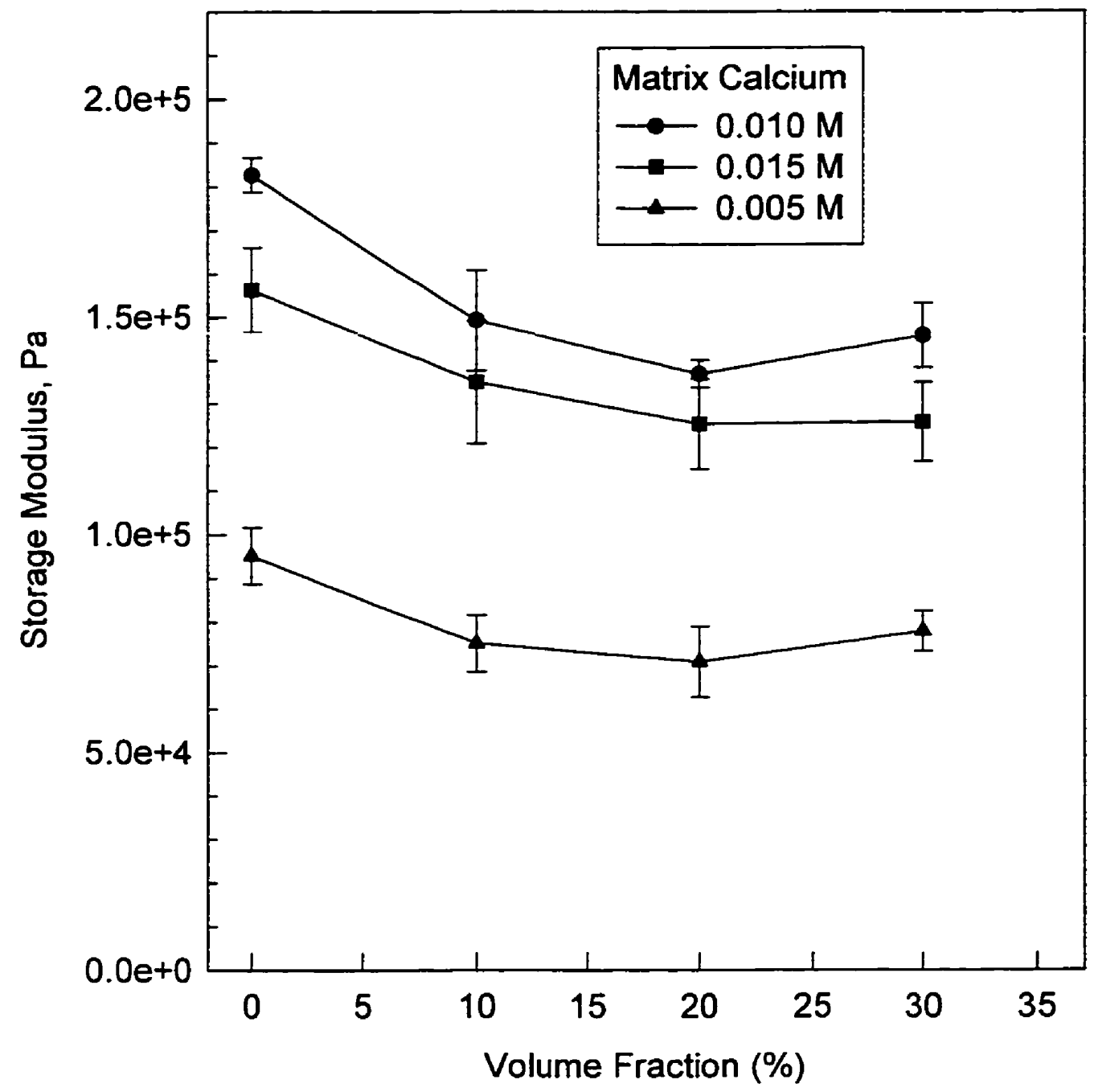

Fig. 5.15 Influence of glass bead inclusions on the storage modulus of $1.0 \%$ gellan matrices containing various $\mathrm{Ca}^{2+}$ concentrations as measured using oscillatory testing.

glass beads in the large deformation data for gellan gels. The apparent increase in gel strength found by other researchers may simply be related to the gel matrix material tested and the interactions between it and the filler particle. Even under different testing protocols (different crosshead speeds), both Langley and Green (1989), and Thomas (1994) found structural reinforcement at higher volume fractions. In the whey protein studies of Langley and Green (1989), as well as 
Thomas (1994), $50 \mathrm{~mm} / \mathrm{min}$ and $12 \mathrm{~mm} / \mathrm{min}$ crosshead speeds were used, respectively. In the present gellan study, a crosshead speed of $20 \mathrm{~mm} / \mathrm{min}$ was used to avoid sample adaptation to the applied stress. This procedure was considered particularly important for the gels with a high $\mathrm{Ca}^{2+}$ ion concentration because at low crosshead speeds, considerable amounts of water would be exuded from those samples. Therefore, there may be intrinsic differences in behaviour between whey protein and gellan gels under large deformation testing which may account for the observed differences in response.

\subsubsection{Gellan Gels With Deformable Filler Particles}

Mechanical and rheological data for gellan gels containing deformable particles (gellan beads) were somewhat different than data obtained for gels with rigid particle inclusions. A linear decrease in true stress at failure with an increase in gellan bead VF was observed for all matrices and bead types (Figure 5.16). In addition, linear decreases in apparent modulus and storage modulus (from oscillatory tests) were observed with an increase in gellan bead VF, as shown in Figures 5.17 and 5.18, respectively. Similar results were observed by Brownsey et al. (1987) studying deformable Sephadex particles in a gelatin protein matrix.

Statistical analyses of stress at failure and storage modulus data for three gellan gels containing three different deformable gellan beads were performed. These analyses found that there was a significant difference in stress at failure and storage modulus only when the three different bead types where added into individual $0.010 \mathrm{M} \mathrm{Ca}^{2+}$ gellan matrices $(p<0.05)$. Further statistical analyses of the 


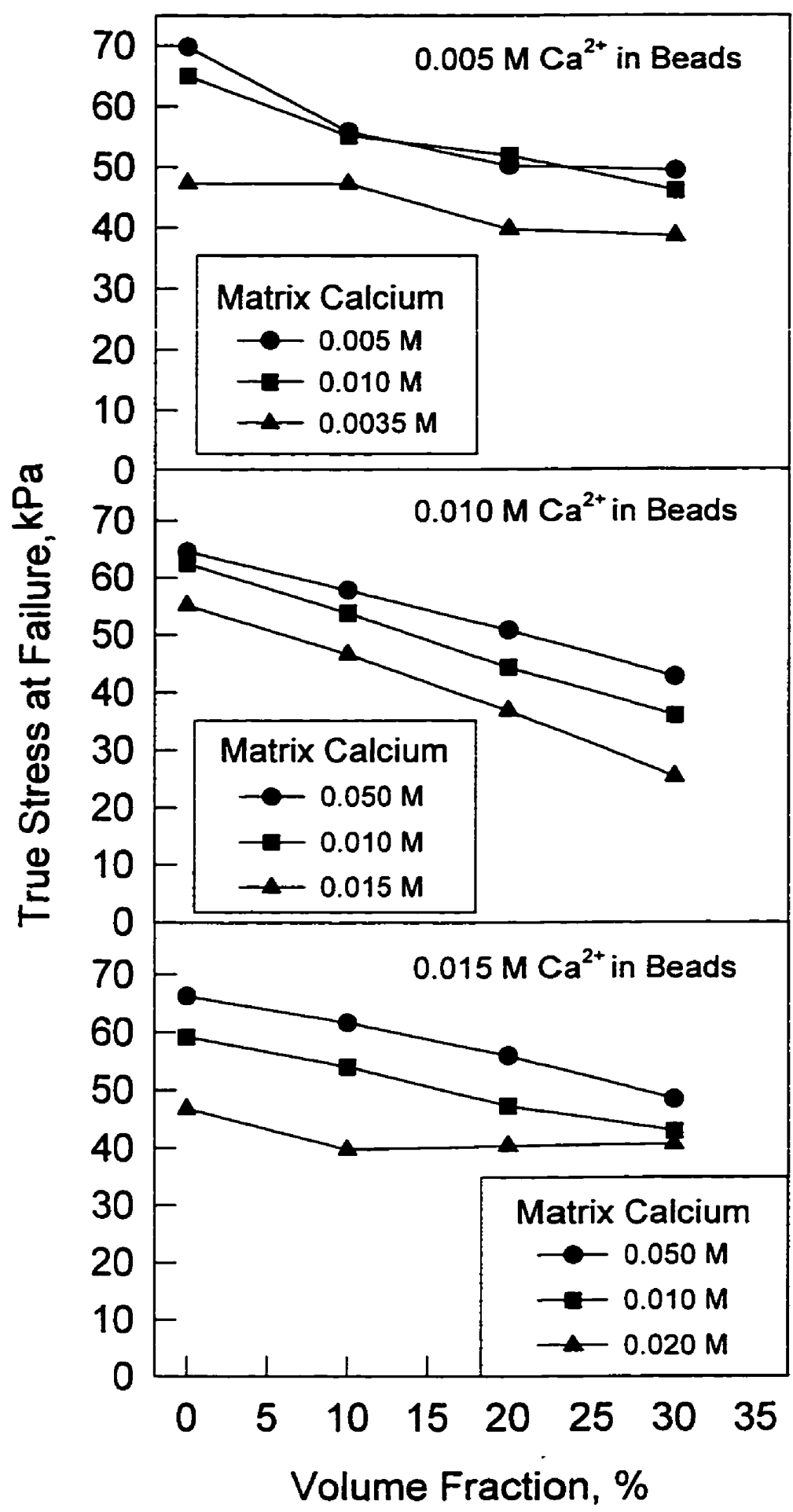

Fig. 5.16 Influence of gellan bead volume fraction on true stress at failure of $1.0 \%$ gellan gels at various $\mathrm{Ca}^{2+}$ concentrations, using beads made with $1.0 \%$ gellan polymer and various $\mathrm{Ca}^{2+}$ concentrations to control bead rigidity. 


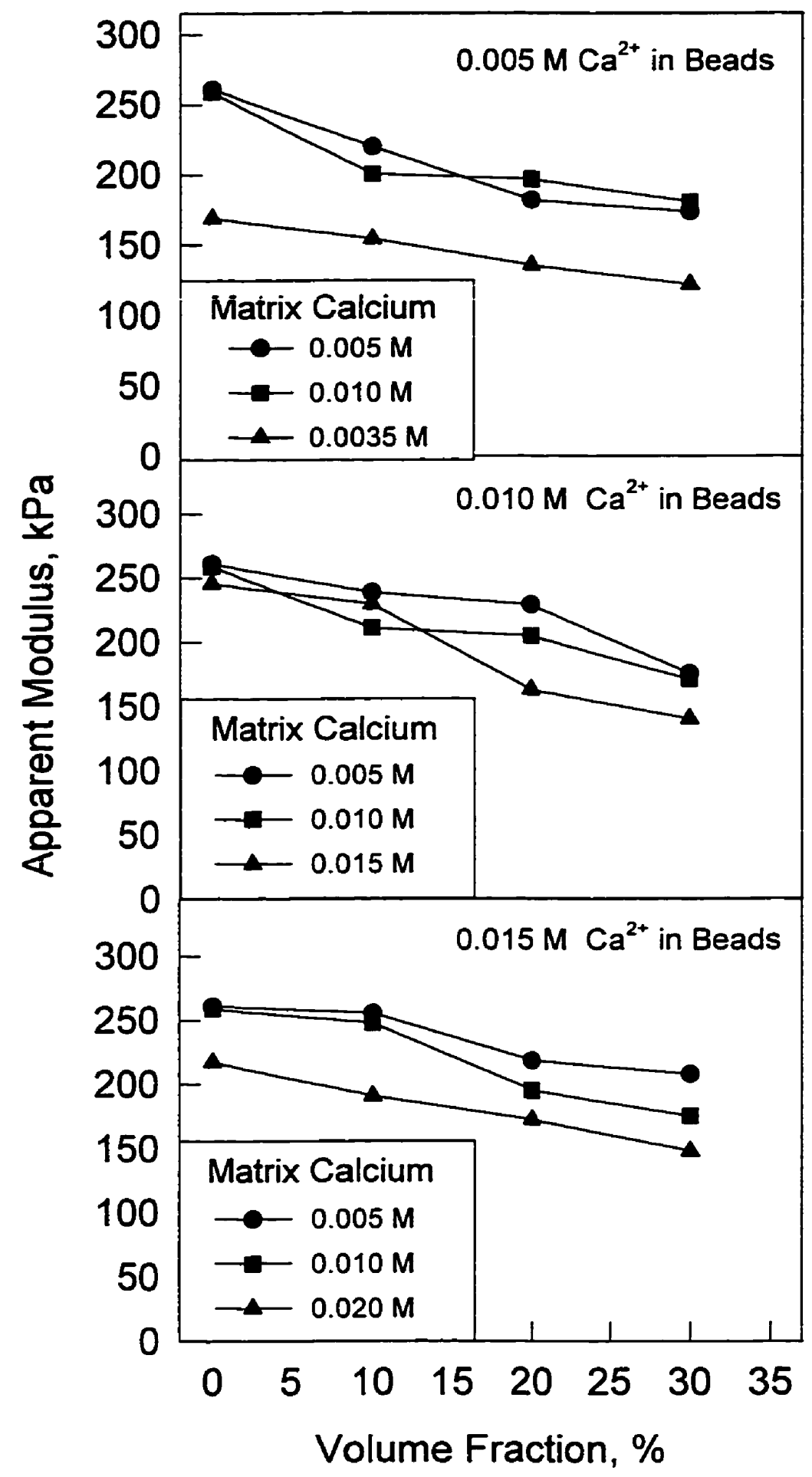

Fig. 5.17 Influence of gellan bead volume fraction on apparent modulus of $1.0 \%$ gellan gels at various $\mathrm{Ca}^{2+}$ concentrations, using beads made with $1.0 \%$ gellan polymer and various $\mathrm{Ca}^{2+}$ concentrations to control bead rigidity. 


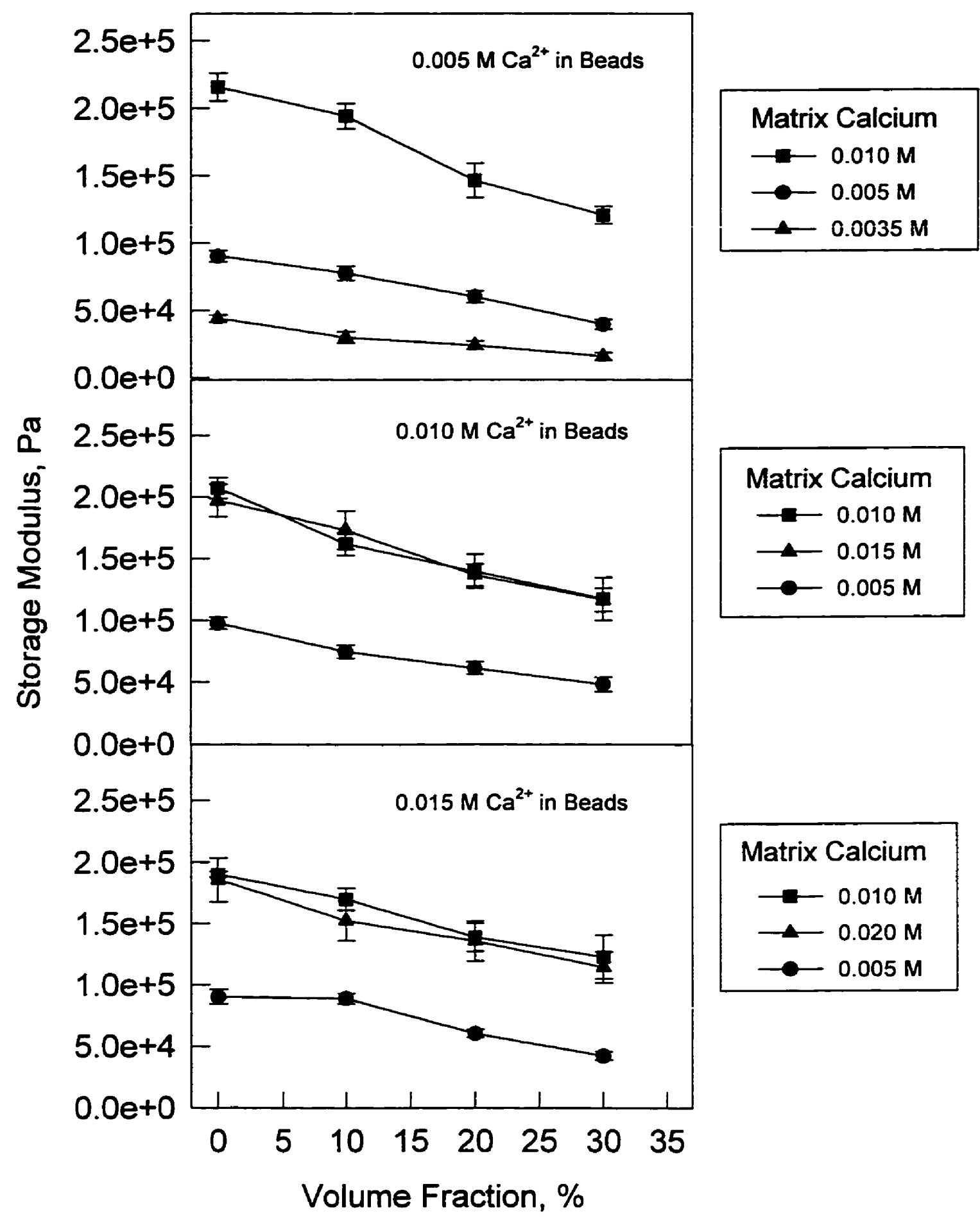

Fig. 5.18 Influence of gellan bead volume fraction on storage modulus, $G^{\prime}$, of $1.0 \%$ gellan gels at various $\mathrm{Ca}^{2+}$ concentrations, using beads made with $1.0 \%$ gellan polymer and various $\mathrm{Ca}^{2+}$ concentrations to control bead rigidity. 
treatment means revealed that it was the $0.005 \mathrm{M} \mathrm{Ca}^{2+}$ bead inclusions that resulted in a significant difference $(p<0.05)$ in the rheological and mechanical behaviour of the $0.010 \mathrm{M} \mathrm{Ca}^{2+}$ gel matrices (Appendix $3 \mathrm{~A}$ ). However, since the effects of volume fraction were also of interest, comparing the slopes of the rheological and mechanical testing data versus volume fraction would provide a more interesting comparison.

A comparison of the slopes from true stress at failure data (Figure 5.16) for the $0.010 \mathrm{M} \mathrm{Ca}^{2+}$ matrix gels versus bead volume fraction revealed a small yet statistically significant difference $(\alpha=0.05)$ in slope for the $0.010 \mathrm{M} \mathrm{Ca}^{2+}$ beads as compared to the other two bead types. However, no significant difference in slope was found with storage modulus data for the same gels and bead types (Appendix $3 \mathrm{~B})$. This inconsistency in results suggests that gellan bead formulations do not play an important role in the overall deformational behaviour of gellan gels containing these inclusions.

An explanation for this inconsistency may be that the strength and/or rigidity of the supporting gel matrix masked any influences due to gellan bead formulation. Perhaps each bead type should be measured in a much weaker matrix. A further explanation may be that there was not enough difference in the strength and/or rigidity of the beads themselves. These experiments were conducted on the premise that an individual gellan bead with a certain ion concentration would have similar rheological properties (i.e., stress at failure, modulus, rigidity) as a larger piece of comparable gellan gel. The composite gel results suggest that $0.010 \mathrm{M}$ beads and $0.015 \mathrm{M}$ beads may not be as different with respect to their rheological 
and mechanical properties as was depicted in Figures 5.9 and 5.10. Therefore, a more deformable particle may have to be created in order to further study the effects of the rheological properties of particle inclusions on structured foods.

The limiting feature of the gellan bead making procedure outlined in section 4.2 is that beads could not be formed with a $\mathrm{Ca}^{2+}$ concentration below $0.004 \mathrm{M}$. The resultant water-in-oil dispersion, formed by blending hot gellan solution (containing $\mathrm{Ca}^{2+}$ below $0.004 \mathrm{M}$ ) and hot oil, was not sufficiently stable and the gelation process was not rapid enough to form discrete spherical particles when the dispersion was poured over ice. Although a different bead formation system may need to be developed, gellan polymer and other polysaccharide systems remain attractive because they could have real food applications in contrast to model systems such as those based on Sephadex beads.

\subsubsection{Particle-matrix Relationships}

The differences in behaviour observed between gels containing rigid and deformable particle inclusions may be better explained by examining the role of individual particles in a matrix. For rigid particles, Thomas (1994) demonstrated that a decrease in particle size corresponded to an increase in protein gel reinforcement. It was suggested that larger particles disrupted the matrix because they did not "fit" into the void space of the matrix; however, there may be another way to interpret these data.

As the size of rigid particles increases, the corresponding number of particles included within the matrix would decrease when compared on a volumetric basis. There would then be more matrix space between adjacent larger particles than 
adjacent smaller particles because of the nature of packing for spherical particles. In the case of numerous small particles, the reduced distance between particles could result in less energy loss through the matrix from an applied force, which would have the effect of greater reinforcement of the matrix. In comparison, a greater volume fraction of larger particles would be necessary to get a sufficient number of particles in close proximity to minimize energy loss. Particle size differences may therefore account for the different gel strength minima obtained in the present study (using $80 \mu \mathrm{m}$ glass beads) in comparison with those observed using much smaller $(0.16 \mu \mathrm{m})$ polystyrene microspheres (Thomas, 1994). A 5\% volume fraction of these smaller particles was found to be sufficient to provide reinforcement, whereas a $20 \%$ volume fraction of the larger glass beads was required to achieve a similar effect.

The relationship between particle size and gel matrix reinforcement may also apply to deformable particles. The concept of particle proximity as it relates to particle size would remain the same as with rigid particles; however, the force applied to the system would be expected to result in deformation or energy absorption in both the matrix and the particle itself, leading to less overall structure. Brownsey et al. (1987) reported a decrease in gelatin gel strength with decreasing Sephadex particle rigidity, but their data may actually be demonstrating two factors involved in gel strength: particle size as well as particle rigidity. Sephadex particle rigidity decreases as size increases with swelling.

The above explanations do not account for the influence of particle and matrix interactions. Yet both theoretical and empirical models for composite 
systems are based on the assumption of strong adhesion between filler particles and the supporting matrix. The influence of particle-matrix interactions was studied by van Vliet (1988) who found that a linear decrease in gel strength with an increase in volume fraction only occurred with non-interacting gel materials. This finding was attributed to the formation of an aqueous boundary layer around the particles so that there was no real contact between the particle and the matrix. The author suggested that the rheological properties of these particles would be as if the particles were made of water.

The existence of an aqueous boundary layer may be a viable explanation for the data in the present study, especially for the deformable gellan beads because of the large amounts of water in the gellan gel systems. As stress is applied to the system, small amounts of water may be released from the polymer gel, thus forming a boundary layer around the gellan beads. This layer would reduce any interactions with the gel matrix and lead to the formation of weak points in the gel which would facilitate fracture. The same mechanism may also hold true for glass bead inclusions in a gellan matrix; however, it does not explain the increase in gel rigidity observed at higher volume fractions with oscillatory tests. In the case of rigid particles, especially at sufficient volume fractions, the previously discussed mechanism relating particle size to matrix reinforcement may be more dominant. True stress-strain plots for gellan gels containing glass beads (Figure 5.19) support this hypothesis. A transition was observed at a strain of 0.38 for gels with various bead volume fractions. With increasing VF, the fracture patterns progressively changed to adopt biaxial "flow" characteristics. The difference between the peak strain at initial fracture and this transition may be attributed to the collapse of the 
matrix space between two adjacent particles. Once in contact with each other, the glass beads would have to slide past or push each other aside because they are not deformable. The frictional forces associated with lateral movement would cause an increase in the force required to cause deformation of the gellan gels. Figure 5.19 illustrates this point well; as the volume fraction of the particles increased, the force required to cause the lateral movement of the particles increased.

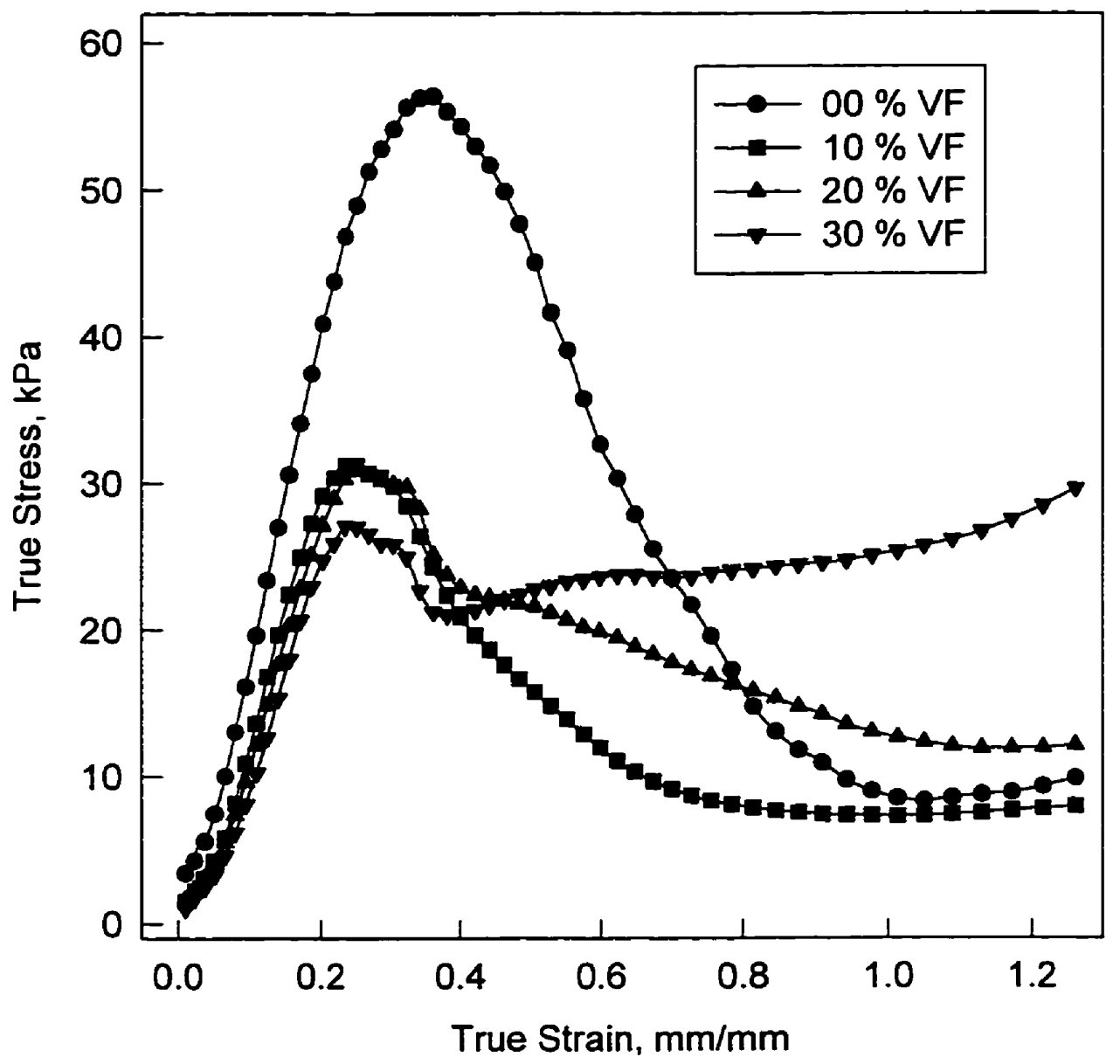

Fig.5.19 Representative true stress-strain curve of $1.0 \%$ gellan gels containing various volume fractions (VF) of glass beads.

Conversely, gellan bead inclusions would be expected to behave differently because deformational forces would cause beads in contact with each other to 
deform along with the gellan matrix. Also, the frictional forces of two gellan beads rubbing against each other would likely be much smaller that those from glass beads.

\subsubsection{Modelling of Gellan Composite Gels}

Mathematical derivations for calculating the deformational behaviour of composites are often based on a relative modulus ratio of filled to unfilled material. For the present study, the storage modulus of the gellan-glass bead composite $\left(G_{c}\right)$ was divided by the storage modulus of the unfilled gel matrix $\left(G_{m}\right)$ and yielded modulus ratios (representing relative rigidity) which were much lower in comparison to the ratios obtained for popular mathematical models applied to the data. When these ratios were plotted against the volume fraction of the filler particles (Figure 5.20), the resultant curves did not correspond well with the theoretical curves obtained using the model derived by Lewis and Nielson (1970). The Lewis and Nielson model does not predict the existence of a minimum point in the modulus ratio as a function of the VF of inclusions. This model is based on the assumption of a strong association between the inclusion and the matrix; however, as discussed in the previous sections, this assumption may not be true for rigid particles.

An examination of other models indicated that some empirical models appear to fit the data more closely, although there were still substantial differences between the model and experimental results, especially at low volume fractions. The best fit was obtained by applying the following quadratic polynomial model:

$$
G_{c}^{\prime} / G_{m}^{\prime}=1.0046-0.0195 \varphi+4.263 \times 10^{-4} \varphi^{2} \quad R^{2}=0.99
$$


where $\varphi$ is the volume fraction. Although this empirical model applies specifically to gellan gels with glass bead inclusions, it may still be useful in assessing other gel systems. A non-linear model is needed to describe the minimum point in modulus ratios associated with the inclusion of rigid filler particles in gel matrices, and a quadratic model based on phase volume would appear to be the simplest to use.

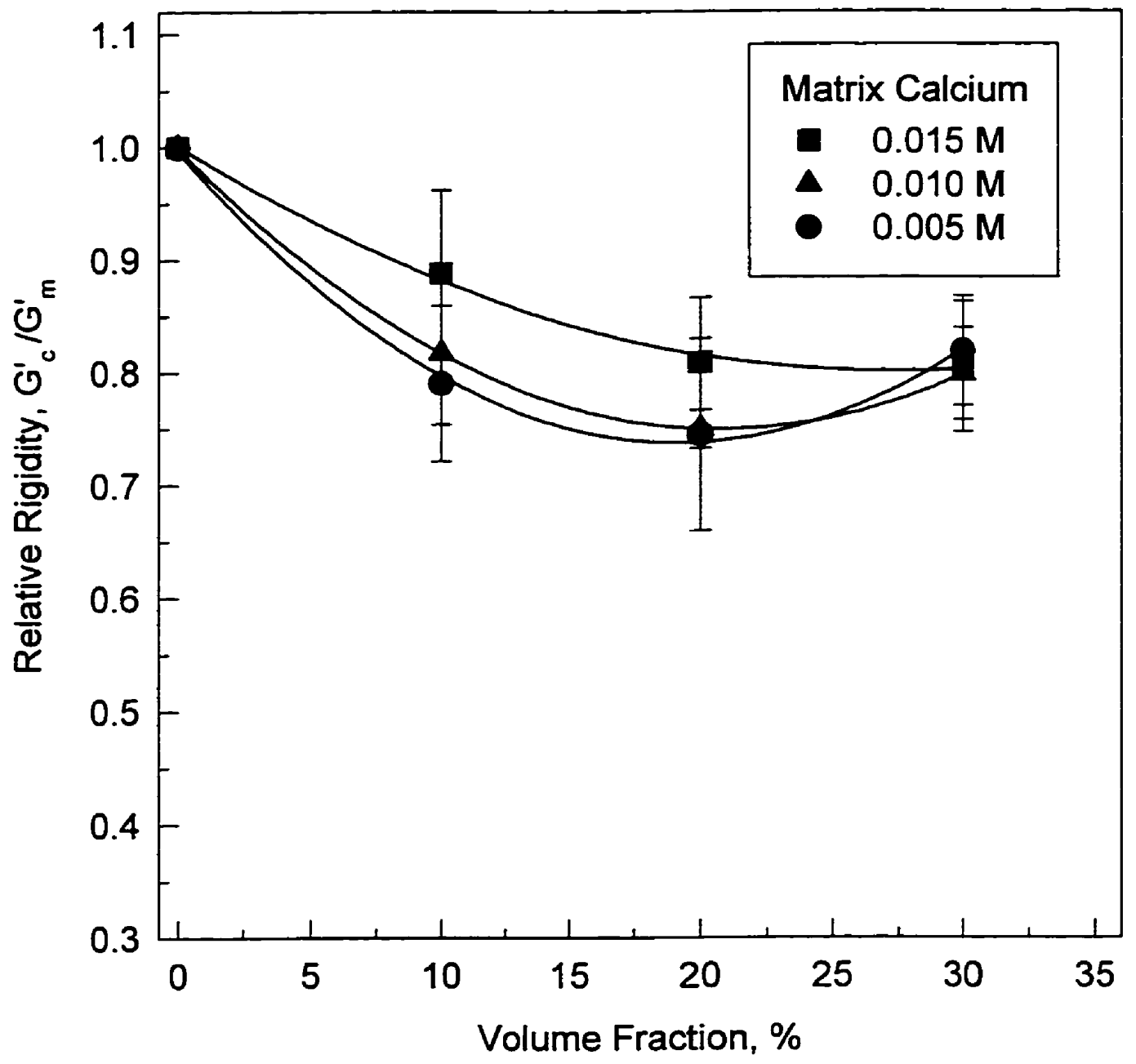

Fig. 5.20 Relative rigidity of composite $1.0 \%$ gellan gels containing glass beads as a function of dispersed phase volume fraction, showing a quadratic function. 
It would be imprudent, however, to conclude that the effects of particle inclusions on gel strength and rigidity are based only on the volume fraction of the filler. Smith (1974) attempted to create a model for filler particles in a matrix using moduli of the filler particles, the unfilled matrix and the Poisson's ratio. His approach was unique in that he used a quadratic function as a starting point. The resultant equation, when applied to the present study, does account for the gel strength minima obtained for gellan gels with rigid particle inclusions.

In the case of composites containing deformable particles, where no increase in gel strength was observed at higher volume fractions, the modulus ratios also did not correspond well with the theoretical model of Lewis and Nielson (1970). However, good agreement was obtained by applying the Smith (1974) model to the data in the present study, but only if it was assumed that the modulus of the filler was zero, (Figure 5.21). Van Vliet (1988) reported similar findings when these assumptions were applied to describe gels in which there were no interactions between particles and their supporting matrix. A modulus of zero was based on the lack of interaction between the filler and the matrix, where the filler particles essentially acted as liquid droplets entrapped in the gel matrix.

A linear regression model applied to the relative storage modulus and volume fraction data resulted in the following equation:

$$
G_{c}^{\prime} / G_{m}^{\prime}=0.998-0.0160 \varphi \quad r^{2}=0.88
$$




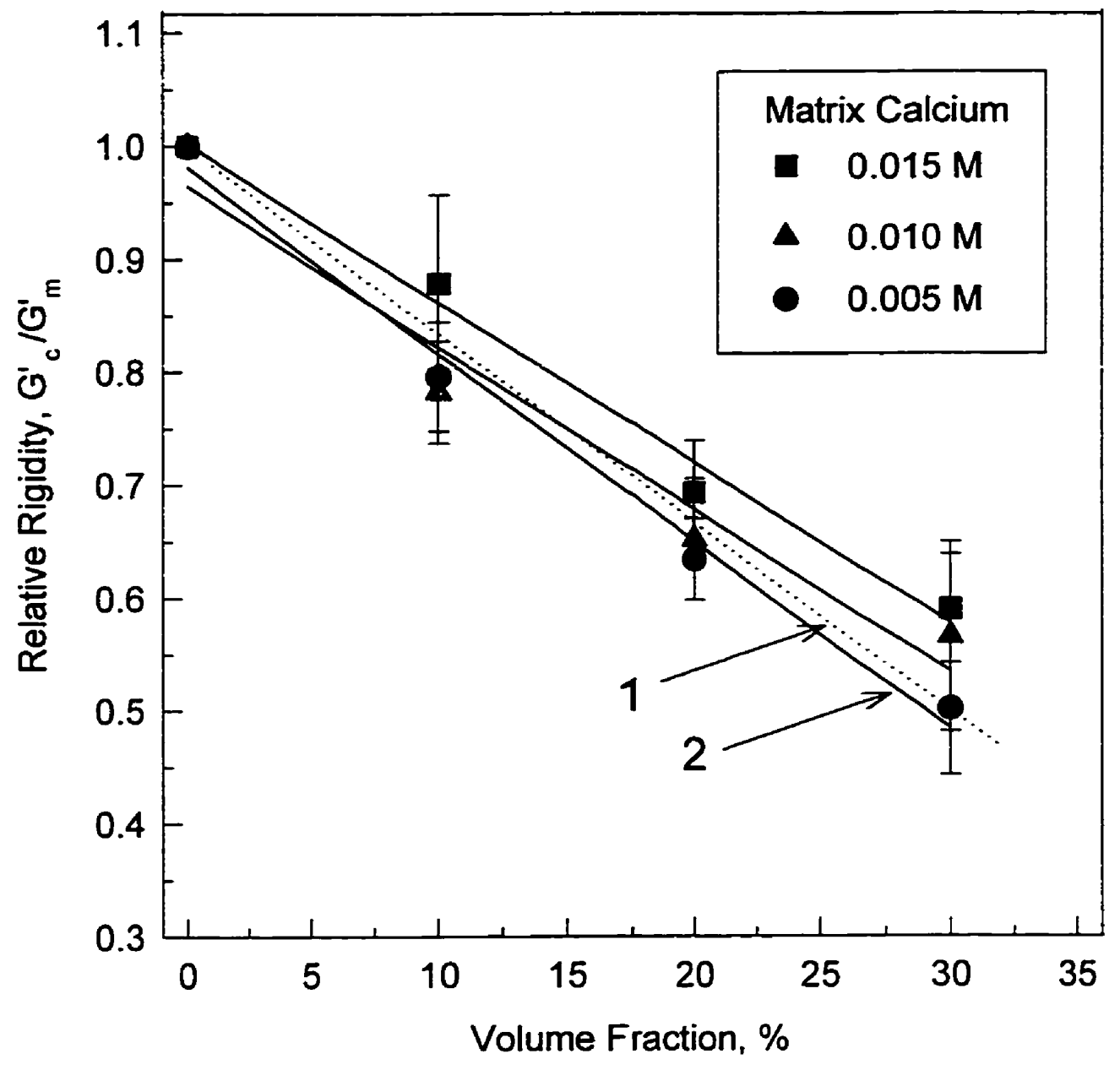

Fig. 5.21 Relative rigidity of composite $1.0 \%$ gellan gels containing $0.010 \mathrm{M}$ $\mathrm{Ca}^{2+}$ gellan beads as a function of dispersed phase volume fraction, showing linear functions: (1) Theoretical model, $G_{f}^{\prime}=0$ (Smith, 1974); (2) Linear regression curve fit. 


\section{CONCLUSIONS}

The fundamental properties and the rheological behaviour of gellan polymer were studied to gain a deeper understanding of the influence of phase separated components on composite food systems. Investigations revealed that gellan behaved like a charged polymer in dilute solutions, exhibiting an increase in reduced viscosity as a function of decreasing polymer concentration due to a reconfiguration of the polymer chains. The addition of a counterion in the form of $\mathrm{NaCl}$ caused dilute gellan solution behaviour to approach that of uncharged polymers. However, intrinsic viscosity values were dependent on counterion concentrations, and decreased with increasing ion concentration. The gellan molecule appeared to become more flexible with an increase in ion concentration, which may be attributed to the substitution of divalent with monovalent ions associated with the charged carboxyl groups within the gellan molecule. This suggests that perhaps gellan has some inherent flexibility within the molecular structure which may then be related to its flow and gel behaviour.

As gellan solutions become more concentrated, there is eventually an overlap and interaction among neighbouring molecules. This, critical concentration, $\mathrm{C}^{*}$, was determined to be at $0.064 \%$ gellan polymer. A further increase in concentration allows for the study of steady shear flow characteristics of the polymer solutions. With increasing concentration, from 0.5 to $2.0 \%$, the flow behaviour of gellan solutions changed from Newtonian to shear rate thinning, and was best described by the Power-law model. A strong Power-law relationship was also observed with respect to the influence of polymer concentration on viscosity. 
Viscosity as a function of decreasing temperature showed a similar transition from Newtonian flow to Power-law flow. The onset of this transition was observed at $28^{\circ} \mathrm{C}$, and may be due to structural changes within the polymer molecule brought about by the combination of residual ions and reduced temperatures, which may have induced localized gelation of the polymer.

In gellan gel systems, gel strength was found to increase with increasing $\mathrm{Ca}^{2+}$ ion concentration to a maximal point at $0.0065 \mathrm{M} \mathrm{Ca}^{2+}$, after which the strength decreased again. A maximal point for true stress at failure near $0.0065 \mathrm{M} \mathrm{Ca}^{2+}$ corresponded to a stoichiometric equivalence of $\left.0.5\left[\mathrm{Ca}^{2+}\right] / \mathrm{COO}\right]$, where the carboxyl group concentration represents the available binding sites of the gellan molecule. However, apparent modulus from large deformation compression testing and small amplitude oscillatory shear data indicated that maximal gel rigidity occurred at about $0.01 \mathrm{M} \mathrm{Ca}^{2+}$, which is greater than the stoichiometric equivalence of 0.5. Scanning electron micrographs of gellan gels at higher calcium ion concentrations revealed a more open structure with large void spaces. These SEM findings, in conjunction with the rheological data, provide supporting evidence of changes in gellan structure at higher cation levels. Increasing calcium ion concentration appears to cause a shift in the mechanism of gellan gelation: the formation of calcium bridges across the carboxyl group of two adjacent polymer chains may be replaced, in part, by direct polymer-polymer association.

The rheological behaviour of composite gellan gels was found to be dependent on the type of particle inclusion added to the system. The addition of rigid particles (in the form of glass beads) resulted in a quadratic relationship between the storage modulus ratio and increasing volume fraction of filler particles. 
However, the addition of deformable particles (in the form of gellan beads) resulted in a linear decrease in the storage modulus ratio as a function of bead volume fraction. The differences in behaviour observed for the rigid and deformable particles may be attributed to the different associations each have with other particles and the gellan matrix.

In future studies, it would be interesting to further explore some of gellan's unique flow properties. Perhaps a better way to quantify the non-linear behaviour of increasing viscosity as a function of decreasing temperature would be to use small amplitude oscillatory measurements. This may reveal additional information about the structural transition that may be occurring. In the model food composite area, possible interactions between particle inclusions and the supporting matrix should also be studied in more depth. Such studies might require the development of a protein-stabilized emulsion or polystyrene microspheres with specific surface characteristics to test these interactions. With greater interaction between the particle and the matrix, perhaps there could be a better transfer of energy from the matrix to the particle, which would result in a better assessment of the effects of particle deformability. The effects of particle deformation could be further addressed, perhaps through the use of other carbohydrate components such as starch granules.

Acquiring a more complete understanding of the structure and rheological behaviour of complex food systems is becoming increasingly important in the formulations of new and unique products. The gellan solutions and composite gels examined in the present study have provided an interesting and valuable model 
system to better investigate the properties of phase-separated structured food systems. 


\section{REFERENCES}

Anonymous. 1992. CRF Part 172 - Food additives permitted for direct addition to food for human consumption: Gellan Gum. Federal Register 57(228): 55444-55445.

Aguilera, J.M. and Kinsella, J.E. 1991. Compression strength of dairy gels and microstructural interpretation. J. Food Sci. 56: 1224-1228.

Aguilera, J.M., Kinsella, J.E. and Liboff, M. 1993. Structure-compressive stress relationships in mixed dairy gels. Food Structure 12: 469-474.

Bachmann, L. and Mayer, E. 1987. Physics of water and ice: implications for cryofixation. In: Cryotechniques in Biological Electron Microscopy. Steibrecht, R.A. and Zierold, K. (Eds.). Springer-Verlag Publishers, New York, NY. pp. 3-34.

Bagley, E.B. 1983. Large deformations in testing and processing of food materials. In: Physical Properties of Foods. Peleg, M. and Bagley, E. (Eds.). AVI Publishing Inc., Westport, CT. pp. 325-342.

Blanshard, J.M.V. and Muhr. A.H. 1982. The molecular basis of long-term changes in polysaccharide based systems. Food Chem. 9: 35-46.

Brownsey, G.J., Chilvers, G.R., l'Anson, K. and Morris, V.J. 1984. Some observations (problems) on the characterization of gellan gum solutions. Int. J. Macromol. 6: 211-214.

Brownsey, G.J., Ellis, H.S., Ridout, M.J. and Ring, S.G. 1986. Reinforcement of gels by deformable particles. In: Gums and Stabilizers for the Food Industry 3. Phillips, G.O., Wedlock, D.J. and Williams, P.A. (Eds.). Elsevier Applied Science Publishers, New York, NY. pp. 525-533.

Brownsey, G.J., Ellis, H.S., Ridout, M.J. and Ring, S.G. 1987. Elasticity and failure in composite gels. J. Rheology 31: 635-649.

Brownsey, G.J. and Morris, V.J. 1988. Mixed and filled gels - Models for foods. In: Food Structure - Its Creations and Evaluation. Blanshard, J.M.V. and Mitchell, J.R. (Eds.). Butterworths, London, UK. pp. 7-23.

Caldwell, K.B., Goff, H.D. and Stanley, D.W. 1992. A low temperature scanning electron microscopy study of ice-cream. I. Techniques and general microstructure. Food Structure 11: 1-9. 
Chandrasekaran, R., Millane, R.P. and Arnott, S. 1988. The crystal structure of gellan. Carbohydrate Res. 175: 1-15.

Chang, C.M., Powrie, W.D. and Fennema, O.R. 1972. Electron microscopy of mayonnaise. Can. Inst. Food Sci. Technol. J. 5: 134-137.

Chow, T.S. 1980. The effect of particle shape on the mechanical properties of filled polymers. J. Material Sci. 15: 1873-1888.

Colombo, V.E. and Späth, P.J. 1981. Structures of various types of gels as revealed by scanning electron microscopy. In: Studies of Food Microstructure. Cohen, S.H., Davis, E.A., Holcomb, D.N and Kalab, M. (Eds.). Scanning Electron Microscopy, Inc., O'Hare, IL. pp. 223-230.

Costello, M.J. and Corless, J.M. 1978. The direct measurement of temperature changes within freeze-fracture specimens during rapid quenching in liquid coolants. J. Microscopy 112: 17-26.

Cuvelier, G. and Launay, B. 1986. Concentration regimes in xanthan gum solutions deduced from flow and viscoelastic properties. Polymer 27: 321333.

Dalgleish, D.G. 1996. Food emulsions. In: Emulsions and Emulsion Stability. Sjöblon, J. (Ed). Marcel Dekker, New York, NY. pp. 287-325.

Dentini, M., Coviello, T., Burchard, W. and Crescenzi, V. 1988. Solution properties of exocellular microbial polysaccharides. 3. Light scattering from gellan and from the exocellular polysaccharide of Rhizobium trifolii (strain TA-1) in the ordered state. Macromolecules 21: 3312-3320.

Emmons, D.B., Kalab, M. and Larmond, E. 1980. Milk gel structure. X. Texture and microstructure in cheddar cheese made from whole and from homogenized low-fat milk. J. Texture Stud. 11: 15-34.

Fixmann, M. 1982. The flexibility of polyelectrolyte molecules. J. Chemical Physics 72: 6346-6353.

Gelin, J.L., Poyen, L. Courthaudon, J.L., LeMeste, M. and Lorient, D. 1994. Structural changes in oil-in-water emulsions during the manufacture of ice cream. Food Hydrocolloids 8: 299-308.

Green, M.L., Marshall, R.J. and Langley, K.R. 1990. Structure and mechanical properties of composite foods. In: Rheology of Food, Pharmaceutical and Biological Materials. Carter, R.E. (Ed.). Elsevier Applied Science Publishers, New York, NY. pp. 1-12. 
Hamman, D.D. 1983. Structural failure in solid foods. In: Physical Properties of Foods. Peleg, M. and Bagley, E.B. (Eds.). AVI Publishers, Westport, CT. pp. 351-383.

Härröd, M. 1989. Modeling of flow properties of starch pastes prepared by different procedures. J. Food Proc. Eng. 11: 257-275.

Hoover, R. and Vansanthan, T. 1992. The flow properties of native, heat-moisture treated, and annealed starches from wheat, oat, potato and lentil. J. Food Biochem. 18: 67-82.

Jansson, P., Lindberg, B. and Sandford, P.A. 1983. Structural studies of gellan gum, an extracelluar polysaccharide elaborated by Pseudomonas elodea. Carbohydrate Res. 124: 135-139.

Jost, R. 1993. Functional characteristics of dairy proteins. Trends Food Sci. Technol. 4: 283-288.

Juvinall, R.C. 1967. Engineering Considerations of Stress and Strength. McGraw-Hill., New York, NY. p 57.

Kuo, M.S., Mort, A.J. and Del, A. 1986. Identification and location of L-glycerate, an unusual acyl substituent in gellan gum. Carbohydrate Res. 156: 173-187.

Krumel, K.L. and Sarkar, N. 1975. Flow properties of gums useful in the food industry. Food Technol. 29: 36,38,40-41, 43-44.

Lapasin, R. and Pricl, S. 1995. Rheology of Industrial Polysaccharides: Theory and Application. Chapman and Hall, New York, NY. pp. 267-281.

Langley, K.R. and Green, M.L. 1989. Compression strength and fracture properties of model particulate food composites in relation to their microstructure and particle-matrix interaction. J. Texture Stud. 20: 191-207.

Launay, B., Cuvelier, G. and Martinez-Reyes, S. 1984. Applications of hydrocolloids. In: Gums and Stabilizers for the Food Industry 2. Phillips, G.O., Wedlock, D.J. and Williams, P.A. (Eds.). Pergamon Press, Oxford, UK. pp. 79-83.

Launay, B., Doublier, J.L. and Cuvelier, G. 1986. Flow properties of aqueous dispersions of polysaccharides. In: Functional Properties of Food Macromolecules. Mitchell, J.R. and Ledward, D.A. (Eds.). Elsevier Applied Science Publishers, New York, NY. pp. 1-78. 
Le Bret, M. 1982. Elastic contribution of the persistence length of a polyelectrolyte. J. Chem. Phys. 76: 6243-6256.

Lewis, T.B. and Nielson, L.E.. 1970. Dynamic mechanical properties of particulatefilled composites. J. Appl. Polym. Sci. 14: 1449-1471.

Lopes Da Silva, J.A., Gocalves, M.P. and Rao, M.A. 1992. Rheological properties of high-methoxy pectin and locust bean gum solutions in steady shear. J. Food Sci. 57: 443-448.

Masi, P. and Addeo, F. 1986. An examination of some material properties of a group of Italian cheeses and their relation to structure and conditions of manufacture. J. Food Eng. 5: 217-229.

McClements, D.J., Monahan, F.J. and Kinsella, J.E. 1993. Effect of emulsion droplets on the rheology of whey protein gels. J. Texture Stud. 24:411-422.

Milas, M., Shi. X. and Rinaudo, M. 1990. On the physicochemical properties of gellan gum. Biopolym. 30: 451-464.

Moritaka, H., Fukuba, H., Kumeno, K., Nakahama, N. and Nishinari, K. 1991. Effects of monovalent and divalent cations on the rheological properties of gellan gels. Food Hydrocolloids 4: 495-507.

Moritaka, H., Nishinari, K., Nakahama, N. and Fukuba, H. 1992. Effect of potassium chloride and sodium chloride on the thermal properties of gellan gum gels. Biosci. Biotechnol. Biochem. 56: 495-507.

Morris, E.R., Cutler, A.N., Ross-Murphy, S.B., Ree, D.A. and Price, J. 1981. Concentration and shear rate dependence of viscosity in random coil polysaccharide solutions. Carbohydrate Polymer 1: 5-21.

Muller, H.G. 1973. An Introduction to Food Rheology. Crane, Russak \& Company Inc., New York, NY.

Nakamura, 1993. Viscoelastic properties of aqueous gellan solutions: the effects of concentration on gelation. Food Hydrocolloids 7: 435-447.

Nussinovitch, A., Ak, M.M., Normand, M.D. and Peleg, M. 1990. Characterization of gellan gels by uniaxial compression, stress relaxation and creep. $J$. Texture Stud. 21: 37-49.

Nussinovitch, A., Velez-Silvestre, R. and Peleg, M. 1992. Mechanical properties of hydrocolloid gels filled with internally produced $\mathrm{CO}_{2}$ gas bubbles. Biotechnol. Prog. 8: 424-428. 
O'Neill, M.A., Selvendran, R.R. and Morris, V.J. 1983. Structure of the acidic extracellular gelling polysaccharide produced by Pseudomonas elodea. Carbohydrate Res. 124: 123-133.

Okamoto, T., Kubota, K. and Kuwahara, N. 1993. Light scattering study of gellan gum. Food Hydrocolloids 7: 363-371.

Rao, M.A. 1977. Measurement of flow properties of fluid foods - developments, limitations, and interpretation of phenomena. J. Texture Stud. 8: 257-283.

Richardson, R.K., Robinson, G., Ross-Murphy, S.B. and Todd, S. 1981. Mechanical spectroscopy of filled gelatin gels. Polymer Bulletin 4: 541-546.

Ring, G.S and Stainsby, G. 1982. Filler reinforcement of gels. Prog. Food Nutr. Sci. 6: 323-326.

Robards, A.W and Sleytr, U.B. 1985. Freezing. In: Practical Methods in Electron Microscopy: Low Temperature Methods in Biological Electron Microscopy. Vol 10. Elsevier Science Pub., New York, NY. pp. 2-146.

Ross-Murphy, S.B. and Todd, S. 1983. Ultimate tensile measurements of filled gelatin gels. Polymer 24: 481-485.

Sanderson, G.R. 1990. Gellan gum. In: Food Gels. Harris, P. (Ed.). Elsevier Applied Science, New York, NY. pp. 201-232.

Sanderson, G.R. and Clark, R.C. 1984. Gellan gum, a new gelling polysaccharide. In: Gums and Stabilizers for the Food Industry 2. Phillips, G.O., Wedlock, D.J. and Williams, P.A. (Eds.). Pergamon Press, Oxford, UK. pp. 201-210.

Shand, P.J., Sofos, J.N. and Schmidt, G.R. 1993. Properties of algin/calcium and salt/phosphate structured beef rolls with added gums. J. Food Sci. 58: 1224-1230.

Slayter, M.S. and Slayter, H.S. 1992. Light and Electron Microscopy. Cambridge University Press, Cambridge, UK. pp. 1-245.

Smidsrød, O. and Haug, A. 1971. Estimation of the relative stiffness of the molecular chain in polyelectrolytes from measurements of viscosity at different ionic strengths. Biopolymers 10:1213-1227.

Smith, J.C. 1974. Correction of an extension of van der Poel's method for calculating the shear modulus of a particulate composite. J. Res. Nat. Bureau of Standards 78A: 355-361. 
Sone, T. 1972. Consistency of Foodstuffs. D. Reidel Publishing Co., Dordrecht, NLD.

Speers, R.A. and Tung, M.A. 1986. Concentration and temperature dependence of flow behaviour of xanthan gum dispersions. J. Food Sci. 51: 96-98.

Steffe, J.F. 1996. Rheological Methods in Food Process Engineering, $2^{\text {nd }}$ Edition. Freeman Press, East Lansing, MI.

Stanley, D.W. and Tung, M.A. 1976. Microstructure of food and its reiation to texture. In: Rheology and Texture in Food Quality. deMan, J.M., Rasper, V., Stanley, D.W. and Voisey, P. (Eds.). AVI Publishing Co., Westport, CT. pp. 29-78.

Stanley, D.W., Stone, A.P. and Tung, M.A. 1996. Mechanical properties of food. In: Handbook of Food Analysis, Vol. 1, Physical Characterization and Nutritional Analysis. Marcel Dekker, Inc., New York, NY. pp. 93-137.

Tang, J., Tung, M.A. and Zeng, Y. 1995. Mechanical properties of gellan gels in relation to divalent cations. J. Food Sci. 60: 748-759.

Tang, J., Tung, M.A. and Zeng, Y. 1996. Compression strength and deformation of gellan gels formed with mono and divalent cations. Carbohydrate Polymers 29: 11-16.

Tang, J., Tung. M.A. and Zeng, Y. 1997. Gelling temperature of gellan solutions containing calcium ions. J. Food Sci. 62: 276-280.

Thomas, R. 1994. An Investigation of Model Colloidal Systems Containing Microspheres and Whey Proteins. Ph. D. Thesis, Faculty of Engineering, Technical University of Nova Scotia, Halifax, NS.

Tobitani, A. and Ross-Murphy, S.B. 1997. The intrinsic viscosity of polyelectrolytes revisited. Polym. Intermat. 44: 338-347.

Tsiami, A., Morris, V.J. and Brownsey, G.J. 1994. Shear hardening of gellan gum gels. In: Gums and Stabilizers for the Food Industry 7. Phillips, G.O., Williams, P.A. and Wedlock, D.J. (Eds.). IRL Press, New York, NY. pp. 157165.

Tung, M.A. and Jones, L.J. 1981. Microscopy of mayonnaise and salad dressing. In: Studies of Food Microstructure. Cohen, S.H., Davis, E.A., Holcomb, D.N and Kalab, M. (Eds.). Scanning Electron Microscopy, Inc., O'Hare, IL. pp. 223-230. 
Upstill, C., Atkins, E.D.T. and Attwool, P.T. 1986. Helical conformations of gellan gum. Int. J. Biol. Macromol. 8: 275-288.

van Vliet, T. 1988. Rheological properties of filled gels: Influence of filler matrix interaction. Colloid Polymer Sci. 266: 518-524.

van Wazer, J.R., Lyons, J.W., Kim, K.Y. and Colwell, R.E. 1963. Viscosity and Flow Measurement: A Laboratory Handbook of Rheology. Interscience, New York, NY.

Walters, K. 1975. Rheometry. Chapman and Hall, London, UK.

Walstra, P., Oortwijn,H. and deGraaf, J.J. 1969. Studies on milk fat dispersions. I. Methods for determining globule-size distribution. Neth. J. Dairy Sci. 23: 12-36. 


\section{APPENDICES}

Appendix $1 \mathrm{~A}$ Examination of the Possibility of Time Effects in a $0.5 \%$ Gellan Polymer Solution

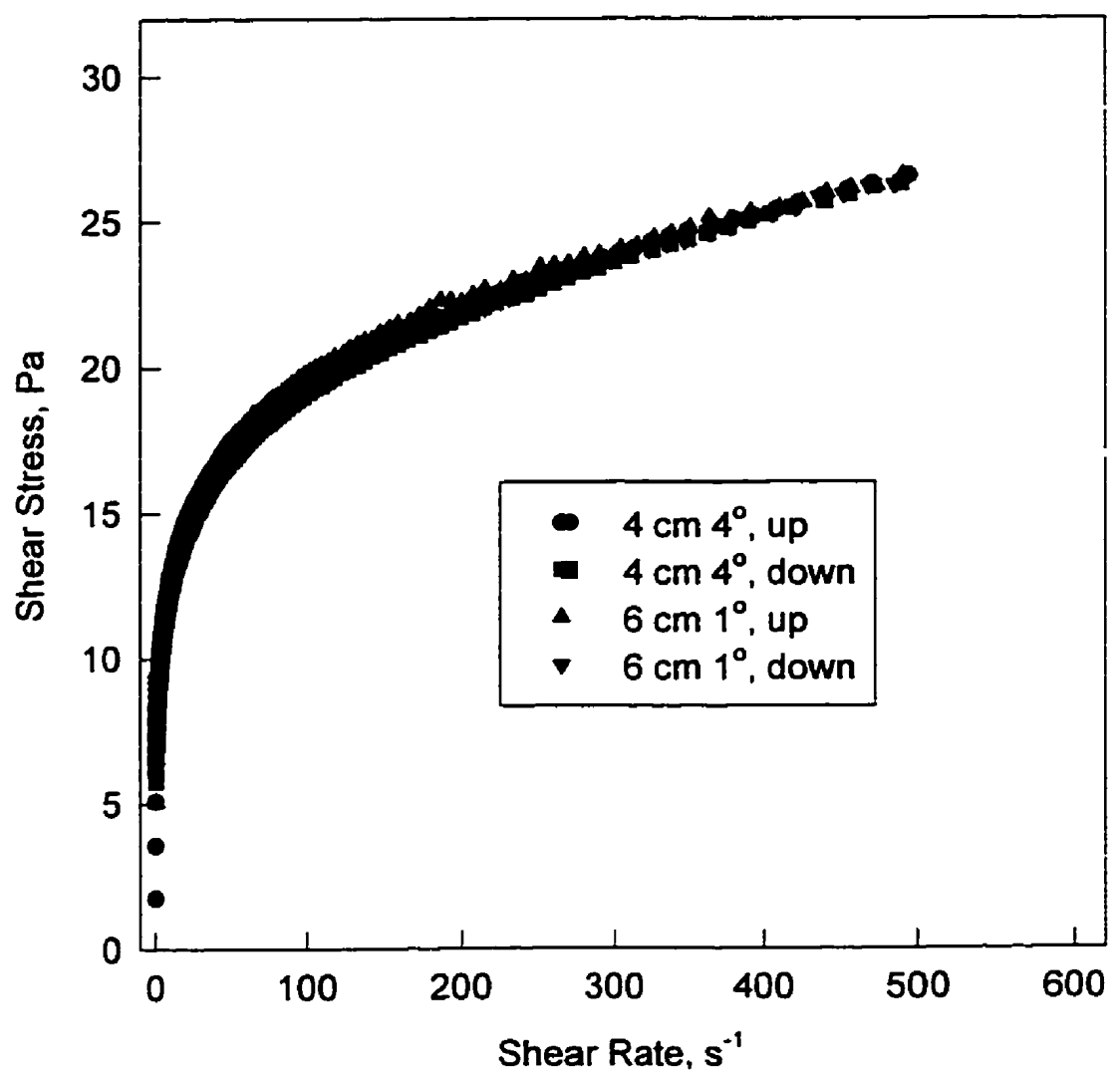

Flow curve of a $0.5 \%$ gellan solution at $5^{\circ} \mathrm{C}$ showing both up and down shear rate curves as tested using two different fixtures.

Result: $\quad$ No hysteresis present between the up and down curves of the applied shear rate sweep.

Conclusion: This indicates the absence of time effects present under the conditions tested. 


\section{Appendix $1 \mathrm{~B} \quad$ Test for Statistical Difference in Flow Data}

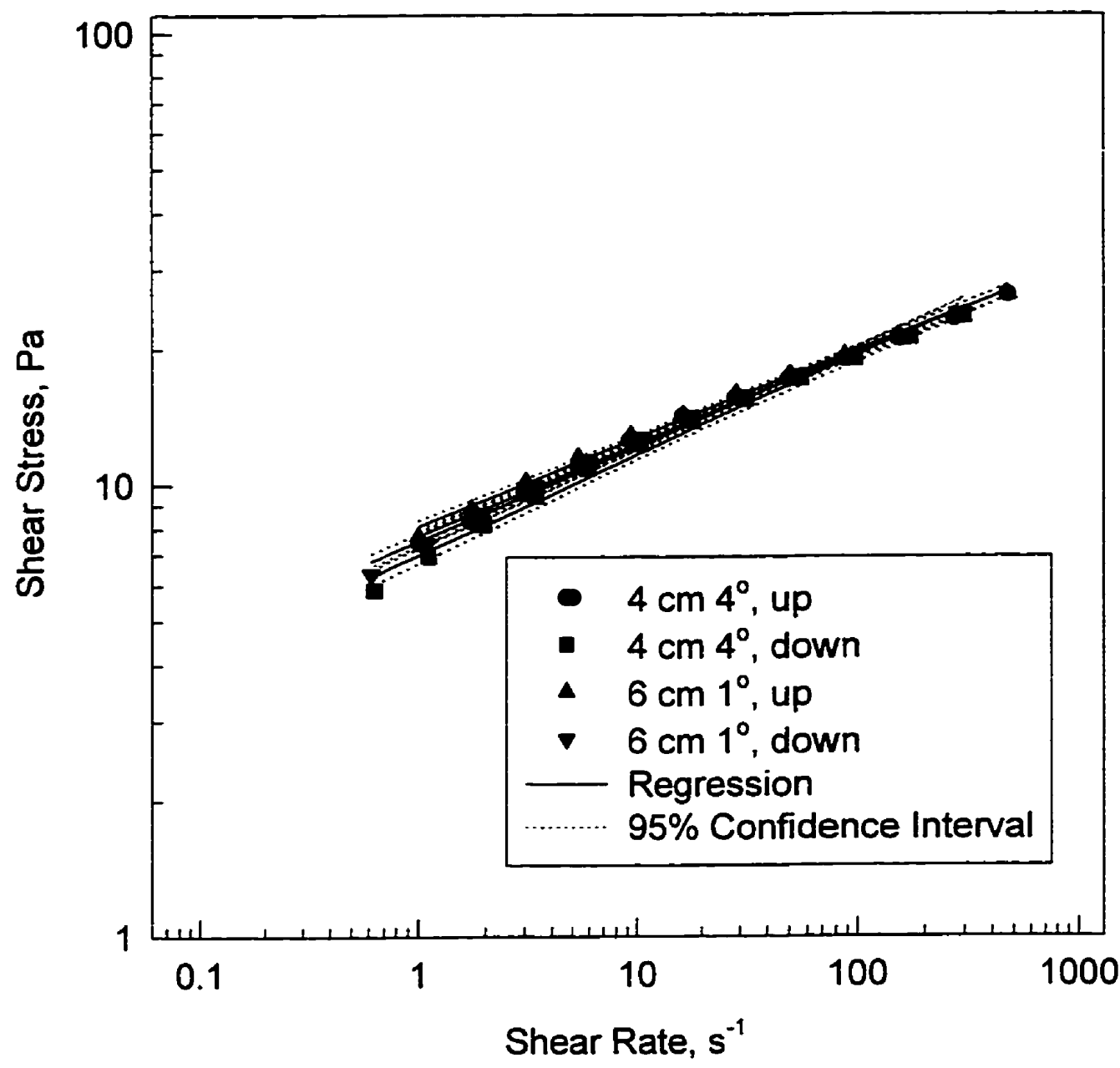

Double log plot of a $0.5 \%$ gellan solution at $5^{\circ} \mathrm{C}$ showing both up and down shear rate curves as tested using two different fixtures.

Result: No statistical differences between either up or down curves, or the different fixture geometries at the $95 \%$ confidence level.

Conclusion: For the experimental gellan solution having the greatest amount of structure, the steady shearing flow curves do not exhibit artifacts due to measurement procedures (fixture, geometry and up vs down sequence). 


\section{Appendix 2 Determination of [COO-] in Gellan Polymer}

Carboxyl group (COO) concentration in gellan polymer was calculated by composition. For example: $1.0 \%(w / v)$ gellan $=1.0 \mathrm{~g} / 100 \mathrm{~mL}$, or $10 \mathrm{~g} / 1000 \mathrm{~mL}$. However, gellan is not free of impurities as was seen in Table 4.1. By considering these impurities and moisture content of the powder (9.8\%), there are $8.5 \mathrm{~g}$ of gellan in $1000 \mathrm{~mL}$ of $1.0 \%(\mathrm{w} / \mathrm{v})$ solution.

The molecular weight of a gellan repeat unit is $648 \mathrm{~g} / \mathrm{mol}$, therefore:

$$
\begin{aligned}
\text { moles of repeat unit } & =\frac{8.5 \mathrm{~g}}{648 \mathrm{~g} / \mathrm{mol}} \\
& =0.013 \text { moles of gellan repeat unit } \\
\text { Therefore, concentration } & =\frac{\text { moles }}{\text { volume }} \\
& =\frac{0.013 \text { mole }}{1 \mathrm{~L}} \\
& =0.013 \mathrm{M}
\end{aligned}
$$

Since there is only one COO' group per repeat unit, the concentration of repeat unit equals the concentration of $\mathrm{COO}^{-}$:

Conclusion: $\quad$ Concentration of $\left[\mathrm{COO}^{-}\right]=0.013 \mathrm{M}$ in a $1.0 \%$ solution 
Appendix 3 A Statistical Analyses of True Stress at Failure Data Representative SAS Output

General Linear Models Procedure

\begin{tabular}{ccl}
\multicolumn{3}{c}{ Class Level Information } \\
Class & Levels & Values \\
BEAD & 3 & 123 \\
VOLFRAC & 4 & 0102030 \\
REP & 2 & 01
\end{tabular}

Number of observations in data set $=24$

FULL MODEL, Stress = bead volfrac rep

Rep was found to be not significant at $\alpha=0.05$, therefore data for the replications were pooled to complete statistical analysis.

REDUCED MODEL, Stress $=$ bead volfrac

Dependent Variable: STRESS

\begin{tabular}{lcrrrr} 
Source & DF & $\begin{array}{c}\text { Sum of } \\
\text { Squares }\end{array}$ & $\begin{array}{c}\text { Mean } \\
\text { Square }\end{array}$ & F Value & $\mathrm{Pr}>\mathrm{F}$ \\
\hline Model & 5 & 1662.5422 & 332.5084 & 64.13 & 0.0001 \\
Error & 18 & 93.3324 & 5.1851 & & \\
Corrected Total & 23 & 1755.8746 & & &
\end{tabular}
R-Square
C.V. Root MSE
0.946846
$4.436188 \quad 2.2771$
STRESS Mean
51.330

Dependent Variable: STRESS

\begin{tabular}{lcrccc} 
Source & DF & Type ISS & Mean Square & $F$ Value & $\operatorname{Pr}>F$ \\
\hline BEAD & 2 & 108.3179 & 54.1589 & 10.45 & 0.0010 \\
VOLFRAC & 3 & 1554.2243 & 518.0748 & 99.92 & 0.0001 \\
& & & & & \\
Source & DF & Type III SS & Mean Square & F Value & $\operatorname{Pr}>$ F \\
BEAD & 2 & 108.3179 & 54.1589 & 10.45 & 0.0010 \\
VOLFRAC & 3 & 1554.2243 & 518.0748 & 99.92 & 0.0001
\end{tabular}


General Linear Models Procedure

Ryan-Einot-Gabriel-Welsch Multiple F Test for variable: STRESS

NOTE: This test controls the type I experimentwise error rate.

$$
\alpha=0.05 \mathrm{df}=18 \mathrm{MSE}=5.185136
$$

Number of Means

2

3

Critical $F$

4.4138734

3.5545571

Means with the same letter are not significantly different.

$\begin{array}{cccc}\text { REGWF Grouping } & \text { Mean } & \text { N } & \text { BEAD } \\ \text { A } & 54.203 & 8 & 1 \\ \text { B } & 50.655 & 8 & 3 \\ \text { B } & 49.132 & 8 & 2\end{array}$

This grouping identifies a statistical difference between the $0.005 \mathrm{M} \mathrm{Ca}^{2+}$ beads and the other two bead types $\left(0.010\right.$ and $\left.0.015 \mathrm{M} \mathrm{Ca}^{2+}\right)$. 
Appendix 3 B Comparison of Slopes of True Stress at Failure Data

\section{Least Square Difference Method}

Test for significance of difference in the slopes of the true stress at failure data.

- test statistic to evaluate is,

$$
t_{0}=\frac{\beta_{o i}-\beta_{o j}}{\left\{s_{i}^{2} / r+s_{j}^{2} / r\right\}^{0.5}} \quad \text { Compare } t_{0} \text { to } t \text { table value } t_{\alpha 0.05, v} v=d f
$$

Table A1 Slope and standard error values for stress at failure versus volume fraction data obtained for the three bead types

\begin{tabular}{ccc} 
Bead Type & Slope & Standard Error \\
\hline 0.005 & -0.6003 & 0.09054 \\
0.01 & -0.888 & 0.01428 \\
0.015 & -0.5535 & 0.03164
\end{tabular}

Comparison of: $\quad t_{0.05,18}=2.101$

0.005 and 0.010 beads

$$
t_{0}=3.138>2.101, \therefore \text { significant }
$$

0.005 and 0.015 beads

$$
t_{0}=0.4879<2.101, \therefore \text { NOT significant }
$$

0.010 and 0.015 beads

$$
t_{0}=9.636>2.101, \therefore \text { significant }
$$

$\therefore 0.010 \mathrm{M}$ beads are different from others

Apparent storage modulus data were analyzed in a similar manner. 
IMAGE EVALUATION
TEST TARGET (QA-3)
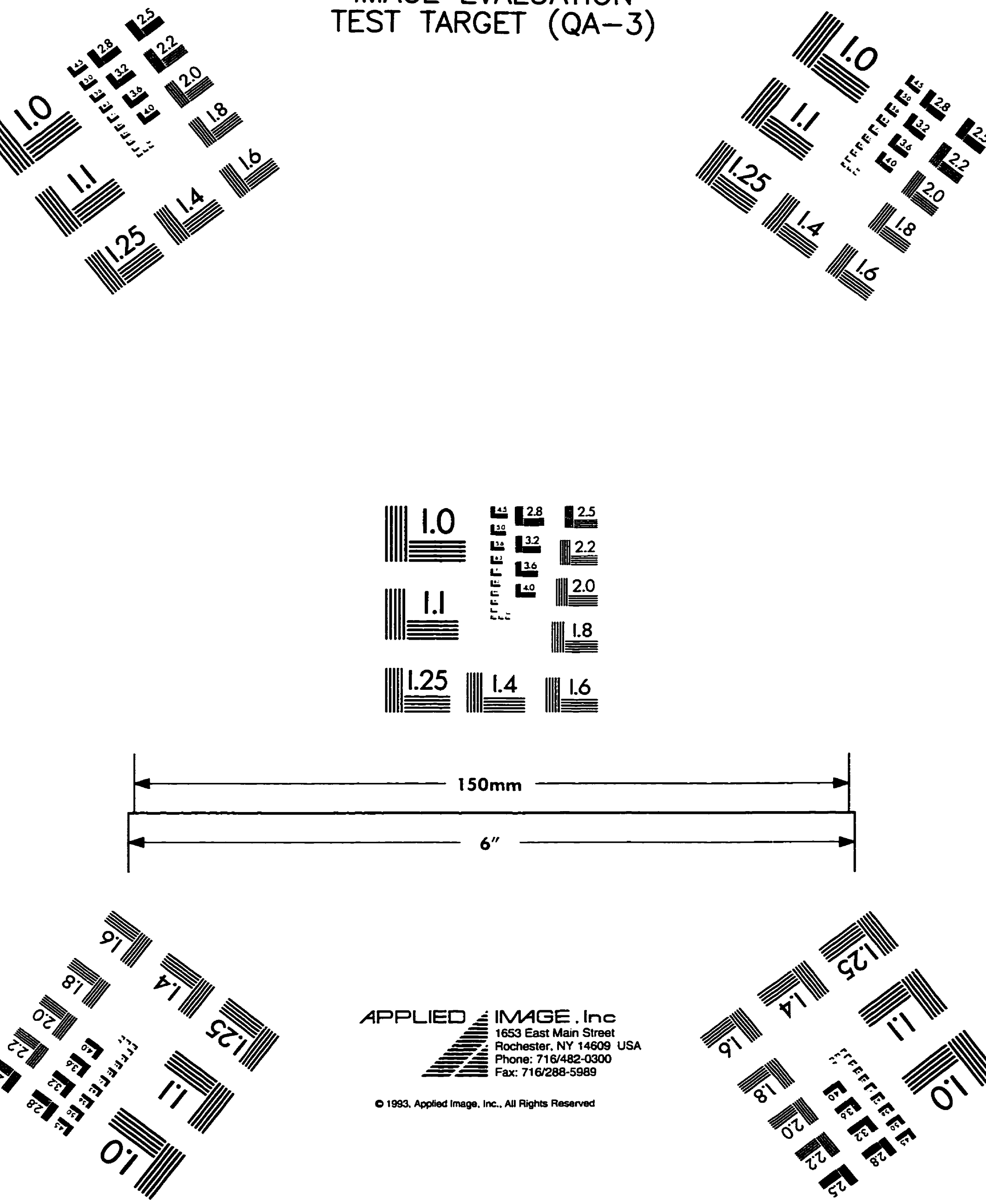